\title{
Comportamiento de los cementos Pórtland con puzolanas silícicas frente al ataque del yeso, determinado mediante el Método ASTM C 452-68
}

\section{Performance of silicic pozzolans and Portland cements in their behavior in front of gypsum attack as determined by ASTM C 452-68}

\author{
R. Talero(*)
}

Recepción/Received: 2-III-12

Aceptación/Accepted: 27-XI-12

\section{RESUMEN}

Para este trabajo se ensayaron durante 2 años 54 PUZC, que contenían humo de sílice (SF) y diatomeas (D y N) (= puzolanas Z), mediante el método ASTM C 452-68, habiéndosele determinado a sus probetas su $\mathrm{Vcl}(=\Delta \mathrm{L}(\%) / \mathrm{día})$. Los resultados obtenidos han confirmado que las reacciones puzolánicas de origen la $\mathrm{SiO}_{2}{ }^{\mathrm{r}-}$ de estas puzolanas $\mathrm{Z}$, en un medio sulfático, han prevalecido más, con $\mathrm{D}$ y $\mathrm{N}$, o menos, con SF, pronto, sobre la hidratación sulfática de sus PUZC, habiendo alcanzado su fin en los primeros 28 días. Luego, habiendo sido positivo el ensayo de Frattini, así como los ensayos normalizados equivalentes, el ensayo ASTM C 452-68 puede usarse también para diferenciar a 28 días, los PUZC preparados con puzolana Z o con cualquier otra puzolana natural o artificial, la cual podría o no, promover el desarrollo de baja, moderada o elevada RS. Únicamente, sería necesario establecer requerimientos y especificaciones químico-físicas apropiadas.

Palabras clave: ataque del yeso; cementos Pórtland; humo de silice; diatomeas.

\section{ABSTRACT}

For this study, ASTM C 452-68 testing was conducted for two years on 54 POZC-silica fume (SF) or diatomites ( $D$ and $N$ ) (=Z pozzolans), were tested for 2 years, by ASTM $C$ 452-68 method, having determined to their specimens their $\mathrm{VCl}(=\Delta L(\%) /$ day $)$. The results have borne out that the pozzolanic reactions from $\mathrm{SiO}_{2}{ }^{\text {- }}$ of these $Z$ pozzolans, in a sulfatic environment, had prevailed sooner (with $D$ and N) or later (with SF) over the sulfatic hydration of their $P O Z C$, reaching completion in the first 28 days. Therefore, after positive result is obtained in the Frattini test, as well as in other equivalent tests standardized, the ASTM C 45268 test can be validly used to differentiate 28-day POZC-Z pozzolan or with any other from natural or artificial origin, which may or may not give rise to the development of low, moderate or high SR. The only requisite would be to establish suitable standard physical-chemical requirements and specifications..

Keywords: gypsum attack; portland cements; silica fume; diatomites.

(*) Instituto de Ciencias de la Construcción Eduardo Torroja (IETcc-CSIC) (Madrid, España). 


\section{INTRODUCCIÓN}

El ensayo ASTM C 452-68 (1) se ha usado como un método acelerado para predecir el comportamiento potencial de los cementos Pórtland (CP) puros frente al ataque de los sulfatos, pero no para el de los CP con puzolanas, ni el de los cementos puzolánicos (PUZC), ni tampoco el de los $\mathrm{CP}$ con escorias siderúrgicas (ES), ni con fíller (calizo o silíceo). Además, los resultados experimentales han demostrado que todas las dimensiones de las probetas ASTM C 452-68 varían con motivo de las reacciones químicas que se producen al penetrar el agua en su interior (2), junto con otros efectos relacionados como se demostrara en un evento internacional sobre el ataque de los sulfatos (3).

Hace unos pocos años, Santhanam y cols. (4) mostraron su desacuerdo sobre la pérdida de interés en el ataque de los sulfatos y abogaban por reanudar las investigaciones para determinar la vida útil o de servicio de las cimentaciones de hormigón sometidas al ataque de los sulfatos. $Y$ para ello haría falta, en primer lugar, precisar con exactitud los reaccionantes químicos implicados y los productos de reacción formados y posiblemente implicados también, cuando un $\mathrm{CP}$ con puzolanas y/o escorias siderúrgicas fuera atacado por el yeso, así como también, sus respectivas morfologías, tamaños, velocidades de formación, interrelación o interconexión durante su formación, consecuencias técnicas. Pero, en definitiva, tanto lo investigado en el pasado como lo investigado en la actualidad viene a demostrar que este tema del ataque de los sulfatos no ha decaído (5-22).

Así, mediante varios artículos publicados sobre este tema se ha logrado demostrar, utilizando las técnicas analíticas de DRX $(14-16)$ y $\operatorname{SEM}(15,16,18)$ y los métodos de ensayo de Le Chatelier-Ansttet (L-A) (14, 15, $22)$, ASTM C $452-68(14,16-18)$ y RT-86: $\Delta \mathrm{L}(14,18)$, que casi todas las adiciones puzolánicas pueden originar ettringita de rápida formación, ett-rf, como consecuencia de su contenido de alúmina reactiva, $\mathrm{Al}_{2} \mathrm{O}_{3}{ }^{\mathrm{r}-}$, la cual puede ser vítrea o amorfa, o más exactamente, alúmina tetra- y/o penta-coordinada, cuya estructura cristalina meta-estable se acaba de confirmar que se encuentra próxima a la de la $\chi$-alúmina (23). Y del mismo modo se ha logrado demostrar también que, en cualquier caso, la velocidad de formación de esta ettringita es mayor que la de la ettringita de lenta formación, ett-lf , o de origen $\mathrm{C}_{3} \mathrm{~A}$ del $\mathrm{CP}$ (14-18). Consecuentemente y como es lógico, el tamaño del monocristal de ett-rf es $\approx 10$ veces más pequeño $(15,16,18)$ que el de la ett-lf, con el añadido de que más bien que reducir sus efectos expansivos por tal motivo, los aumenta por el contrario considerablemente, aunque menos que lo que debería, si el volumen molar de la $\mathrm{Al}_{2} \mathrm{O}_{3}{ }^{\text {r- }}$ fuera el de la $\gamma$-alúmina, lo que no es cierto.

\section{INTRODUCTION}

The ASTM C 452-68 test (1) has been used as an accelerated method for predicting the potential behaviour of plain Portland cements (PC) only under gypsum attack, but not the potential behaviour of Portland cement blended with pozzolans or POZC and/or with blast furnace slags (BFS) and/or with fillers (calcareous or siliceous). Moreover, experimental results have shown that the overall dimensions of ASTM C 452-68 specimens change during water diffusion and chemical reactions (2), and attention was drawn to other related effects in an international meeting on sulphate attack (3).

A few years ago, Santhanam et al. (4) expressed their disappointment over the loss of interest in sulphate attack, an area to which so much importance had been attached in the past, and advocated the resumption of research to determine the service life of concrete foundations subject to sulphate attack. This would call, firstly, for an understanding of the reagent substances involved and reaction products formed and possibly also involved when pozzolanic additions and/or BFS come into contact with Portland cements attacked by gypsum, as well as their respective morphologies, sizes, formation rates, inter-reaction or inter-connection during formation, technological consequences and other possible aspects. In short, both past and present research (5-22) all shows that sulphate attack has not withered (4).

Several prior papers on this subject have shown, with XRD (14-16) and SEM $(15,16,18)$ techniques and Le Chatelier-Ansttet $(L-A)(14,15,22)$, ASTM C 452-68 (14, $16-18)$ and $R T-86: \Delta L(14,18)$ tests, that almost all pozzolanic additions can bring about the rapid formation of ettringite, ett-rf, a process dependent upon their reactive alumina, $\mathrm{Al}_{2} \mathrm{O}_{3}{ }^{r-}$, content, which may be vitreous or amorphous, or more exactly, tetra- or penta-coordinated alumina, recently confirmed to be a meat-stable near $\chi$-alumina (23). It has likewise been found that the formation rate, $\boldsymbol{V}_{\boldsymbol{f}}$ of this ettringite is higher than the $\boldsymbol{V}_{\boldsymbol{f}}$ of slower forming ettringite, ett-lf, whose origin is the $C_{3} A$ in OPC (14-18). Consequently, the ett-rf particle is, approximately 10-fold smaller $(15,16,18)$, as logical. Rather than reducing its expansive properties during formation, such smaller size was found to have the opposite effect, actually increasing such properties, and indeed, less than it theoretically should have, because the molar volume of the $\mathrm{Al}_{2} \mathrm{O}_{3}{ }^{r-}$ was considered to be equivalent to the molar volume of the $y$-alumina only, which is an inaccurate assumption. 
Asimismo y por otra parte, todas estas técnicas analíticas y métodos de ensayo utilizados han puesto de manifiesto también que ninguno de los PUZC, preparados con metakaolín (MK o puzolana M), se pudo considerar de elevada ni aún de moderada resistencia sulfática (RS) $(14-18,22)$. Puesto que toda o la mayor parte de su alúmina hubo de considerarse "reactiva", $\mathrm{Al}_{2} \mathrm{O}_{3}{ }^{\mathrm{r}}$, , (16), y por esta razón precisamente, todas sus pastas, morteros y hormigones fueron degradados mucho más rápidamente, por ataque del yeso, que lo fueron los de su propio CP puro (14-18, 22). Hasta el punto de ser muy adverso, por intenso y rápido, por lo que ha sido denominado "ataque rápido del yeso" (14-18), habiendo podido ser vaticinado además, mediante la expansión, a la edad de 28 días, de las probetas de dicho método de ensayo ASTM C 452-68 $(14,16)$.

Por consiguiente, las únicas cuestiones que aún quedan por dilucidar acerca del tema del ataque de los sulfatos (19) son las referidas a:

- establecer una metodología patrón para el análisis sistemático de datos y desarrollo de hipótesis de comportamiento,

- establecer métodos apropiados para un ataque acelerado de los sulfatos $(1,6-19)$ (ratificado por Hooton años más tarde (20)),

- establecer la relación existente entre la durabilidad de la pasta, de su mortero y de su hormigón (6-18) atacados por sulfatos, $y$

- asegurar el papel que desarrollan las puzolanas en el ataque de los sulfatos $(6-18,21,22)$, en el ataque de los cloruros $(24,25)$ y en el calor de hidratación generado en las edades iniciales de las reacciones de hidratación (22),

las cuales se han podido abordar ahora mejor, hasta el punto de conseguir ser mejor explicadas y comprendidas.

Además, se ha logrado demostrar también que la formación conjunta de ett-rf y ett-If en un medio selenitoso común (en probetas ASTM C 452-68, en este caso), no tiene lugar de una forma independiente entre ambas, sino de una forma inter-dependientemente o combinada o interactiva —co-precipitación (16-18)—. Y cuanto más cercanas entre sí se encuentren las partículas de $\mathrm{Al}_{2} \mathrm{O}_{3}{ }^{\mathrm{r}}$ and $\mathrm{C}_{3} \mathrm{~A}$, más inter-dependiente resultará ser su formación conjunta. Esto significa, por tanto, que en un medio selenitoso común, ambos tipos de ettringitas se originan en mayor o menor medida, pero estando siempre el producto final resultante más cercano a la ett-rf que a la ett-If, y especialmente, cuando mayor cantidad de MK ha sido añadida al CP (40\%), y viceversa (20\%). Por el contrario y en estas mismas circunstancias, la formación conjunta de ett-rf y etttringita de muy lenta formación,
Furthermore, all these applied test methods and techniques have also proved that none of the POZC prepared with metakaolin (MK or M pozzolan) could be considered to be highly or even moderately sulfate-resistant $(14-18,22)$. Since nearly all or at least the greater part of the alumina present in $M K$ must be regarded as being "reactive", $\mathrm{Al}_{2} \mathrm{O}_{3}{ }^{r-},(16)$, and for this reason, all the POZC paste, mortar and concrete specimens would be damaged by gypsum attack much more quickly than those made with plain PC (14-18, 22). The adverse effect arising as a result of gypsum attack is so extensive and rapid that it has been described as "rapid gypsum attack" (14-18). In addition, this adverse behavior could be predicted by means of the ASTM C 452-58 test carried out for their respective specimens at 28 days age $(14,16)$.

Hence, the questions about sulphate attack issue (19) referred to:

- establishing a standard methodology for systematic data analysis and development of hypothesis

- establishing appropriate methods for accelerating sulphate attack $(1,6-19)$ (ratified by Hooton years later (20),

- establishing relationship between paste, mortar and concrete (6-18) durability, and

- assessing the role of pozzolans in sulphate attack (6$18,21,22)$, chloride attack $(24,25)$ and heat emitted in the early phases of hydration reactions (22),

can be now well-explained and addressed with a better understanding.

In addition, it was also demonstrated that: The combined formation of ett-rf and ett-If in a common plaster-bearing solution (in ASTM C 452-68 specimens in this case), does not take place independently from one another, but inter-dependently in a joint way or interactive way -co-precipitation (16-18)-, and for closer the $\mathrm{Al}_{2} \mathrm{O}_{3}{ }^{r-}$ and $\mathrm{C}_{3} \mathrm{~A}$ particles were the more inter-dependent this formation is. This mean, therefore, that both ettringites appear to greater or lesser extension and the final reaction product must be closer to ett-rf than to ett-If when dealing with gypsum and water environments, but especially when more $M K(40 \%)$ has been added, and vice versa (20\%). In these same circumstances, in contrast, the joint formation of ett-rf and ettvlf (from $C_{4} A F$ origin of the same OPC) must be 
ett-vlf (o de origen el $\mathrm{C}_{4} \mathrm{AF}$ del mismo $\mathrm{CPO}$ en las mismas circunstancias), debe de ser lógicamente más bien independiente que inter-dependiente o combinada (16-18).

Pero independientemente del medio selenitoso que se considere (probetas ASTM en este caso), y según sea de elevado el contenido de $\mathrm{Al}_{2} \mathrm{O}_{3}{ }^{\mathrm{r}-}(\%)$ de la puzolana, la mayor o menor, respectivamente, hidratación selenitosa provocada al $\mathrm{C}_{3} \mathrm{~A}$ de la fracción del $\mathrm{CPO}$ con el que se haya mezclado, es inducida a que se produzca de una forma más intensa y rápida que la que se le produce al propio CPO de referencia exento de $\mathrm{MK}$, confirmándose así que la actividad puzolánica de la $\mathrm{Al}_{2} \mathrm{O}_{3}{ }^{\mathrm{r}-}$ del MK es más específica que genérica $(18,22)$, viéndose ensalzada, además, con el contenido de puzolana. Por el contrario, en el caso del humo del sílice ensayado en las mismas circunstancias, sólo un $20 \%$ de dosificación provocó, como se esperaba, que la hidratación selenitosa de dicha cantidad de $C_{3} A$ se viera obstruida, dificultada e incluso impedida, es decir, que su correspondiente PUZC fuera protegido, en mayor o menor medida, del ataque del yeso. Por consiguiente, la actividad puzolánica de la $\mathrm{SiO}_{2}{ }^{\mathrm{r}-}$ del humo de sílice se tiene que considerar inespecífica para el mismo resultado que la $\mathrm{Al}_{2} \mathrm{O}_{3}{ }^{\mathrm{r}-}$ del $\mathrm{MK}$. Pues no en vano el carácter químico del humo de sílice es, según R. Talero (14), totalmente contrario u opuesto al del MK, es decir, silícico (14, 18, 21, 22, 24, 25).

Por otra parte y de acuerdo con todo lo anterior, se ha de concluir que las opiniones vertidas por Felekoğlu y cols. (26), acerca de que el método ASTM C 452-68 no es apropiado para cementos de mezcla y si únicamente para CP puros, carecen de sentido alguno porque no tienen el fundamento debido. Puesto que los resultados y conclusiones que obtuvieron de haber ensayado $1 \mathrm{CPO}$ y sus 2 PUZC con FA (BC1 y BC2), 1 PUZC con NP (BC3) y 1 CPRS con dicho método (1) y el método ASTM C 1012 (27), son además muy discutibles, al haber utilizado una arena caliza local en sustitución de la arena silícea graduada tipo ASTM C 778-92a (28), la cual es obligatorio utilizar para ambos métodos de ensayo. Puesto que, como es sabido, el árido calizo, fino y grueso, facilita a la par que aumenta el ataque de los sulfatos al hormigón, y el filler calizo también lo facilita como el propio Felekoğlu y cols. (29), Calleja y Aguanell (30), Talero et al. (31) and Irassar et al. (32) lo han demostrado, aún incluso cuando el cemento utilizado sea CPRS $(26,30$ 32). Tanto por vía directa (33), en su doble vertiente: estimulación de la hidratación selenitosa, en este caso, del $\mathrm{C}_{3} \mathrm{~A}$ del $\mathrm{CPO}$, por el agua de amasado que los humedeció inicialmente, y formación adicional con dicho $C_{3} A$ de tri-, mono- y/o hemi-carboaluminato de calcio hidratado, como por vía indirecta, pero esta vez, sin actividad puzolánica alguna de por medio, lógicamente (formación preferente de mono-carboaluminato de calcio hidratado en detrimento de Fase AFm que se transforma en ett-If logically independent rather than inter-dependent or combined (16-18),

But regardless of the gypsum media used (ASTM C 45268 specimens), and according to the high or low $\mathrm{Al}_{2} \mathrm{O}_{3}{ }^{-}$ content, the prompted greater or lesser, respectively, but speedier gypsum hydration of $C_{3} A$ from the OPC fraction is induced than it occurs for the OPC reference exempt from $\mathrm{MK}$, confirming the $\mathrm{Al}_{2} \mathrm{O}_{3}{ }^{r^{-}}$(present in the $\mathrm{MK}$, in this case) specificity for gypsum and water environments (enhanced with the pozzolan dosage), i.e., the $\mathrm{Al}_{2} \mathrm{O}_{3}{ }^{\text {r- 's }}$ pozzolanic activity is more specific than generic $(18,22)$, being, in addition, enhanced when more $M K$ is added. On the contrary, in case of silica fume (SF) studied for the same circumstances, only $20 \%$ of its dosage causes gypsum-mediated $C_{3} A$ hydration to be obstructed, and as expected, to protect this pozzolan its corresponding POZC from gypsum attack. Finally, the pozzolanic activity of $\mathrm{SiO}_{2}{ }^{r-}$ (present in $\mathrm{SF}_{1}$ in this case) has to be necessarily regarded as being unspecific for the same result. Because its chemical character is silicic $(14,18,21,22$, $24,25)$, according to R. Talero (14), i.e., totally contrary to the chemical character of $M K$.

On the other hand and according to all the mentioned previously, the statements made by Felekoğlu et al. (26) about the uselessness and inappropriateness of the ASTM C 452-68 when applied to Portland cement blends, (i.e. its appropriateness for a pure Portland cement only), must be indicated as meaningless and lack of any fundamental. Because of the results and the conclusions obtained by these authors (26), achieved in base of the following cementitious materials: 1 SRPC, 1 OPC and its 2 POZC with FA+NP (BC1 and BC2) and 1 POZC with NP (BC3), which have been submitted to the both ASTM $C$ 452 (1) and $C 1012$ (27) methods, these final statements might be debatable only when calcareous fine aggregate instead of the siliceous and graduated one of the ASTM C 778-92a type (28) would have been used, which is mandatory for these two methods. Since the calcareous aggregate, both fine and coarse and their respective filler, facilitates and increases the sulphate attack to concrete, even when the applied cement is $\operatorname{SRPC}(26,30-32)$, by means of both direct way (33) (in its double aspect: sulphatic hydration stimulation of the $C_{3} A$ present in $O P C$, in this case, by the mixing water that moistens the surface of their particles during initial mixing, and additional calcium tri- mono- and/or hemi-carboaluminate hydrated formation from $C_{3} A$ origin of $O P C$ ), and indirect way (33), but this time, with no pozzolanic activity, logically (preferential formation of calcium mono-carboaluminate hydrated instead of AFm phase which is transformed 
(33), como es también lógico, dando por resultado final mayor expansión, y pudiendo ser, además, precursora de la formación ulterior de thaumasita a edades avanzadas (34)), pero sin olvidar tampoco la vía no-directa (33) de estimulación de la hidratación (selenitosa, en esta caso también), sin más, del $\mathrm{C}_{3} \mathrm{~S}$ y el $\mathrm{C}_{2} \mathrm{~S}$ del $\mathrm{CP}$. Por esta razón, no tiene por qué extrañar que ningún cemento tipo CEM II/A-L, II/B-L, II/A-LL, II/B-LL, II/A-M ni II/B-M de la Instrucción RC-08 (35), ni de la nueva norma EN 197-1 (36), haya sido considerado RS. Pero no obstante y a pesar de todo, dichos autores (26) llegaron a escribir incluso entre sus infundamentadas conclusiones que, "This test method procedure, ASTM C 452-68, may not be an appropriate tool for determination of sulfate resistance of blended cements, since sulfate exposure occurs before the pozzolanic effect", no habiéndose percatado de que esta afirmación, en el supuesto que fuera cierta que no lo es, como se ratificará mediante este nuevo trabajo, es aplicable también al método ASTM C 1012 (27), porque excepto el SF y el MK, que cumplen el ensayo de Frattini a la edad de 2 días $(18,22,23,25)$, y a 1 día inclusive (25), muchas puzolanas naturales y artificiales incluidas las cenizas volantes, necesitan al menos 28 días (14, 35-46) para poder desarrollar la mayor parte de toda su actividad puzolánica. De aquí que este método ASTM C 1012 sea más discriminatorio aún que el ASTM C 452 para las puzolanas naturales y cenizas volantes, porque además, no las trata a todas por igual antes de someter a sus POZC al ataque de los sulfatos. Puesto que para el comienzo de dicho ataque sulfático, unas puzolanas pueden haber desarrollado ya bastante más actividad puzolánica que otras y eso no favorece el estudio comparativo ni se corresponde tampoco con lo que se realiza en una obra real. Y ni mucho menos curar su hormigón correspondiente con agua saturada de cal antes del inicio del ataque sulfático. Además y respecto al método ASTM C 1012, W. Hime y L. Backus (47) comentaron lo siguiente sobre el trabajo de Tikalsky y cols. (48): si su propósito fue determinar la relación entre ataque sulfático y contenido de $\mathrm{C}_{3} \mathrm{~A}(\%)$, los autores (48) deberían haber utilizado sulfato de calcio en lugar de sulfato de sodio, puesto que como ellos mismos afirman, el sulfato de sodio complica algunos análisis porque provoca también la formación de sulfato de calcio, lo que puede (o no puede, dependiendo de lo hayan hecho previamente los investigadores) provocar también expansión. Además, si existe relación entre el ataque de los sulfatos y el contenido de $\mathrm{Al}_{2} \mathrm{O}_{3}{ }^{\mathrm{r}-}$ de la puzolana, se confirma, con mucha mayor razón, la necesidad de sulfato de calcio en lugar de sulfato de sodio, como es lógico. Pero en cualquier caso, o todos los PUZC-puzolana $Z$ se conservan bajo agua a $(23 \pm 1,7){ }^{\circ} \mathrm{C}$ durante 14 días, antes del ataque de los sulfatos, como indica el método $L e$ Chatelier-Ansttet (L-A) $(6)(15,22,34)$, o no se conservan, como indica el método ASTM C 452-68 (1). Sin embargo, la perspectiva de conservar algunos PUZC-puzolana $Z$ en agua saturada de cal a $(23 \pm 1,7){ }^{\circ} \mathrm{C}$ durante varios días in ett-If (33), resulting finally in greater expansion, as logical as well; in addition, it may also be a precursor to thaumasite formation at advanced ages (34), but also not forgetting the non-direct sulphatic hydration stimulation (33) to the $C_{3} S$ and $C_{2} S$ of PC. And the calcareous filler also facilitates this attack as Felekoğlu et al. (29), Calleja and Aguanell (30), Talero et al. (31) and Irassar et al. (32) have demonstrated it, and for this reason, neither cement type as CEM II/A-L, II/B-L, II/A-LL, II/B-LL, II/A-M nor II/B-M of the Spanish rule RC-08 (35), nor of the new EN 197-1 standard (36) are considered as SRPC type. Nevertheless and unfoundedly due to the obtained results, the mentioned authors (26) state as a conclusion that "This test method procedure, ASTM C 452-68, may not be an appropriate tool for determination of sulphate resistance of blended cements, since sulfate exposure occurs before the pozzolanic effect", since whether this affirmation was supposedly true, it had also been applicable for the ASTM C 1012 method. The reason for such a supposition is that, except the pozzolans SF and $M K$, which fulfill the Frattini test already at 2 days age $(18,22,23,25)$, and inclusively at 1 day age (25), many natural and artificial pozzolans (fly ash included) need at least 28 days $(14,35-46)$ in order to develop the mayor part of their whole pozzolanic activity (14-18). Moreover, this method, ASTM C 1012, would be more discriminatory than the ASTM C 452 is for both natural pozzolans and fly ash, since it does not treat them all the same before the sulphate attack is applied to their POZC. Since some pozzolans could have already developed sufficiently their pozzolanic activity more than the others, in the beginning of the sulphate attack, which does not facilitate the comparative study nor corresponds to the construction real work. It is also in no way to curing the correspondent concrete with calcium hydroxide saturated water before the sulphate attack begins. In addition and respect to the ASTM C 1012 method, W. Hime and L. Backus (47) commented the Tikalsky et al. work (48) as follows: if their purpose was to determine the relationship between sulphate attack and $C_{3} A(\%)$ content, the authors (48) should have used calcium sulphate instead of sodium sulphate, since and as they state, sodium sulphate complicates any analysis by also causing calcium sulphate precipitation that may (or may not, depending on your choice of previous researchers) also cause expansion. Moreover, if there is relationship between sulphate attack and $\mathrm{Al}_{2} \mathrm{O}_{3}{ }^{-}$- of pozzolans, the need of calcium sulphate instead of sodium sulphate is confirmed with all the more reason yet, as logical. In any case, either all the POZC-Z pozzolan are store in a curing tank of water at $(23 \pm 1.7){ }^{\circ} \mathrm{C}$ for 14 days, before the sulphate attack, like the Le Chatelier-Ansttet test (6, 15, $22,34)$ points out, or none does not, like the ASTM C 452-68 (1) points out. However, a perspective of some POZC-Z pozzolan storing in a curing tank of saturated limewater at (23 \pm 1.7 ) ${ }^{\circ} \mathrm{C}$ during several days (different 
(diferente número de días para cada PUZC-puzolana Z) antes de someterlos al ataque del sulfato de sodio, ni es real ni tampoco aceptable conceptualmente.

En resumen, a estas fechas existe ya, por tanto, un elevado número de estudios e investigaciones sobre las adiciones minerales, puzolánicas y no puzolánicas, que se añaden a los $\mathrm{CP}$, más no tantas, en cambio, cuando los sulfatos están presentes. Alguna de ellas (26) consideran que las adiciones puzolánicas, naturales y artificiales, desarrollan su actividad puzolánica lentamente en las construcciones reales y en el método ASTM C 452-68 (1). Por esta razón y según la referida investigación (26), dicho método de ensayo no proporciona el tiempo suficiente para que dicha reacción puzolánica se desarrolle entre la portlandita de la hidratación del CP y la puzolana Z. Sin embargo, esta creencia es cierta solamente en la vida real, donde el desarrollo de la actividad puzolánica total de cualquier puzolana está mediatizado, en la mayoría de los casos, por el agua de lluvia, la cual suele ser por lo común más estacional que permanente, con las consecuencias pertinentes para el ascenso y descenso periódico del correspondiente nivel freático de las aguas subálveas, contengan sulfatos o no. Porque si la presencia del agua fuera permanente, el desarrollo de dicha actividad puzolánica total o casi total, o al menos, su mayor parte, sea cual fuere el carácter químico de la puzolana (14), no sería lento sino rápido, es decir, durante los primeros 28 días a lo sumo. Este aspecto ha sido, por tanto, el motivo principal de este nuevo estudio con puzolanas silíceas en naturaleza (45) y silícicas en carácter químico $(14,18,21,22,24,25)$, el cual ha sido precedido por otro semejante (16), realizado con MK o puzolana M (puzolana silícea y aluminosa en naturaleza (45) y alumínica en carácter químico (14-18, 22-25, 31). Por esta razón, cualquiera de los métodos y normas que se usan habitualmente para caracterizar químicamente (35-46), mecánicamente (35-37, 42-46), sulfáticamente $(14,49)$ las puzolanas, necesita agua para que se desarrolle la mayor parte de su actividad puzolánica tan pronto como sea posible, pero nunca después de la edad de 28 días, es decir, no se desarrolla lentamente como en la vida real, sino rápidamente. Esta y no otra es la razón por la que las calificaciones obtenidas por Jaspers (6) y Talero (14) para varios CP y sus PUZC con cenizas volantes y otras puzolanas, mediante el método L-A (6, $14,22,34$ ) (ataque "interno" por sulfatos en forma de yeso, $\mathrm{CaSO}_{2} \mathrm{H}_{2} \mathrm{O}$, cuyas probetas están constituidas por pasta parcialmente hidratada de cemento Pórtland, con o sin puzolana o escoria siderúrgica, y un exceso de yeso del $33,33 \%$ ) y el método ASTM C 452-68 (ataque también "interno" por sulfatos en forma de yeso, $\mathrm{CaSO}_{2} \mathrm{H}_{2} \mathrm{O}$, cuyas probetas de mortero, $1: 2,75$, están constituidas por cemento anhidro con un exceso de yeso del $15,05 \%$ de yeso $\approx 7,0 \% \mathrm{SO}_{3}$ ), fueron concordantes. En cambio, las obtenidas con el método ASTM C 1012 (27) no lo habrían day number applied for each POZC-Z pozzolan) before the sodium sulphate attack occurs, is neither realistic nor conceptually acceptable.

In sum up, there are a lot of studies and dissertations that treat the mineral additions, pozzolanic and nonpozzolanic, added to PC, but, however, when sulfates are present there are not much. Some of them (26) consider that pozzolanic mineral additions, natural and artificial, develop their total pozzolanic activity slowly in real life situation and in the ASTM C 452-68 test (1). For this reason and according to the referred research (26), this test procedure does not provide enough time to this pozzolanic reaction which proceeds between the portlandite from PC hydration and the $Z$ pozzolan. However, this belief is true only in real life situation, since the development of the total pozzolanic activity is mainly influenced by the rainwater which is more seasonal than permanent. If the presence of water is permanent, the development of the total pozzolanic activity would not be slow but fast, i.e., during the first 28 days age at the most. This aspect is the chief objective of this new study with siliceous pozzolans in nature (45) and silicic in chemical character (14, 18, 21, 22, 24, 25), whose preceding research (16) apply the 7 or 14 days age only for the metakaolin (MK or M pozzolan) to its all pozzolanic activity development in the plaster-bearing solution (ASTM C 452-68 specimens (1)). It confirmed that the chemical character of $M K$ which is on the contrary, aluminic $(14-18,22-25,31)$, even though its nature is siliceous and aluminous (45). For this reason, any methods and standards used commonly to characterize pozzolans chemicallly (35-46) and/or mechanically (35-37, 42-46) and/or sulphatically (14) (49), needs water for developing the greater part of the pozzolanic activity as soon as possible but never more than 28 days age, i.e., it does not occur slowly like in real life situation, but quickly. This is the reason why the qualifications obtained by M.J. Jaspers (6) and Talero (14) for several PC and POZC by means of the L-A $(6,14,22,34)$ (gypsum attack from within whose specimens are manufactured with very selenitous cement paste partially hydrated of PC with or without pozzolans or SBF and excess of gypsum, 33,33\%,) and ASTM C 452-68 (1) (whose specimens are manufactured with selenitous, $15.05 \%$ of gypsum $=7.0 \% \mathrm{SO}_{3}$, cement mortar) methods, were the same, but with $L-A$ test and ASTM C 1012 test (27) (external gypsum attack whose specimens of ASTM mortar type, 1:2.75, of $P O Z C-Z$ pozzolan have to be storage in lime saturated water at $(23 \pm 1,7){ }^{\circ} \mathrm{C}$, if $Z$ pozzolan is less active, the necessary time up to its compressive strength is $\geq 20$ $M P a$, before being then submitted to sulfate attack -50 $\mathrm{g} / \mathrm{l} \mathrm{Na} \mathrm{SO}_{2}$ solution - but if $\mathrm{Z}$ pozzolan is more active is not; in addition, all its mortars, while still in their moulds and once they all have set, have also to be storage 
sido (ataque "externo" por sulfatos cuyas probetas de mortero tipo ASTM, 1:2,75, de cemento Pórtland con puzolana, se han de conservar en agua saturada de cal a $(23 \pm 1,7){ }^{\circ} \mathrm{C}$, si la puzolana es menos activa, el tiempo necesario hasta que su resistencia mecánica a compresión sea $\geq 20 \mathrm{MPa}$, antes de someterlas al ataque de los sulfatos -disolución de $50 \mathrm{~g} / \mathrm{l}$ de $\mathrm{Na}_{2} \mathrm{SO}_{4}$ - pero si es más activa, no; además, tanto los morteros de las unas como los de las otras, aún en su moldes y una vez fraguados, se han de conservar también $23 \frac{1}{2} \mathrm{~h} \pm 30 \mathrm{~min}$., bajo agua a $\left(35 \pm 3^{\circ} \mathrm{C}\right)$. Porque las fases operativas de ambos métodos: (6) (todas las puzolanas sufren curado hídrico previo antes de ser sometidos sus cementos al ataque de los sulfatos) y (1) (ninguna puzolana sufre curado hídrico previo antes de ser sometidos sus cementos al ataque de los sulfatos), por un lado, y (27) (unas puzolanas, las menos activas, sufren curado hídrico previo en agua saturada de cal a $(23 \pm 1,7){ }^{\circ} \mathrm{C}$, antes de ser sometidos sus cementos al ataque de los sulfatos, pero otras, en cambio, no lo sufren, las más activas), por otro, son significativamente diferentes y, además, las de este último (27) están muy alejadas de la realidad. Por consiguiente, el objetivo último del método ASTM C 45268 coincide más con el ataque selenitoso en la vida real española (y el del método L-A más aún, tratándose además ambos métodos de ataque sulfático nada más), que el método ASTM C 1012, cuyo ataque químico, además de sulfático es natrémico, el cual también es nocivo para los geles $\mathrm{CSH}$, en este caso, especialmente.

En definitiva, el desacuerdo existente entre investigadores acerca del efecto causado por las puzolanas sobre la cineto-química de la formación de ettringita (14-18) y sobre los métodos existentes para acelerar el ataque sulfático $(1,6-22,26,27,34)$, han convertido a este nuevo estudio en hipótesis de comportamiento definitiva. Además y por la última conclusión de la referencia (16) precisamente, resulta necesario hacer ahora el examen del efecto de la ettringita de origen $\mathrm{C}_{3} \mathrm{~A}$ del $\mathrm{CPO}$, principalmente, cuando le son añadidas a dicho CPO, puzolanas con carácter químico silícico, diatomeas ( $\mathrm{D}$ y N) y humo de sílice (SF), en lugar de puzolanas con carácter químico alumínico como el metakaolín. Tal ha sido entonces el principal objetivo de este nuevo trabajo. $Y$ para este propósito, se han realizado una serie de ensayos en los que se ha usado de nuevo el parámetro indirecto, Velocidad de Crecimiento Longitudinal, Vcl $(=\Delta L(\%) / d i ́ a)$, de sus probetas tipo ASTM C 452-68, el cual ha permitido comprobar que estando presentes puzolanas silíceas, en naturaleza, según la norma ASTM C 618 (45), y silícicas, en carácter químico, según R. Talero $(14,18,21,22,24,25)$, en cantidad apropiada, la formación de Fase AFt de origen $C_{3} A$ de CPO, se ve dificultada e incluso impedida.
$231 / 2 h \pm 30$ min., in water at $\left(35 \pm 3^{\circ} \mathrm{C}\right)$, would not have been it. Because the operative phases of both methods, a) on the one hand, all the POZC-Z pozzolan suffer previous curing water before being submitted to sulfate attack (6), or no POZC-Z pozzolan suffer it (1), respectively, and b) on the other hand, (27), some $Z$ pozzolans, the less active, suffer previous curing lime water at $(23 \pm 1,7){ }^{\circ} \mathrm{C}$ before being submitted to sulfate attack, but other pozzolans, the more active, do not, are appreciably different and, in addition, the latter (27) are very far from the reality. Hence, the latest purpose of the ASTM C 452-68 test is more concurrent (and of the $L-A$ test is more yet) with real life selenitous (= sulfatic attack only) situations than the ASTM C 1012 test (27), whose chemical attack is with $\mathrm{Na}_{2} \mathrm{SO}_{2}$, i.e., being also present $\mathrm{Na}^{+}$which interchanges with $\mathrm{Ca}^{2+}$ in $\mathrm{CSH}$ gels which is detrimental as well.

Therefore, researcher's disagreement about the effect caused by pozzolans on ettringite kinetic-chemistry (14-18) and the appropriate methods for accelerating sulphate attack (1, 6-22, 26, 27, 34) have converted this new study into definitive behavioral hypothesis, thanks to the additional reasons and proofs stated below. In addition and by the latest conclusion referred before precisely (16), it is necessary to make now the exam once again of the ettringite effect from $C_{3} A$ origin of OPC mainly, when pozzolans with silicic chemical character, silica fume and diatomites, are added to OPC instead of pozzolans with aluminic chemical character like metakaolin. Such, then, has been the chief objective of this continuation of a preceding research (16). And for this purpose, a series of experiments were conducted a new, and a hitherto little used indirect parameter, the Length Growth Rate, Vcl $(=\Delta L(\%) /$ day $)$, and a new line of reasoning were deployed not to confirm or verify, but to actually prove with this approach, that when siliceous pozzolans in nature, according to ASTM C 618-08 standard (45), and silicic in chemical character, according to R. Talero (14, 18, 21, 22, $24,25)$, are added to each OPC in appropriate amount, AFt phase formation from C3A origin of OPC is hindered if not fully prevented. 


\section{OBJETIVOS}

Los objetivos de esta investigación han sido, por tanto, los siguientes:

1. Determinar si toda o la mayor parte de dichas reacciones puzolánicas de origen la $\mathrm{SiO}_{2}{ }^{\mathrm{r}-}$ de la puzolana $\mathrm{Z}$, se desarrollan en las probetas tipo ASTM C 452-68 de los cementos PUZC-puzolana Z, durante sus primeros 28 días de edad, o aún más pronto todavía -14 a 21 días - y, en consecuencia, que el método ASTM C 452-68 puede ser aplicado también a los cementos Pórtland con puzolanas de naturaleza silícea y carácter químico silícico hasta un contenido del $40 \%$.

2. Probar con el método ASTM C 452-68, vía parámetro Vcl (= $\Delta \mathrm{L}(\%) /$ día) de sus probetas), que la velocidad de formación de los productos de la reacción puzolánica de la $\mathrm{SiO}_{2}{ }^{\mathrm{r}-}$ de la puzolana Z (SF, D y N) con la portlandita, en un medio con yeso y agua en este estudio, tuvo que terminar siendo siempre mayor que la velocidad de formación de la ett-If o de origen $\mathrm{C}_{3} \mathrm{~A}$ especialmente del CPO (análisis comparativo o semi-cuantitativo nada más).

3. Determinar si existe o no alguna relación entre la ett-If de origen $\mathrm{C}_{3} \mathrm{~A}$ del $\mathrm{CPO}$ y dichos productos de la reacción puzolánica de la $\mathrm{SiO}_{2}{ }^{\mathrm{r}-}$ de la puzolana $\mathrm{Z}(\mathrm{SF}$, $\mathrm{D}$ y $\mathrm{N}$ ) con la portlandita, durante su correspondiente formación en un medio selenitoso común.

4. Diferenciar el valor "predictivo" del $\mathbf{\Delta} \mathbf{L}_{\mathbf{1 4}}$ days $\leq$ $\mathbf{0 , 0 4 0 \%}$ (50) y del $\Delta L_{\mathbf{2 8 d a y s}} \leq \mathbf{0 , 0 5 4 \%}(14,16$, $34,51)$, en relación con el comportamiento potencial de un $\mathrm{CP}$ frente al ataque de los sulfatos, pero sobre todo, el de sus correspondientes PUZC con las puzolanas SF, D ó N.

\section{MATERIALES Y METODOLOGIA}

\subsection{Los materiales de partida seleccionados para este nuevo estudio se encuentran en las Tablas 1 y 2}

De acuerdo con el diagrama ternario de Eitel (52), se seleccionaron los siguientes materiales cementíceos:

- $\quad$ Seis CPO -P1, P-2, P4, P32, P31 y P5- y 4 CPRS -PY5, PY1, PY4 y PY6- (37).

- Tres adiciones puzolánicas, siliceas en naturaleza y silicicas en carácter químico: humo de sílice (SF), y diatomeas, D y N (de forma abreviada, puzolana Z), estando además su composición granulométrica en consonancia con la norma ASTM C 595M-95 (cantidad máxima retenida mediante su tamizado en húmedo con el tamiz no $325-45 \mu \mathrm{m}$ de luz de malla-, 20\%) (46).

\section{OBJECTIVES}

The objectives sought in this research were primarily:

1. To determine whether all or the greatest amount of pozzolanic reactions involving $\mathrm{SiO}_{2}{ }^{- \text {p }}$ present in $\mathrm{Z}$ pozzolan (SF, $D$ and $N$ ), take place in ASTM C 452-68 specimens during the first 28 days, or even earlier -14-21 days - for most of the POZC tested.

2. To prove with the ASTM C 452-68 test, via the parameter: $\mathbf{V c l}(=\Delta L(\%) /$ day), that the formation rate of $\mathrm{CSH}$ gels and silanol groups from $\mathrm{SiO}_{2}{ }^{r-}$ origin present in $Z$ pozzolan finished being higher than the formation rate of ett-If from $C_{3} A$ origin present in OPC (comparative or semiquantitative analysis, only).

3. To determine whether there is or not any relationship between ett-If from $C_{3} A$ origin present in $O P C$ and $\mathrm{CSH}$ gels (subsequently transformed into tobermorites) and silanol groups, Si-OH, (later converted into hydrated silicic acid) from $\mathrm{SiO}_{2}{ }^{r-}$ origin present in $Z$ pozzolan, during their respective formation in a common gypsum and water environment (ASTM C 452-68 specimens in this study).

4. To differentiate the "predictive" value of $\mathbf{\Delta} \mathbf{L}_{\mathbf{1 4 d a y s}} \leq$ $\mathbf{0 . 0 4 0 \%}$ (50) and $\Delta \mathbf{L}_{\mathbf{2 8 d a y s}} \leq \mathbf{0 . 0 5 4 \%}(14,16,34$, 51) with respect to the potential behaviour of a given $P C$ under gypsum attack, and for POZC with SF, D or $N$ pozzolan, as well.

\section{MATERIALS AND METHODOLOGY}

\subsection{Starting materials selected for this study are shown in Tables 1 and 2}

Pursuant to Eitel's ternary diagram (52) the following materials were chosen:

- $\quad$ Six OPC (37) -P1, P-2, P4, P32, P31 and P5 - and 4 SRPC (37) - PY5, PY1, PY4 and PY6-.

- Three pozzolanic additions, siliceous in nature (45) and silicic in chemical character $(14)(18)(21,22)$ (24,25): silica fume (SF), and diatomites, $D$ and N (abbreviate, $Z$ pozzolan), being its granular composition in accordance with ASTM C 595M-95 standard (46)

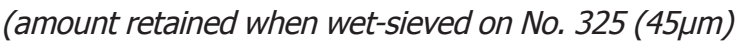
sieve, $\max .=20 \%$ ). 
Tabla 1 / Table 1

Determinaciones químico-físicas de los CP. Chemical-physic determinations of PC.

\begin{tabular}{|c|c|c|c|c|c|c|c|c|c|c|}
\hline \multirow{4}{*}{$\begin{array}{c}\text { Parámetros Químicos I } \\
\text { Chemical Parameters (\%) (36) }\end{array}$} & \multicolumn{10}{|c|}{ Cementos Portland / Portland Cements } \\
\hline & \multicolumn{6}{|c|}{ CPO / OPC } & \multicolumn{4}{|c|}{ CPRS / SRPC } \\
\hline & \begin{tabular}{l|l|} 
P1 & \\
\end{tabular} & P2 & P4 & P32 & P31 & P5 & PY5 & PY1 & PY4 & PY6 \\
\hline & $(3.08)^{2^{*}}$ & $(3.06)$ & $(3.12)$ & $(3.06)$ & $(3.06)$ & $(3.09)$ & $(3.17)$ & $(3.12)$ & $(3.16)$ & $(3.21)$ \\
\hline P.C. / L.O.I. & 1.60 & 2.61 & 1.28 & 2.47 & 3.45 & 2.31 & 0.80 & 2.28 & 1.64 & 1.11 \\
\hline R.I. / I.R. * & 0.70 & 1.21 & 0.97 & 1.57 & 0.86 & 0.62 & 0.40 & 0.54 & 0.43 & 0.15 \\
\hline $\mathrm{SiO}_{2}$ & 19.18 & 19.36 & 19.70 & 18.53 & 18.13 & 21.10 & 19.00 & 18.75 & 22.10 & 21.70 \\
\hline $\mathrm{Al}_{2} \mathrm{O}_{3}$ & 6.44 & 6.03 & 5.70 & 5.54 & 5.30 & 4.30 & 4.70 & 4.97 & 1.98 & 1.52 \\
\hline $\mathrm{Fe}_{2} \mathrm{O}_{3}$ & 1.75 & 2.89 & 2.80 & 3.18 & 3.80 & 2.70 & 4.70 & 5.52 & 4.46 & 4.11 \\
\hline $\mathrm{CaO}$ & 63.94 & 59.49 & 64.0 & 62.39 & 61.68 & 64.40 & 65.11 & 60.82 & 65.59 & 67.97 \\
\hline $\mathrm{MgO}$ & 1.46 & 1.21 & 1.77 & 1.31 & 1.82 & 1.31 & 1.59 & 2.59 & 0.83 & 0.42 \\
\hline $\mathrm{Na}_{2} \mathrm{O}$ & 0.90 & 1.23 & 1.00 & 1.11 & 0.76 & 0.81 & 0.43 & 0.56 & 0.15 & 0.43 \\
\hline $\mathrm{K}_{2} \mathrm{O}$ & 0.52 & 0.69 & 0.21 & 0.28 & 0.31 & 0.21 & 0.06 & 0.23 & 0.05 & 0.20 \\
\hline $\mathrm{SO}_{3}$ & 3.50 & 4.94 & 2.80 & 3.68 & 3.86 & 2.30 & 3.30 & 3.72 & 2.78 & 2.34 \\
\hline TOTAL & 100.01 & 99.96 & 100.03 & 99.94 & 99.97 & 100.06 & 100.09 & 99.98 & 100.01 & 99.95 \\
\hline $\mathbf{H}_{2} \mathbf{O}\left(105^{\circ} \mathrm{C}\right)$ & 0.24 & 0.93 & 0.61 & 0.04 & 0.33 & 0.42 & 0.20 & 0.66 & 0.22 & 0.22 \\
\hline $\mathrm{CaO}$ libre / $\mathrm{CaO}$ free & 1.90 & 0.70 & 0.90 & 1.20 & 0.63 & 0.90 & 1.44 & 0.68 & 1.20 & 1.75 \\
\hline $\begin{array}{c}\text { Composición Mineralógica / } \\
\text { MineralogicalComposition (\%) (36) }\end{array}$ & \multicolumn{10}{|c|}{ CÁLCULO POTENCIAL DE BOGUE I BOGUE POTENTIAL CALCULUS } \\
\hline $\mathrm{C}_{3} \mathrm{~S}$ & 51.05 & 33.47 & 57.45 & 55.67 & 58.70 & 58.84 & 68.07 & 50.44 & 58.19 & 79.43 \\
\hline $\mathrm{C}_{2} \mathrm{~S}$ & 16.48 & 30.26 & 13.14 & 11.13 & 7.70 & 10.16 & 3.12 & 15.71 & 19.46 & 2.29 \\
\hline $\mathrm{C}_{3} \mathrm{~A}$ & 14.11 & 11.09 & 10.71 & 9.30 & 7.62 & 6.83 & 4.50 & 3.83 & 0.00 & 0.00 \\
\hline $\mathrm{C}_{4} \mathrm{AF}+\mathrm{C}_{2} \mathrm{Fss}$ & 5.33 & 8.79 & 7.91 & 9.68 & 11.56 & 8.22 & 14.30 & 16.80 & 11.75 & 10.19 \\
\hline $\mathrm{C}_{4} \mathrm{AF}+2 \mathrm{C}_{3} \mathrm{~A}$ & 33.55 & 30.97 & 29.33 & 28.28 & 26.80 & 21.88 & 23.30 & 24.46 & 11.75 & 10.19 \\
\hline $\mathrm{C}_{4} \mathrm{AF}+\mathrm{C}_{3} \mathrm{~A}$ & 19.44 & 19.88 & 18.62 & 18.98 & 19.18 & 15.05 & 18.80 & 20.63 & 11.75 & 10.19 \\
\hline Superficie Específica / Specific Surface & P1 & P2 & P4 & P32 & P31 & P5 & PY5 & PY1 & PY4 & PY6 \\
\hline Blaine (SEB/BSS) (m²/Kg) (54) & 319 & 302 & 306 & 306 & 325 & 310 & 309 & 321 & 323 & 329 \\
\hline
\end{tabular}

* Residuo Insoluble / Insoluble Residue; 2* Peso Específico / Specific Gravity (g/cm³) (53).

Tabla 2 / Table 2

Composición químico-física de las puzolanas $Z$.

Chemical-physic composition of " $Z$ " pozzolans.

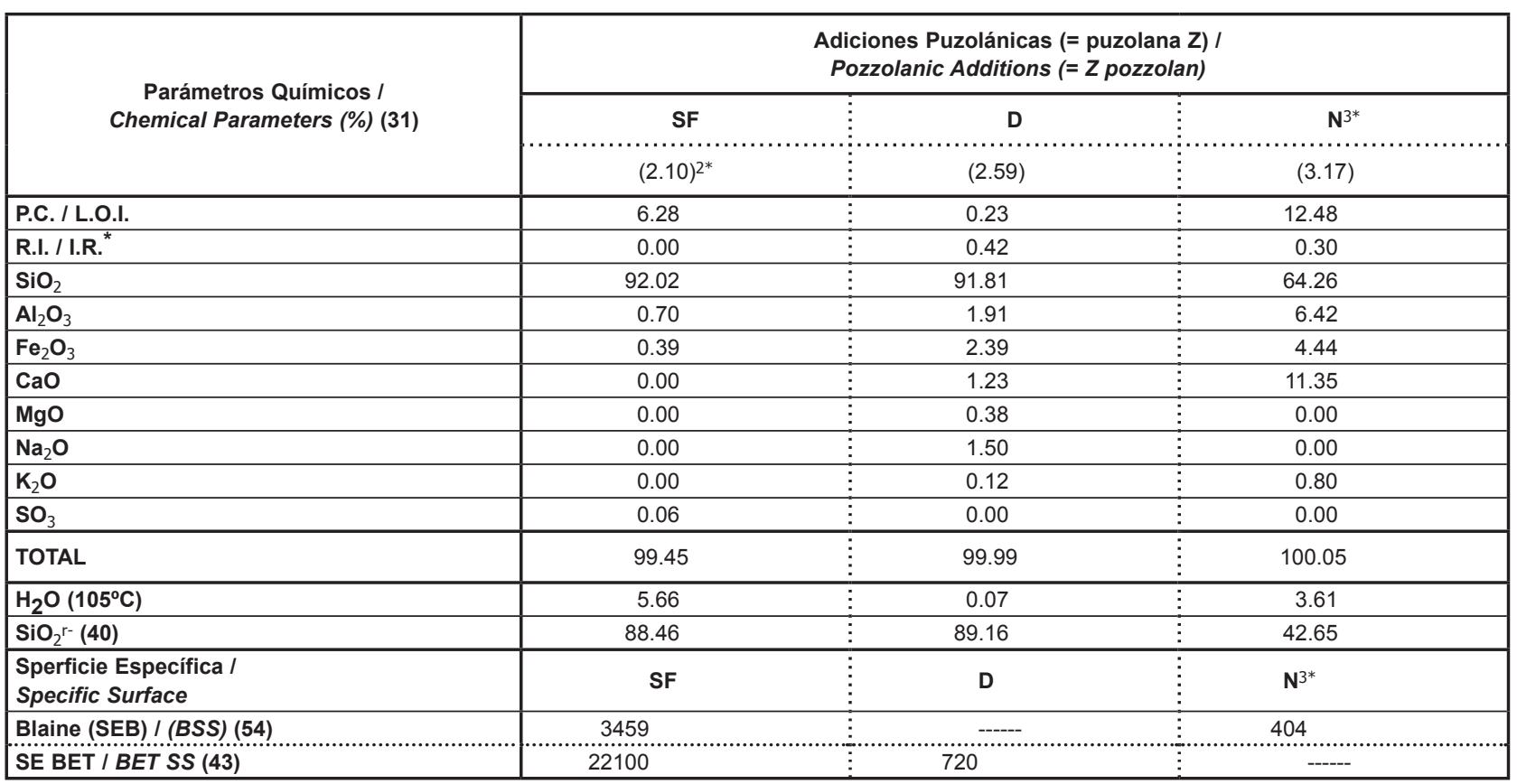

${ }^{*}$ Residuo Insoluble / Insoluble residue; 2* Peso Específico / Specific gravity $\left(\mathrm{g} / \mathrm{cm}^{3}\right)(53) ; 3 * \mathrm{CO}_{2}=8.95 \%=20.34 \% \mathrm{CaCO}_{3}(36,47)$. 
- Como medio agresivo se utilizó piedra de yeso natural, $\mathrm{CaSO}_{4} \cdot 2 \mathrm{H}_{2} \mathrm{O}$, con un elevado grado de riqueza (14-18, $21,22)$.

\subsection{Procedimiento experimental}

En primer lugar se prepararon 54 PUZC, con relaciones en masa $80 \% / 20 \%, 70 \% / 30 \%$ y $60 \% / 40 \%$ (\%CPO/\%puzolana Z ó \%CPRS/\%puzolana Z), con $10 \mathrm{CP}-6 \mathrm{CPO}$ y 4 CPRS- y las puzolanas SF, D y N, separadamente. La relación $100 \% / 00 \%$ (=100/00) ha correspondido al propio CPO ó CPRS puro. A tal efecto se ha de aclarar que, las mezclas PUZC PC/SF ó PC/D $70 \% / 30 \%$ y $60 \% / 40 \%$ fueron preparadas y ensayadas para este investigación nada más. Puesto que ninguna de ellas se suele utilizar para fabricar hormigones de elevada resistencia (HAR) ni elevada durabilidad, porque con la puzolana $D$ aquellas disminuyen muy claramente, y con el SF la que disminuye es su durabilidad, lógicamente. En cambio, el PUZC CP/SF $80 \% / 20 \%$ se suele utilizar en ocasiones aunque su fabricación está condicionada por la realización de pruebas previas para verificar su efectividad.

La composición química de los CP (37) y de las puzolanas (38-40) se encuentra en las Tablas 1 y 2, respectivamente, así como también, su densidad real (53) y superficie específica Blaine (SEB) (54) o BET (43). En las Tablas 3(a), 3(b) y 3(c), se encuentran los valores de resistencias mecánicas a flexotracción y compresión de sus correspondientes morteros normalizados tipo EN 196-1 (55) (en probetas de $4 \times 4 \times 16 \mathrm{~cm}$ ) y ASTM C 452-68 (en probetas de $1 \times 1 \times 6$ $\mathrm{cm})$, mientras que en la Tabla 4 se encuentran las correspondientes relaciones $\mathrm{a} / \mathrm{c}$ de estos últimos. En cambio, los tiempos de fraguado y estabilidades de volumen (56) (Agujas de Le Chatelier), de los PUZC-SF y PUZC-D especialmente, pueden verse en la referencia (18), mientras que los resultados de los PUZC-N se pueden considerar comprendidos entre los de los correspondientes PUZC-SF y PUZC-D. Ambas puzolanas SF y D se caracterizan por su muy elevado y similar contenido de sílice, $\mathrm{SiO}_{2}(\%)$, total y sílice reactiva, $\mathrm{SiO}_{2}{ }^{\mathrm{r}}$, $(23,35,40)$ (Tabla 2$)$, de naturaleza vítrea principalmente, aunque la morfología de sus partículas es muy diferente -esferitas de muy pequeño tamaño en el caso del SF, y frústulos (grandes estuches geométricos perforados y huecos, Figura $6(a)$ ) en el caso de la puzolana D-, hasta el punto que: por una parte, las relaciones agua/cemento de sus morteros normalizados han sido muy diferentes (Tabla 4), y por otra, la puzolana $D$ ha cumplido el ensayo de Frattini a la edad de 7 y/o 28 días, mientras que el SF lo ha cumplido a la edad de 1 día tan sólo, ver la Tabla 5(a), lo que significa que estos otros resultados han sido muy diferentes también.
- Gypsum, natural stone (with high $\mathrm{CaSO}_{4} \cdot 2 \mathrm{H}_{2} \mathrm{O}$ content) was used as aggressive media (1). See its chemical composition in references $(14-18,21,22)$.

\subsection{Operating procedure}

First of all, 54 POZC, with ratios of $80 \% / 20 \%, 70 \% / 30 \%$ and $60 \% / 40 \%$ (\%OPCO/\%Z pozzolan or SRPCO/\%Z pozzolan) were first prepared with 10 PC -6 OPC and 4 SRPC - and SF, D and N pozzolans, separately, and subsequently tested using the ASTM C 452-68 method. Be it said in this connection that $70 \% / 30 \%$ and $60 \% / 40 \%$ PC/ $S F$ or D POZC were prepared and tested for this research only; all these mixes are never used to manufacture high strength concrete (HSC) and/or high performance concrete (HPC) (nor D because mechanical strengths decrease very clearly). While $80 \% / 20 \%$ blends of OPC or SRPC and SF are used on occasion, their manufacture is subject to prior testing for effectiveness. A ratio of $100 \% / 00 \%(=100 / 00)$ is indicative of the plain OPC or SRPC used in this study.

The chemical composition of the Portland cements (PC) (37) and the pozzolanic additions (38-40) are given in Tables 1 and 2. Both of the PC has been analyzed according to the EN 196-2 standard (38), whereas the pozzolanic additions have been analyzed by ASTM C 311 standard (39). However, their respective reactive silica, $\mathrm{SiO}_{2}{ }^{r-},(23,35)$ contents have been determined according to the UNE 80-225-93 standard (40) (Table 2). On the other hand, the physical parameters, real density (53) and Blaine specific surface (BSS) (54) of the materials are listed in Tables 1 and 2. Moreover, the specific area BET of some of the pozzolans has been estimated by nitrogen adsorption method in isothermal conditions (43). Additional results of mechanical strengths, flexural and compressive strength (mortars EN 196-1 type (55) - 4x4x16 cm specimens- and ASTM C 452-68 type $-1 \times 1 \times 6 \mathrm{~cm}$ specimens-), times of setting and volume stability (Le Chatelier's needles) (56) of some POZC-SF and $P O Z C-D$ specially, can be seen in Tables $3(a)(b)(c)$ and reference (18), respectively, while that the results of the rest of POZC with N pozzolan were included between POZC-SF and POZC-D values; in addition, their respective $w / c$ ratios are listen in Table 4. Both of them, SF and D pozzolans, are characterized by their very high and similar $\mathrm{SiO}_{2}(\%)$ and $\mathrm{SiO}_{2}{ }^{-}(\%)$ contents (Table 2) of vitreous type mainly, but the morphology of its frustules in D pozzolan (geometrically big particles and empty, perforated sheaths, Figure. 6(a)) is completely different from the very small SF spherical particles, until the point that water/binder ratios are also very different (Figures 1,2,3,4 and 5). In addition, for this reason and despite of their similar physical state and $\mathrm{SiO}_{2}(\%)$ and $\mathrm{SiO}_{2}{ }^{-}(\%)$ contents, the $D$ pozzolan fulfills the Frattini 
Tabla 3(a) / Table 3(a)

Resistencias mecánicas de los CPO, P1, P2 y P4 y de sus PUZC con puzolana $\mathrm{Z}$.

Mechanical strengths of the OPC P1, P2 and P4 and of their POZC with Z pozzolan.

\begin{tabular}{|c|c|c|c|c|c|c|c|c|}
\hline \multirow{5}{*}{$\begin{array}{c}\text { Cementos I } \\
\text { Cements }\end{array}$} & \multicolumn{8}{|c|}{ Resistencia Mecánicas, RM / Mechanical Strengths, MS (Mpa) } \\
\hline & \multicolumn{8}{|c|}{ Morteros de cemento tipo / Cement mortars types: $-7.0 \% \mathrm{SO}_{3} \rightarrow \mathrm{EN} 196-1(55) ;+7.0 \% \mathrm{SO}_{3} \rightarrow$ ASTM C $452-68(1)$} \\
\hline & \multicolumn{4}{|c|}{ Flexotracción / Flexural Strength, FS } & \multicolumn{4}{|c|}{ Compresión / Compressive Strength } \\
\hline & \multicolumn{2}{|c|}{28 días / days } & \multicolumn{2}{|c|}{90 días / days } & \multicolumn{2}{|c|}{28 días / days } & \multicolumn{2}{|c|}{90 días / days } \\
\hline & $-7.0 \% \mathrm{SO}_{3}$ & $+7.0 \% \mathrm{SO}_{3}$ & $-7.0 \% \mathrm{SO}_{3}$ & $+7.0 \% \mathrm{SO}_{3}$ & $-7.0 \% \mathrm{SO}_{3}$ & $+7.0 \% \mathrm{SO}_{3}$ & $-7.0 \% \mathrm{SO}_{3}$ & $+7.0 \% \mathrm{SO}_{3}$ \\
\hline P1 $100 / 00$ & 7.7 & 4.4 & 7.3 & 8.9 & 47.7 & 27.7 & 50.3 & 53.0 \\
\hline $\mathrm{P} 1 / \mathrm{SF}$ 95/05 & 8.6 & $€$ & $€$ & $€$ & 51.5 & $€$ & $€$ & $€$ \\
\hline $\mathrm{P} 1 / \mathrm{SF}$ 90/10 & 9.2 & $€$ & $€$ & $€$ & 59.0 & $€$ & $€$ & $€$ \\
\hline $\mathrm{P} 1 / \mathrm{SF} 85 / 15$ & 11.4 & $€$ & $€$ & $€$ & 63.7 & $€$ & $€$ & $€$ \\
\hline $\mathrm{P} 1 / \mathrm{SF} 80 / 20$ & 10.9 & 5.0 & 8.5 & 6.0 & 67.0 & 15.0 & 51.6 & 20.6 \\
\hline $\mathrm{P} 1 / \mathrm{SF} \quad 70 / 30$ & 7.4 & 4.6 & 7.9 & 6.0 & 43.4 & 12.1 & 43.3 & 19.3 \\
\hline $\mathrm{P} 1 / \mathrm{SF} 60 / 40$ & 4.3 & 4.5 & 4.6 & 5.6 & 31.7 & 14.3 & 34.6 & 19.1 \\
\hline $\mathrm{P} 1 / \mathrm{D} \quad 80 / 20$ & 1.3 & 4.5 & 2.6 & 6.0 & 5.1 & 27.8 & 10.0 & 31.2 \\
\hline $\mathrm{P} 1 / \mathrm{D} \quad 70 / 30$ & $€$ & 4.0 & $€$ & 5.3 & $€$ & 24.7 & $€$ & 31.7 \\
\hline $\mathrm{P} 1 / \mathrm{D} \quad 60 / 40$ & $€$ & 2.9 & $€$ & 4.3 & $€$ & 12.2 & $€$ & 23.1 \\
\hline $\mathrm{P} 1 / \mathrm{N} \quad 80 / 20$ & $€$ & 6.5 & $€$ & 6.2 & $\dddot{€}$ & 31.5 & $€$ & 32.4 \\
\hline $\mathrm{P} 1 / \mathrm{N} \quad 70 / 30$ & $€$ & 4.5 & $€$ & 7.3 & $€$ & 22.0 & $€$ & 38.8 \\
\hline $\mathrm{P} 1 / \mathrm{N} \quad 60 / 40$ & $€$ & 4.4 & $€$ & 5.7 & $€$ & 15.0 & $€$ & 26.0 \\
\hline P2 $100 / 00$ & 4.0 & 4.4 & 4.2 & 5.2 & 27.3 & 18.3 & 32.4 & 29.7 \\
\hline P2/D $80 / 20$ & $€$ & 4.2 & $€$ & 4.7 & $€$ & 34.5 & $€$ & 32.8 \\
\hline $\mathrm{P} 2 / \mathrm{D} \quad 70 / 30$ & $€$ & 3.9 & $€$ & 4.6 & $€$ & 20.5 & $€$ & 28.9 \\
\hline P2/D $\quad 60 / 40$ & $€$ & 3.5 & $€$ & 3.9 & $€$ & 13.5 & $€$ & 23.1 \\
\hline $\mathrm{P} 2 / \mathrm{N} \quad 80 / 20$ & $€$ & 7.2 & $\dddot{\epsilon}$ & 7.5 & $\dddot{€}$ & 32.2 & $\dddot{€}$ & 31.7 \\
\hline $\mathrm{P} 2 / \mathrm{N} \quad 70 / 30$ & $€$ & 4.0 & $€$ & 6.1 & $€$ & 16.4 & $€$ & 25.4 \\
\hline $\mathrm{P} 2 / \mathrm{N} \quad 60 / 40$ & $€$ & 4.6 & $€$ & 5.8 & $€$ & 19.7 & $€$ & 25.5 \\
\hline P4 $100 / 00$ & $€$ & 6.0 & $€$ & 7.2 & $€$ & 29.0 & $€$ & 42.1 \\
\hline P4/D $\quad 80 / 20$ & $€$ & 4.1 & $€$ & 3.6 & $€$ & 25.2 & $€$ & 35.8 \\
\hline P4/D $\quad 70 / 30$ & $€$ & 3.8 & $€$ & 4.4 & $€$ & 17.0 & $€$ & 27.2 \\
\hline P4/D $\quad 60 / 40$ & $€$ & 3.3 & $€$ & 4.0 & $€$ & 15.1 & $€$ & 24.0 \\
\hline
\end{tabular}

$€$ Estos valores no fueron necesarios para comparación / These values were not necessary for comparison.

Tabla 3(b) / Table 3(b)

Resistencias mecánicas de los CPO P32, P31 y P5 y de sus PUZC con puzolana Z.

Mechanical strengths of the OPC P32, P31 and P5 and of their POZC with Z pozzolan.

\begin{tabular}{|c|c|c|c|c|c|c|c|c|c|}
\hline \multirow{5}{*}{\multicolumn{2}{|c|}{$\begin{array}{c}\text { Cementos I } \\
\text { Cements }\end{array}$}} & \multicolumn{8}{|c|}{ Resistencias Mecánicas, RM / Mechanical Strengths, MS (Mpa) } \\
\hline & & \multicolumn{8}{|c|}{ Morteros de cemento tipo / Cement mortars types: $-7.0 \% \mathrm{SO}_{3} \rightarrow$ EN $196-1 ;+7.0 \% \mathrm{SO} 3 \rightarrow$ ASTM C $452-68$} \\
\hline & & \multicolumn{4}{|c|}{ Flexotracción / Flexural Strength, FS } & \multicolumn{4}{|c|}{ Compresión / Compressive Strength } \\
\hline & & \multicolumn{2}{|c|}{28 días / days } & \multicolumn{2}{|c|}{ días / 90 days } & \multicolumn{2}{|c|}{28 días / days } & \multicolumn{2}{|c|}{90 días / days } \\
\hline & & $-7.0 \% \mathrm{SO}_{3}$ & $+7.0 \% \mathrm{SO}_{3}$ & $-7.0 \% \mathrm{SO}_{3}$ & $+7.0 \% \mathrm{SO}_{3}$ & $-7.0 \% \mathrm{SO}_{3}$ & $+7.0 \% \mathrm{SO}_{3}$ & $-7.0 \% \mathrm{SO}_{3}$ & $+7.0 \% \mathrm{SO}_{3}$ \\
\hline P32 & $100 / 00$ & $€$ & 6.0 & $€$ & 7.2 & $€$ & 29.0 & $\bar{€}$ & 42.1 \\
\hline $\mathrm{P} 32 / \mathrm{D}$ & $80 / 20$ & $€$ & 4.5 & $\dddot{\epsilon}$ & 5.4 & $€$ & 27.6 & $€$ & 32.5 \\
\hline P32/D & $70 / 30$ & $€$ & 3.9 & $€$ & 4.6 & $€$ & 16.4 & $€$ & 23.2 \\
\hline P32/D & $60 / 40$ & $€$ & 3.4 & $€$ & 4.4 & $€$ & 15.3 & $€$ & 23.6 \\
\hline P31 & $100 / 00$ & 8.5 & 5.1 & 8.4 & 7.2 & 59.7 & 25.1 & 59.8 & 42.7 \\
\hline P31/D & $80 / 20$ & $€$ & 4.7 & $€$ & 6.7 & $€$ & 29.4 & $€$ & 28.8 \\
\hline P31/D & $70 / 30$ & $€$ & 3.8 & $€$ & 5.1 & $€$ & 15.7 & $€$ & 24.9 \\
\hline P31/D & $60 / 40$ & $€$ & 3.6 & $€$ & 4.7 & $€$ & 15.2 & $€$ & 22.7 \\
\hline $\mathrm{P} 31 / \mathrm{N}$ & $80 / 20$ & $\dddot{\epsilon}$ & 7.2 & $\dddot{€}$ & 7.5 & $€$ & 32.2 & $\dddot{\epsilon}$ & 31.7 \\
\hline $\mathrm{P} 31 / \mathrm{N}$ & $70 / 30$ & $€$ & 4.0 & $€$ & 6.1 & $€$ & 16.4 & $€$ & 25.4 \\
\hline $\mathrm{P} 31 / \mathrm{N}$ & $60 / 40$ & $€$ & 4.6 & $€$ & 5.9 & $€$ & 19.7 & $€$ & 25.5 \\
\hline P5 & $100 / 00$ & $€$ & 5.0 & $€$ & 6.3 & $€$ & 27.3 & $€$ & 32.3 \\
\hline $\mathrm{P} 5 / \mathrm{D}$ & $80 / 20$ & $\dddot{€}$ & 4.7 & $\dddot{€}$ & 6.7 & $€$ & 29.4 & $\dddot{€}$ & 28.8 \\
\hline P5/D & $70 / 30$ & $€$ & 3.8 & $€$ & 5.1 & $€$ & 15.7 & $€$ & 24.9 \\
\hline P5/D & $60 / 40$ & $€$ & 3.6 & $€$ & 4.7 & $€$ & 15.2 & $€$ & 22.7 \\
\hline $\mathrm{P} 5 / \mathrm{N}$ & $80 / 20$ & $€$ & 5.6 & $\dddot{€}$ & 7.6 & $€$ & 26.0 & $€$ & 37.9 \\
\hline $\mathrm{P} 5 / \mathrm{N}$ & $70 / 30$ & $€$ & 4.3 & $€$ & 6.1 & $€$ & 21.0 & $€$ & 26.2 \\
\hline $\mathrm{P} 5 / \mathrm{N}$ & $60 / 40$ & $€$ & 3.6 & $€$ & 6.1 & $€$ & 14.5 & $€$ & 25.0 \\
\hline
\end{tabular}

$€$ Estos valores no fueron necesarios paar comparación / These values were not necessary for comparison 
Finalmente, la puzolana $\mathrm{N}$ es lógicamente más similar a la puzolana D que al SF, y contiene además por su origen y devenir geológico una fracción de filler calizo, $\approx 20,34 \%$. test at later ages ( 7 and/or 28 days, Table 5(a)), and such additional results can be seen that are very different as well, and similarly, mechanical strengths. Finally, $N$ pozzolan is logically more similar to $D$ pozzolan than to $S F$ pozzolan, even though $N$ pozzolan by its geological origin contains also a fraction of calcareous filler $\approx 20.34 \%$.

Tabla 3(c) / Table 3(c)

Resistencias mecánicas de los CPRS, PY1, PY4 y PY6 y de sus PUZC con puzolana Z.

Mechanical strengths of the SRPC PY1, PY4 and PYG and of their POZC with Z pozzolan.

\begin{tabular}{|c|c|c|c|c|c|c|c|c|}
\hline \multirow{5}{*}{$\begin{array}{c}\text { Cementos / } \\
\text { Cements }\end{array}$} & \multicolumn{8}{|c|}{ Resistencia Mecánicas, RM / Mechanical Strengths, MS (Mpa) } \\
\hline & \multicolumn{8}{|c|}{ Morteros de cemento tipo / Cement mortars types: $-7.0 \%$ SO3 $\rightarrow$ EN $196-1 ;+7.0 \%$ SO3 $\rightarrow$ ASTM C $452-68$} \\
\hline & \multicolumn{4}{|c|}{ Flexotracción / Flexural Strength, FS } & \multicolumn{4}{|c|}{ Compresión / Compressive Strength } \\
\hline & \multicolumn{2}{|c|}{28 días / days } & \multicolumn{2}{|c|}{90 días / days } & \multicolumn{2}{|c|}{28 días / days } & \multicolumn{2}{|c|}{90 días / days } \\
\hline & $-7.0 \% \mathrm{SO} 3$ & $+7.0 \% \mathrm{SO} 3$ & $-7.0 \% \mathrm{SO} 3$ & $+7.0 \% \mathrm{SO} 3$ & $-7.0 \% \mathrm{SO} 3$ & $+7.0 \% \mathrm{SO} 3$ & $-7.0 \% \mathrm{SO} 3$ & $+7.0 \% \mathrm{SO} 3$ \\
\hline PY1 $100 / 00$ & $\bar{€}$ & 6.0 & $\bar{€}$ & 7.5 & $\bar{€}$ & 32.1 & $\bar{\epsilon}$ & 51.6 \\
\hline PY1/D $80 / 20$ & $€$ & 5.0 & $€$ & 6.5 & $€$ & 20.3 & $€$ & 31.1 \\
\hline PY1/D 70/30 & $€$ & 4.1 & $€$ & 5.7 & $€$ & 17.9 & $€$ & 26.4 \\
\hline PY1/D 60/40 & $€$ & 2.5 & $€$ & 4.0 & $€$ & 16.8 & $€$ & 22.6 \\
\hline PY $1 / N \quad 80 / 20$ & $€$ & 6.1 & $€$ & 7.6 & $€$ & 31.8 & $€$ & 37.9 \\
\hline PY1/N 70/30 & $€$ & 5.1 & $€$ & 6.5 & $€$ & 20.4 & $€$ & 33.4 \\
\hline PY1/N 60/40 & $€$ & 5.7 & $€$ & 6.7 & $€$ & 21.7 & $€$ & 25.6 \\
\hline PY4 $100 / 00$ & $€$ & 6.0 & 7.1 & 7.3 & 39.1 & 32.1 & 57.1 & 33.3 \\
\hline PY4/D 80/20 & $€$ & 3.9 & $€$ & 6.8 & $€$ & 20.0 & $€$ & 27.9 \\
\hline PY4/D $\quad 70 / 30$ & $€$ & 3.2 & $€$ & 5.9 & $€$ & 17.8 & $€$ & 25.8 \\
\hline PY4/D $\quad 60 / 40$ & $€$ & 2.4 & $€$ & 5.7 & $€$ & 15.0 & $€$ & 24.1 \\
\hline PY4/N 80/20 & $\dddot{\epsilon}$ & 5.1 & $\dddot{\epsilon}$ & 6.4 & $€$ & 27.2 & $€$ & 33.6 \\
\hline PY4/N $\quad 70 / 30$ & $€$ & 4.4 & $€$ & 5.2 & $€$ & 16.7 & $€$ & 19.6 \\
\hline PY4/N $\quad 60 / 40$ & $€$ & 3.8 & $€$ & 4.8 & $€$ & 10.8 & $€$ & 15.1 \\
\hline PY6 $100 / 00$ & $€$ & 6.1 & 7.3 & 7.4 & 54.5 & 30.9 & 63.0 & 32.7 \\
\hline PY6/SF 95/05 & 8.7 & $€$ & $€$ & $\dddot{€}$ & 61.9 & $\dddot{€}$ & $€$ & $€$ \\
\hline PY6/SF $\quad 90 / 10$ & 8.8 & $€$ & $€$ & $€$ & 64.3 & $€$ & $€$ & $€$ \\
\hline PY6/SF $85 / 15$ & 9.3 & $€$ & $€$ & $€$ & 63.5 & $€$ & $€$ & $€$ \\
\hline PY6/SF $\quad 80 / 20$ & 10.1 & 5.7 & 8.7 & 6.5 & 65.2 & 20.4 & 55.4 & 26.6 \\
\hline PY6/SF $\quad 70 / 30$ & 6.9 & 5.2 & 8.2 & 6.5 & 41.8 & 18.1 & 47.9 & 26.2 \\
\hline PY6/SF $\quad 60 / 40$ & 3.6 & 5.5 & 5.3 & 6.5 & 26.2 & 18.2 & 40.1 & 23.4 \\
\hline PY6/D $\quad 80 / 20$ & 1.26 & 4.2 & 3.2 & 7.1 & 5.9 & 28.3 & 11.6 & 36.5 \\
\hline PY6/D $\quad 70 / 30$ & $€$ & 3.7 & $€$ & 6.2 & $€$ & 21.8 & $€$ & 33.2 \\
\hline PY6/D $60 / 40$ & $€$ & 2.7 & $€$ & 5.7 & $€$ & 18.8 & $€$ & 29.3 \\
\hline PY6/N $\quad 80 / 20$ & $€$ & 5.2 & $€$ & 7.1 & $€$ & 24.4 & $€$ & 29.0 \\
\hline PY6/N $\quad 70 / 30$ & $€$ & 5.0 & $€$ & 6.1 & $€$ & 17.9 & $€$ & 22.4 \\
\hline PY6/N $\quad 60 / 40$ & $€$ & 4.4 & $€$ & 4.8 & $€$ & 15.2 & $€$ & 18.8 \\
\hline
\end{tabular}

$€$ Estos valores no fueron necesarios para comparación / These values were not necessary for comparison.

A continuación, todos los PUZC se analizaron mediante el ensayo de Frattini (41) al objeto de confirmar sus propiedades puzolánicas a 1, 2, 28 y/ó 7 días (Tablas $5(a)$ y $5(b))$, más tarde relacionadas con el ataque de los sulfatos, pero esta vez, estando presentes, junto al $\mathrm{CP}$, puzolanas silícicas, en carácter químico, en lugar de puzolanas alumínicas como el metakaolín (14-18, 22-25, 31).

Finalmente, cada PUZC y sus CP fueron ensayados conforme al método ASTM C 452-68 para determinarles su incremento de longitud, $\Delta \mathrm{L}(\%)$. $\mathrm{A}$ todas las probetas se les determinó su longitud a las edades de 1, 7, 14, 21,
The Frattini test (41) was then conducted on all these POZC to determine their pozzolanic properties at 1, 2, 7 and/or 28 days (Tables 5(a) and (b)), later related to sulphate attack, but in this case being present silicic pozzolans in chemical character, SF, D and N pozzolans, with $P C$, instead of aluminic pozzolan like metakaolin (14-18, 22-25, 31).

Lastly, each POZC and PC, were tested with the ASTM C 452-68 method (1). Only four specimens (1"x1"x111/4") were manufactured with each $P C$ and $P O Z C$, to determine their increase in length (\%), $\mathbf{\Delta L}(\%)$, along with three 
Tabla 5(a) / Table 5(a)

Puzolanicidad (ensayo de Frattini). Resultados. Edad: 1, 2, 7 y 28 días. Pozzolancity (Frattini test). Results. Age: 1, 2, 7 and 28 days.

\begin{tabular}{|c|c|c|c|c|c|c|c|c|}
\hline \multirow{2}{*}{$\begin{array}{c}\text { Cementos I } \\
\text { Cements }\end{array}$} & \multicolumn{2}{|c|}{1 día / day } & \multicolumn{2}{|c|}{2 días $/$ days } & \multicolumn{2}{|c|}{7 días / days } & \multicolumn{2}{|c|}{28 días / days } \\
\hline & [OH-] (mM/l) & [CaO] $(\mathrm{mM} / \mathrm{l})$ & [OH-] (mM/l) & [CaO] (mM/l) & [OH-] (mM/l) & [CaO] (mM/l) & [OH-] (mM/l) & {$[\mathrm{CaO}](\mathrm{mM} / \mathrm{l})$} \\
\hline P1 $100 / 00$ & 66.50 & 8.73 & 72.50 & 7.60 & 71.25 & 6.80 & 78.00 & 6.45 \\
\hline P1/SF 80/20 & 57.50 & 6.13 & 55.50 & 5.50 & 40.00 & 4.90 & 45.00 & 2.35 \\
\hline P1/SF 70/30 & $€$ & $€$ & 49.00 & 4.75 & 15.11 & 2.75 & 74.50 & 3.30 \\
\hline P1/SF $60 / 40$ & $€$ & $€$ & 35.50 & 1.90 & 4.95 & 1.95 & 72.00 & 2.85 \\
\hline P1/D $80 / 20$ & 62.25 & 9.90 & 65.00 & 9.00 & 68.75 & 7.40 & 76.00 & 4.15 \\
\hline P1/D 70/30 & 62.75 & 10.00 & 61.00 & 9.75 & 62.25 & 6.05 & 74.50 & 3.30 \\
\hline P1/D $\quad 60 / 40$ & 56.50 & 10.73 & 60.00 & 9.95 & 58.85 & 4.80 & 72.00 & 2.85 \\
\hline $\mathrm{P} 1 / \mathrm{N} \quad 80 / 20$ & $€$ & $€$ & $€$ & $€$ & 41.50 & 4.00 & e & e \\
\hline $\mathrm{P} 1 / \mathrm{N} \quad 70 / 30$ & e & e & $€$ & $€$ & 22.64 & 3.05 & e & e \\
\hline $\mathrm{P} 1 / \mathrm{N} \quad 60 / 40$ & $€$ & $€$ & $€$ & $€$ & 10.56 & 2.80 & e & e \\
\hline PY6 $100 / 00$ & 42.75 & 28.33 & 42.50 & 21.50 & 39.45 & 16.55 & 42.00 & 16.10 \\
\hline PY6/SF80/20 & 33.25 & 18.33 & 32.00 & 15.25 & 27.00 & 11.75 & 21.50 & 7.50 \\
\hline PY6/SF70/30 & $€$ & $€$ & 27.00 & 12.50 & 12.20 & 6.20 & 12.75 & 2.60 \\
\hline PY6/SF60/40 & $€$ & $€$ & 22.00 & 10.25 & 7.22 & 4.35 & 1.00 & 0.55 \\
\hline PY6/D 80/20 & 43.25 & 25.24 & 44.00 & 20.20 & 47.40 & 16.25 & 47.50 & 8.80 \\
\hline PY6/D 70/30 & 43.00 & 24.29 & 42.50 & 20.50 & 45.50 & 14.60 & 46.50 & 7.00 \\
\hline PY6/D 60/40 & 42.75 & 22.73 & 41.00 & 21.50 & 41.40 & 13.25 & 45.50 & 4.05 \\
\hline PY6/N 80/20 & e & $€$ & $€$ & $€$ & 21.63 & 11.60 & e & e \\
\hline PY6/N 70/30 & $€$ & $€$ & $€$ & $€$ & 14.08 & 11.23 & e & e \\
\hline PY6/N $60 / 40$ & e & e & e & $€$ & 2.01 & 9.95 & e & e \\
\hline
\end{tabular}

$€$ Estos valores no fueron necesarios para comparación / These values were not necessary for comparison.

Los pares de valores en negrita significan que el punto se encuentra en la zona de subsaturación (= resultado positivo a 1,2,7 y/o 28 días /

The paired values in bold mean that the point is in the subsaturation region ( $=+$ result at 1,2,7 and/or 28 days).

28, 60, 90 días, ó hasta 2 años dependiendo del propósito. Con estas mediciones se obtuvieron, en primer lugar, los correspondientes valores del parámetro absoluto ó directo: incremento de longitud, $\mathbf{\Delta L}(\%)$, para seguidamente obtener también los valores del parámetro relativo ó indirecto: velocidad de crecimiento longitudinal, $\mathrm{Vcl}(=\Delta \mathrm{L}(\%) / \mathrm{día})$, el cual no se obtuvo lógicamente día a día, sino mediante cálculos matemáticos, sin más que dividir la diferencia entre los valores de $\mathbf{\Delta} \mathbf{L}(\%)$ de dos edades sucesivas por el número de días transcurridos entre ambas. Por ejemplo: $\left(\Delta \mathrm{L}_{14 \text { días }}(\%)-\Delta \mathrm{l}_{7 \text { días }}(\%)\right) /$ (diferencia entre 14 y 7 días = 7 días), o más generalmente, el número de días transcurridos entre dos $\Delta \mathbf{L}(\%)$ sucesivos, es decir, entre 60-28 díass, 90-60 días, 270180 díass, 365-270 días, y así sucesivamente (Figuras 1 , $2,3,4$ y 5$)$.

Otras pruebas y determinaciones complementarias fueron las siguientes: 1. Imágenes por SEM de las diatomeas, antes (Figura 6(a), y después (Figuras $6(\mathrm{~b})-(\mathrm{g})$ ) de haber desarrollado su actividad puzolánica parcial o total y haber fraguado, para lo que previamente se habían mezclado y agitado en un frasco de polietileno los siguientes materiales: 12,32 g de CPRS PY6, 5,28 g de diatomeas D, additional specimens to ratify any questionable doubtful $\mathbf{\Delta L}(\%)$ (the leftover mortar amount was practically always the same). Length was measured a 1, 7, 14, 21, 28, 60, 90 days, or even later, depending on the purpose. In this study, length measurements were taken for up to 2 years. Thus, first, the direct parameter, $\mathbf{\Delta L}(\%)$, was measured, after which and therefore, the indirect or relative parameter $\mathbf{V c l}(=\Delta L(\%) /$ day) was not measured directly day by day, but mathematically calculated by dividing the measured $\boldsymbol{\Delta L}(\%)$ by the time lapsing between any two successive measurements, i.e. by the amount of time lapsing since the last measurement in each case. For instance: $\left[\Delta L_{14 d a y s}(\%)\right.$ $\left.-\Delta /_{7 \text { days }}(\%)\right] /[$ difference between 14 and 7 days $=7$ days], or more generally, the number of days between two successive length measurements which for other cases would be 60-28 days, 90-60 days, 270-180 days, 365-270 days, and so forth. This means that the rate is not a rate at a specific moment, but the average rate between zero (= any considered age) and a moment in time ( = up to the following considered age) (Figures1, 2, 3, 4 and 5).

Other complementary determinations were: 1. Chemical analysis of cementing materials used (Tables 1 and 2), specific properties of some cements tested and SEM examination of diatomites (Figure 6(a), before and after having developed its partial or total pozzolanic activity. These latter two analysis was performed on $12.32 \mathrm{~g}$ of SRPCPY6, 5.28g diatomite $D, 2.40$ gypsum $\left(\mathrm{CaSO}_{4} \cdot 2 \mathrm{H}_{2} \mathrm{O}\right)$ 
Tabla 5(b) / Table 5(b)

Puzolanicidad (ensayo de Frattini). Resultados. Edad: 7 días.

Pozzolanicicty (Frattini test). Results. Age: 7 days.

\begin{tabular}{|c|c|c|c|c|c|c|c|}
\hline \multirow{2}{*}{\multicolumn{2}{|c|}{$\begin{array}{c}\text { Cementos I } \\
\text { Cements }\end{array}$}} & \multicolumn{2}{|c|}{7 días / days } & \multirow{2}{*}{\multicolumn{2}{|c|}{ Cementos / Cements }} & \multicolumn{2}{|c|}{7 días / days } \\
\hline & & \multirow{2}{*}{$\frac{[\mathrm{OH}-](\mathrm{mM} / \mathrm{l})}{47.73}$} & \multirow{2}{*}{$\frac{[\mathrm{CaO}](\mathrm{mM} / \mathrm{l})}{9.48}$} & & & {$[\mathrm{OH}-](\mathrm{mM} / \mathrm{l})$} & {$[\mathrm{CaO}](\mathrm{mM} / \mathrm{l})$} \\
\hline $\mathrm{P} 2 / \mathrm{D}$ & $80 / 20$ & & & $\mathrm{P} 2 / \mathrm{N}$ & $80 / 20$ & 30.94 & 7.80 \\
\hline P2/D & $70 / 30$ & 45.22 & 8.30 & $\mathrm{P} 2 / \mathrm{N}$ & $70 / 30$ & 11.57 & 4.25 \\
\hline P2/D & $60 / 40$ & 42.71 & 7.13 & $\mathrm{P} 2 / \mathrm{N}$ & $60 / 40$ & 11.07 & 0.75 \\
\hline P32/L & $80 / 20$ & 69.60 & 5.30 & $\mathrm{P} 32 / \mathrm{N}$ & $80 / 20$ & 44.77 & 4.00 \\
\hline P32/L & $70 / 30$ & 68.91 & 4.50 & $\mathrm{P} 32 / \mathrm{N}$ & $70 / 30$ & 27.16 & 2.80 \\
\hline P32/L & $60 / 40$ & 68.08 & 3.70 & $\mathrm{P} 32 / \mathrm{N}$ & $60 / 40$ & 13.08 & 1.90 \\
\hline P4/D & $80 / 20$ & 57.50 & 7.75 & $\mathrm{P} 4 / \mathrm{N}$ & $80 / 20$ & 32.70 & 5.75 \\
\hline P4/D & $70 / 30$ & 55.76 & 7.45 & $\mathrm{P} 4 / \mathrm{N}$ & $70 / 30$ & 25.15 & 3.65 \\
\hline P4/D & $60 / 40$ & 53.79 & 6.59 & $\mathrm{P} 4 / \mathrm{N}$ & $60 / 40$ & 9.05 & 3.60 \\
\hline P31/L & $80 / 20$ & 65.83 & 4.55 & $\mathrm{P} 31 / \mathrm{N}$ & $80 / 20$ & 48.29 & 4.05 \\
\hline P31/L & $70 / 30$ & 63.52 & 3.55 & $\mathrm{P} 31 / \mathrm{N}$ & $70 / 30$ & 40.24 & 3.75 \\
\hline P31/L & $60 / 40$ & 61.22 & 2.15 & $\mathrm{P} 31 / \mathrm{N}$ & $60 / 40$ & 11.57 & 2.90 \\
\hline P5/D & $80 / 20$ & 58.32 & 11.72 & $\mathrm{P} 5 / \mathrm{N}$ & $80 / 20$ & 36.72 & 6.40 \\
\hline P5/D & $70 / 30$ & 51.41 & 8.60 & $\mathrm{P} 5 / \mathrm{N}$ & $70 / 30$ & 7.55 & 4.75 \\
\hline P5/D & $60 / 40$ & 44.56 & 5.50 & $\mathrm{P} 5 / \mathrm{N}$ & $60 / 40$ & 5.05 & 6.20 \\
\hline PY5/L & $80 / 20$ & 46.81 & 7.35 & PY5/N & $80 / 20$ & 19.25 & 5.75 \\
\hline PY5/L & $70 / 30$ & 46.27 & 6.20 & PY5/N & $70 / 30$ & 9.35 & 5.10 \\
\hline PY5/L & $60 / 40$ & 45.79 & 5.05 & PY5/N & $60 / 40$ & 2.62 & 4.50 \\
\hline PY1/L & $80 / 20$ & 68.01 & 8.88 & PY1/N & $80 / 20$ & 16.53 & 15.00 \\
\hline PY1/L & $70 / 30$ & 54.01 & 6.95 & PY1/N & $70 / 30$ & 6.04 & 11.40 \\
\hline PY1/L & $60 / 40$ & 40.01 & 4.90 & PY1/N & $60 / 40$ & 2.52 & 5.85 \\
\hline PY4/L & $80 / 20$ & 49.37 & 17.50 & PY4/N & $80 / 20$ & 18.10 & 17.15 \\
\hline PY4/L & $70 / 30$ & 44.61 & 16.50 & PY4/N & $70 / 30$ & 8.05 & 12.23 \\
\hline PY4/L & $60 / 40$ & 41.94 & 12.80 & PY4/N & $60 / 40$ & 2.52 & 9.25 \\
\hline PY6/L & $80 / 20$ & 47.41 & 16.25 & PY6/N & $80 / 20$ & 21.63 & 11.60 \\
\hline PY6/L & $70 / 30$ & 45.01 & 14.87 & PY6/N & $70 / 30$ & 14.08 & 11.23 \\
\hline PY6/L & $60 / 40$ & 41.40 & 13.25 & PY6/N & $60 / 40$ & 2.01 & 9.95 \\
\hline
\end{tabular}

a Los pares de valores en negrita significan que el punto se encuentra situado en la zona de subsaturación (= resultado +). /

The paired values in bold mean that the point is in the subsaturation region ( $=+$ result).

$2,40 \mathrm{~g}$ de yeso $\left(\mathrm{CaSO}_{4} \cdot 2 \mathrm{H}_{2} \mathrm{O}\right)$ y $100 \mathrm{~cm}^{3}$ de agua destilada. 2. La determinación de la adsorción de humedad por cada puzolana Z, se realizó colocando en un desecador de laboratorio, que contenía en su fondo agua destilada en lugar de gel de sílice, un crisol de porcelana, limpio y tarado, con $\approx 1 \mathrm{~g}$ de puzolana $Z$ totalmente seca a (100 \pm $3)^{\circ} \mathrm{C}$, y a dicho conjunto se le determinó su peso inicial y a las edades de $1,3,7,14,21$ y 28 días, habiéndosele podido determinar finalmente, de este modo, a cada puzolana Z, su ganancia porcentual de humedad.

\section{RESULTADOS Y DISCUSIÓN}

Los resultados experimentales del parámetro $\mathrm{Vcl}$ se encuentran en las Figuras 1 (a)-(f), 2 (g)-(j), 3 (a)-(d), 4 (e)-(g) y 5 (a)(b), y para su discusión e interpretación se dividieron en dos grupos de curvas diferentes de acuerdo con su similitud a una curva de Gauss (su rama izquierda o la derecha especialmente). Observaciones:

(A) CPO puros -6- y CPRS puros -4- (Figuras 1 , 2, 3, 4 y 5). and $100 \mathrm{~cm}^{3}$ of distilled water. 2. Moisture adsorption (= indirect water adsorption), in turn, was found for pozzolans SF and D only, at 1, 3, 7, 14, 21 and 28 days (Table 6). Approximately one gram of each, previously dried at $100 \pm 3^{\circ} \mathrm{C}$, was placed in a tared porcelain crucible and stored at $100 \%$ RH in an air-tight receptacle consisting of a glass dryer in which the silica gel was replaced with distilled water. The crucibles were reweighed at the ages specified.

\section{RESULTS AND DISCUSSION}

The experimental results for $\mathbf{V c l}$ parameter are shown in Figures 1 (a)-(f), 2 ( $g$ )-(i) and (j), 3 (a)-(d), 4 (e)-(g), 5 (a)(b) and 6 (a)-(g). In the discussion and interpretation that follows, the curves are grouped on the basis of their similarity to a Gauss curve (specifically, the right and/or left arm of a normal curve). Observations:

(A) Plain OPC -6- and plain SRPC -4- (Figures 1, 2, 3, 4 and 5). 


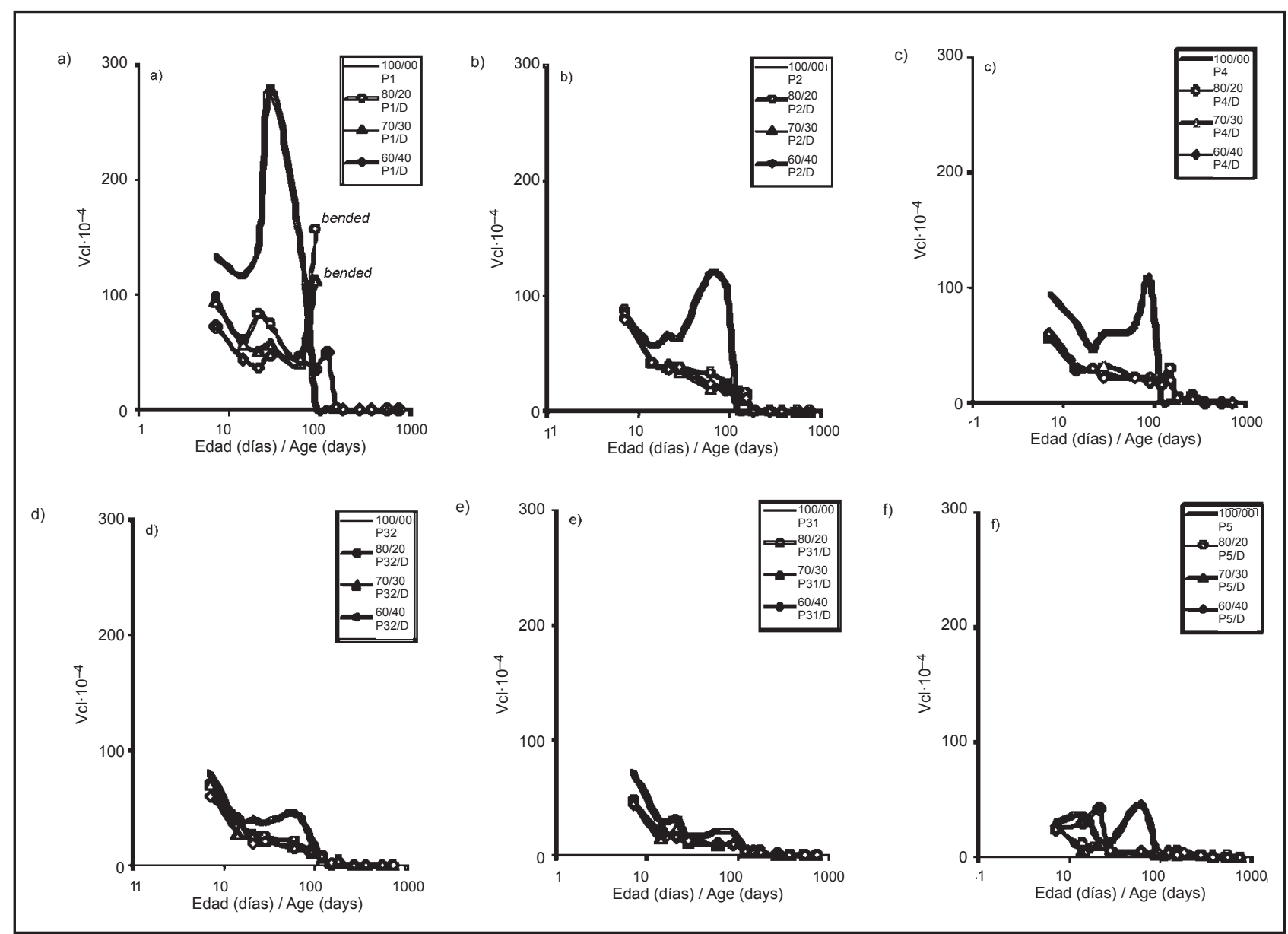

Figura 1. Morteros ASTM C 452-68. Parámetro: $\mathrm{Vcl}(=\Delta \mathrm{L}(\%) /$ día). Cementos: 6 OPC y 18 POZC. Puzolana: D. Figure 1. Mortars: ASTM C 452-68 type. Parameter: $\mathrm{VCl}(=\Delta L(\%) / d a y)$. Cements: 6 OPC and 18 POZC. Pozzolan: $D$.

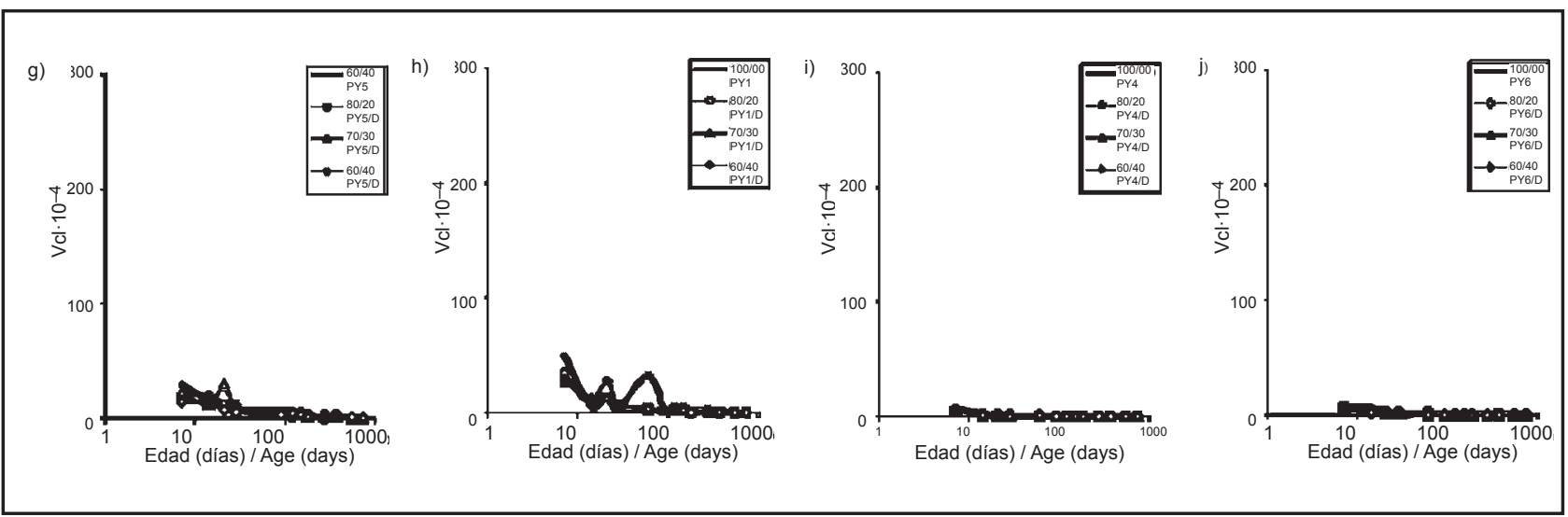

Figura 2. Morteros ASTM C 452-68. Parámetro: $\mathrm{Vcl}(=\Delta \mathrm{L}(\%) /$ día). Cementos: 4 OPC y 12 POZC. Puzolana: D. Figure 2. Mortars: ASTM C 452-68 type. Parameter: $\mathrm{VCl}(=\Delta L(\%) /$ day). Cements: 4 OPC and 12 POZC. Pozzolan: $D$.

En general, el origen, evolución y desarrollo de los valores de $\mathrm{Vcl}$ de los $10 \mathrm{CP}$ ensayados se puede comparar a dos curvas de Gauss sucesivas unidas por el brazo derecho de la $1^{\mathrm{a}}$ curva y el izquierdo de la $2^{\mathrm{a}}$, pero en cualquier caso, las pendientes negativas finales (brazo o rama derecha de
The origin, evolution and development of the $\mathbf{V c l}$ values for the 10 PC tested can generally be compared to two successive Gauss curves joined at the downward arm of the first, and the upward arm of the second curve. But in any case, the final negative slopes (left arm of the 2nd. 


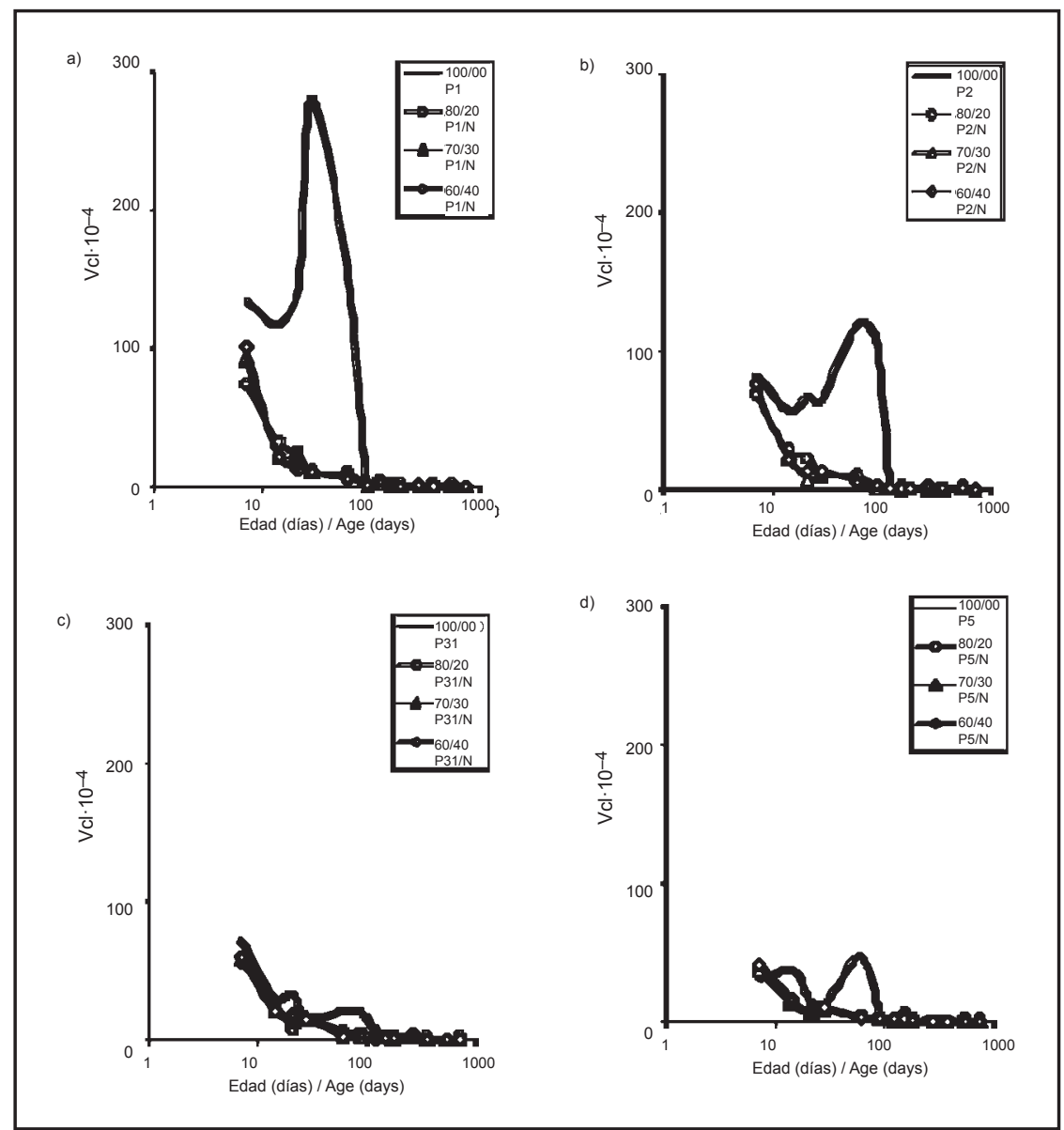

Figura 3. Morteros ASTM C 452-68. Parámetro: Vcl (= $\Delta \mathrm{L}(\%) /$ día). Cementos: 4 OPC y 12 POZC. Puzolana: $N$. Figure 3. Mortars: ASTM C 452-68 type. Parameter: VCl (= $\Delta L$ (\%)/day). Cements: 4 OPC and 12 POZ. Pozzolan: $N$.

la $2^{\mathrm{a}}$ curva de Gauss) poseen un valor absoluto muy pequeño el cual además, a partir de una edad dada, tiende a cero en todos los casos. Y lógicamente, las áreas definidas por cada curva son proporcionales al contenido de $\mathrm{C}_{3} \mathrm{~A}(\%)$ del CP al que corresponde cada una de ellas.

NOTA: Ninguna de las Figuras de los CP ni de sus PUZC con cualquier puzolana $Z$ posee origen o punto de partida, es decir, que el día cuando se fabricaron las probetas de cada familia ó día 0 , no se muestra en ninguna de las Figuras 1, 2, 3, 4 y 5. Por consiguiente, el punto de 7 días, $\mathrm{VCl}_{7 d}$ que si aparece por contra en todas ellas, se debe de considerar unido por una línea imaginaria al del correspondiente día 1, ó día de su desmoldeado. Y esta línea imaginaria se deberá considerar a su vez que pertenece a la rama o brazo izquierdo de la $1^{a}$ curva de Gauss.

El resto de observaciones que se pueden hacer de este apartado (A) se pueden ver en la referencia (16), por cuyo motivo, su análisis, estudio, discusión e interpretación no es necesario repetirlo en este nuevo artículo.
Gauss curve), have very small absolute values, decreasing to zero in all cases after a given age. The areas defined by plain $P C$ curves are logically proportional to their $C_{3} A(\%)$ content.

NOTE: No initial point, i.e., the day when the specimens were manufactured or day zero, is shown in these figures (Figures 1, 2, 3, 4 and 5). Therefore, the initial point for 1 day, $\mathbf{V c l}_{\mathbf{1 d}}$, should be considered to be joined by an imaginary line to the day 0 point, $\mathbf{V c l}_{\boldsymbol{O d}}$. This imaginary line must be considered together with the left arm of the first Gauss curve.

The following observations may be made with respect to (A): All the observations can be seen in reference (16), and for this reason, their analysis, study, discussion and interpretation are not once again needed. 
(B) PUZC -57- Figuras 1 (a)-(f), 2 (g)-(j), 3 (a)-(d), 4 (e)-(g) y 5 (a)(b):

En primer lugar, se debe de llamar la atención sobre el hecho de que las áreas definidas por cada curva PUZC deben de ser proporcionales a sus respectivos contenidos de $\mathrm{C}_{3} \mathrm{~A}(\%)$. Puesto que el contenido de $\mathrm{Al}_{2} \mathrm{O}_{3}{ }^{\mathrm{r}}$ - de estas tres puzolanas silícicas, SF, D y N, es $0 \%(14,18,21-25)$.
(B) POZC -57- Figures 1 (a)-(f), 2 (g)-(j), 3 (a)-(d), 4 (e)-(g) and 5 (a)(b):

Attention must first be drawn to the fact that the areas defined by POZC curves must also be proportional to their respective $C_{3} A(\%)$ contents, because these three silicic pozzolans had not any reactive alumina, $\mathrm{Al}_{2} \mathrm{O}_{3}{ }^{--}(\%)$, content $(14,18,21-25)$.
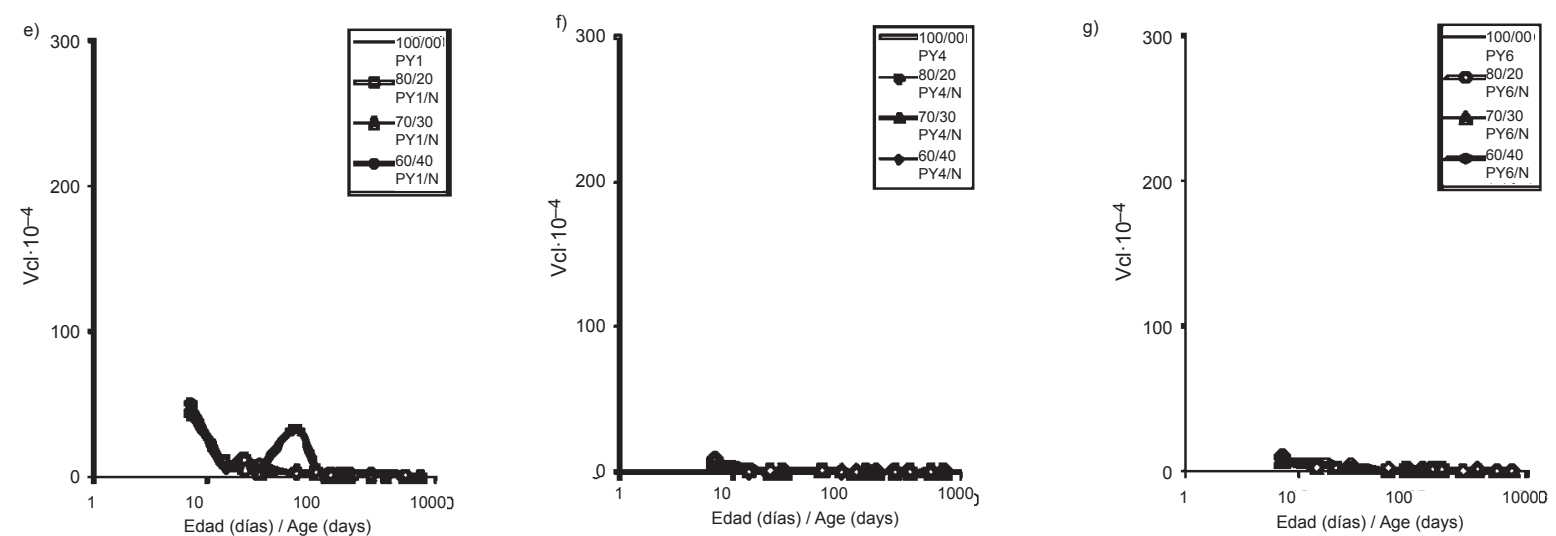

Figura 4. Morteros ASTM C 452-68. Parámetro: $\mathrm{Vcl}(=\Delta \mathrm{L}(\%) /$ día). Cementos: 3 OPC y 9 POZC. Puzolana: N. Figure 4. Mortars: ASTM C 452-68 type. Parameter: $V C l(=\Delta L(\%) / d a y)$. Cements: 3 OPC and 9 POZC. Pozzolan: $N$.
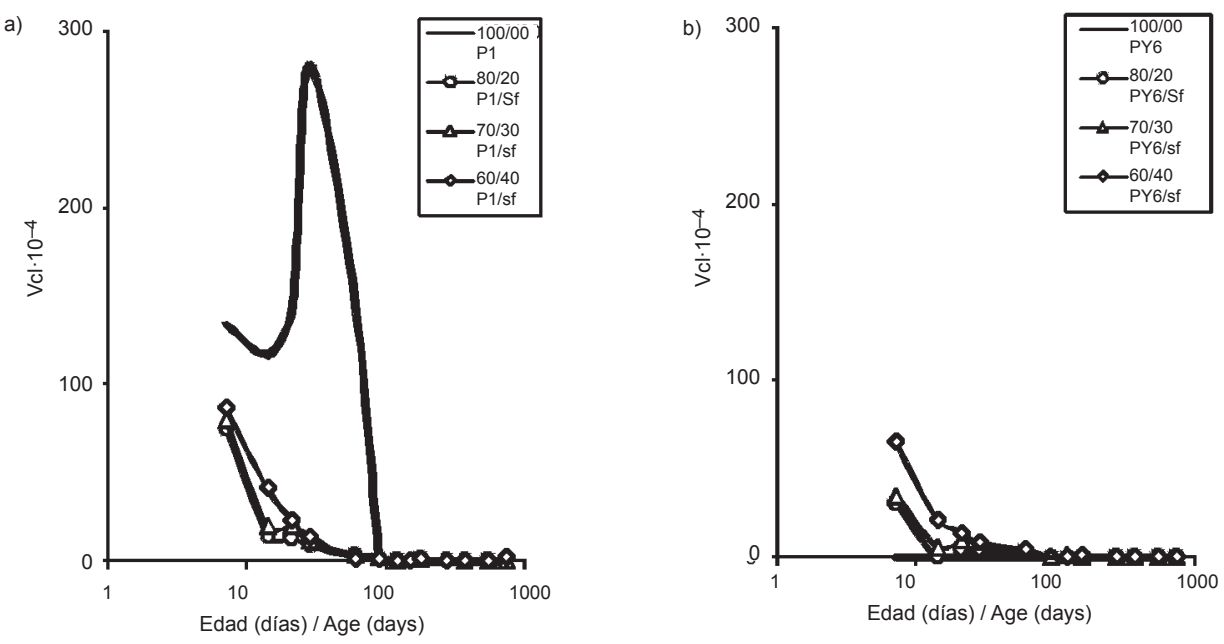

Figura 5. Morteros ASTM C 452-68. Parámetro: Vcl ( $=\Delta \mathrm{L}(\%) /$ día). Cementos: 2 OPC y 6 POzC. Puzolana: SF (22). Figure 5. Mortars: ASTM C 452-6 type. Parameter: VCl (= $\Delta L(\%) /$ day). Cements: 2 OPC and 6 POZC. Pozzolan: SF (22). 


\section{Observaciones:}

1. Los valores de $\mathrm{Vcl}$ de las probetas fabricadas con todos y cada uno de los PUZC disminuyeron desde la edad de 7-28 días hasta la edad final del ensayo cuando alcanzaron el valor cero, habiendo sido incluso el valor de $\mathrm{Vcl}$ a tales edades el mayor de todos, aunque en cualquier caso, dicha mayoría la alcanzó siempre más pronto que la de su correspondiente CP puro (Figuras 1, 2, 3, 4 y 5), y en general, tanto más pronto, cuanto mayor cantidad de puzolana Z le fuera añadida al CPO.

En definitiva, los valores de Vcl comenzaron a disminuir inmediatamente después de haber llegado a su máximo valor, el cual lo alcanzó por la general entre las edades de 7 y 28 días, excepto las de los PUZC P1/D 80/20 y $70 / 30$ que fue a los 90 días de edad, debido a que sus probetas estaban ya curvadas a esa edad (Figura 1(a)). Con lo que su correspondiente $\Delta \mathrm{L}(\%)_{120 d}$ y $\mathrm{Vcl}_{120 \mathrm{~d}}$ no se pudieron medir ya con la precisión debida. En cambio, los de las probetas del PUZC P1/D 60/40, sí se pudieron medir (Figura 1(a)).

2. Cuando la cantidad de puzolana $Z$ aumentó, los valores de $\mathrm{VCl}_{7-28 \mathrm{~d}}$ aumentaron también con el SF pero disminuyeron con las diatomeas $\mathrm{D}$ y $\mathrm{N}$, aunque en cualquier caso siendo todos ellos menores que los de sus correspondientes CPO puros, y lógicamente menores aún, si la puzolana $Z$ hubiera sido un material totalmente "inerte", desde el punto de vista del ataque de los sulfatos ó "inerte ${ }_{\mathrm{RS}}$ ". Por este motivo, los correspondientes valores de $\mathrm{VCl}_{7-28-760 \mathrm{~d}}$ cumplieron las siguientes desigualdades:

Vcl ; CPO/puzolana SF 100/00 > 80/20 < $70 / 30<60 / 40$, desde 7 hasta 28 días Ec.[1]

\section{Vcl ; CPO/puzolana SF 100/00 > 80/20 >70/30 $>\mathbf{6 0 / 4 0}$, desde 150 hasta 545 días Ec.[2] \\ Vcl ; CPO/puzolana D y N 100/00 > 80/20 > 70/30 > 60/40, desde 7-28 hasta 760 días Ec.[3]}

3. Los valores de $\mathrm{Vcl}$ de cada CPO o CPRS puro ensayado y los de sus correspondientes PUZC, fueron una consecuencia directa de su diario $\Delta \mathrm{L}(\%)$ solamente. Esto ha sido debido a la formación de ettringita de lenta formación, ett-If, o de origen el $\mathrm{C}_{3} \mathrm{~A}$ presente en dicho CPRS ó CPO principalmente (14-18). Además y por lo general,

- los máximos valores de $\mathrm{Vcl}_{7 \mathrm{~d}}$ se produjeron cuanta más cantidad de puzolana $\mathrm{Z}$ reemplazó al $\mathrm{CP}$, ver las Figuras $1,2,3,4$ y 5 , y

- en muchos casos estudiados, dicho reemplazo de puzolana Z logró transformar dos ó tres curvas de Gauss sucesivas del $\mathrm{CP}$ puro (cuyo contenido de $\mathrm{C}_{3} \mathrm{~A}(\%)$ difería del de los demás $\mathrm{CP}$ ) en una sola curva de su(s)

\section{Observations:}

1. In all ASTM C 452-68 specimens made with the 57 $P O Z C$, by the end of the test, the $\mathrm{VCl}$ values declined to zero from the 7-21-day figure. It will also be noted that in all $57 \mathrm{POZC}$, the $\mathrm{VCl}$ values always peaked during the first 28 days, and some cases during the first 7-21 days, but in any event always earlier than in the respective plain $P C$ (Figures 1, 2, 3, 4 and 5), and by and large, at even earlier ages when higher proportions of $Z$ pozzolan were added to the OPC.

In other words, Vcl always dropped faster for any family of $P O Z C$ tested than for its respective plain $P C$, and by and large, faster yet as the $Z$ pozzolan content increased. The values began to decrease immediately after peaking, normally at the age of 7-28 days, except for POZC 80/20 and $70 / 30$ P1/D that were at 90 days age due to their respective specimens were bended (Figure 7), and respective real increase in length, $\mathbf{\Delta L}(\%)_{120 d}$ and $\mathbf{V c l}_{120 d}$ could not be already measured. In contrast, for 60/40 POZC $P 1 / D$ could (Figure 1(a)).

2. When $Z$ pozzolan increased, $V c_{7-28 d}$ values increased with SF and decreased with $D$ and $N$ diatomites, but they all being always lower than the corresponding $\mathrm{VCl}$ value of their respective plain OPC, and lower still than the corresponding $\mathrm{VCl}$ value which would have been achieved regarding $Z$ pozzolan as being "inert" from the point of view the sulphate attack or "inert" $S R$, as logical. Thus, the $\mathbf{V c l}_{\mathbf{7 - 2 8 - 7 6 0 d}}$ values fit the following inequality:

$$
\begin{aligned}
& <V c l<O P C / S F \text { pozzolan } 100 / 00>>80 / 20< \\
& 70 / 30<60 / 40 \text {, from } 7 \text { up to } 28 \text { days Eq.[1] } \\
& <\mathrm{Vcl}<\text { OPC/Z pozzolan } 100 / 00>80 / 20> \\
& 70 / 30>60 / 40 \text {, from } 7-28 \text { up to } 760 \text { days } \mathbf{E q} \cdot[2] \\
& <\mathrm{Vcl}<\mathrm{OPC} / Z \text { pozzolan } 100 / 00>>80 / 20> \\
& 70 / 30>60 / 40 \text {, from } 150 \text { to } 545 \text { days } \mathbf{E q} \cdot[3]
\end{aligned}
$$

3. VCl value for any plain OPC $\left(=P n^{\circ}\right)$ or $\operatorname{SRPC}\left(=P Y n^{\circ}\right)$ tested and for their respective POZC-Z pozzolan, was a direct consequence of its daily $\Delta L(\%)$ only; this is due to the ett-If formation from $C_{3} A$ origin present in the SRPC and OPC mainly (14-18). Furthermore and by and large,

- $\quad$ the peak $\mathrm{Vcl}_{7 \mathrm{~d}}$ values brought down as more $\mathrm{Z}$ pozzolan was added, see Figures 1,2,3,4 and 5, and

- for most cases studied, the additional Z pozzolan transformed two or three combined Gauss curves for each $\mathrm{PC}$ (whose $\mathrm{C}_{3} \mathrm{~A}(\%)$ content differed from all the other $\mathrm{PC}$, be it recalled) into one curve for the 


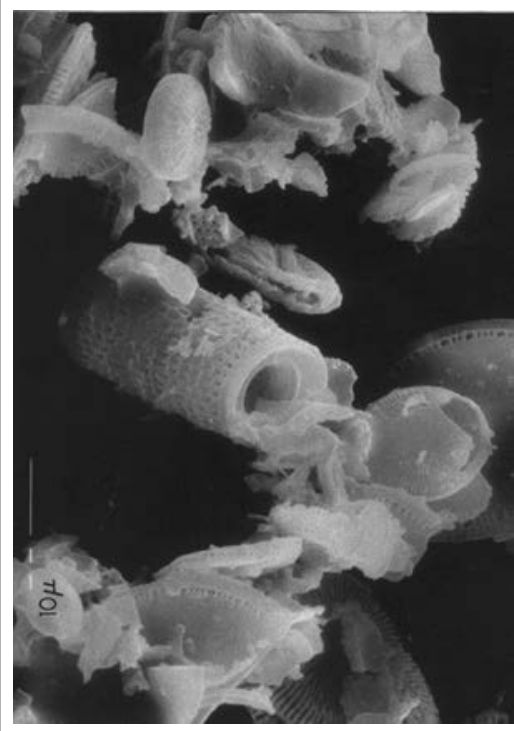

Figura 6 (a). Imágenes SEM de diatomeas céntricas y fusiformes, ambas de tipo $D$, antes de haber desarrollado su actividad puzolánica con portlandita.

A 1710 aumentos.

Figure 6 (a). SEM images of central diatomites and diatomite with spindle shape, both of them $D$ type, before having developed its pozzolanic activity with portlandite. At 1710x magnification.

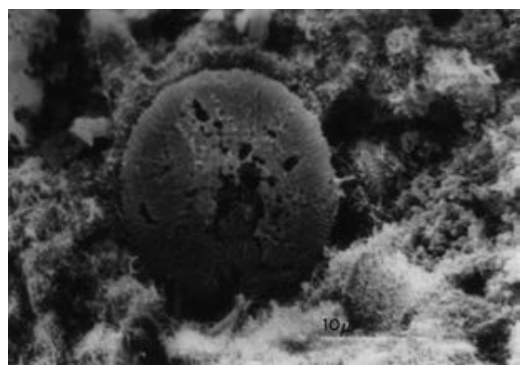

Figura 6 (d). Imágenes SEM de diatomeas céntricas tipo $D$, en pleno desarrollo de su actividad puzolánica con portlandita para originar geles CSHE protectores del ataque del yeso. A 2000 aumentos.

Figure 6 (d). SEM images of central

diatomite $D$ type, developing its pozzolanic activity with portlandite to originate protective $\mathrm{CSH}^{\mathrm{E}}$ gels against gypsum attack. At 2000x magnification.

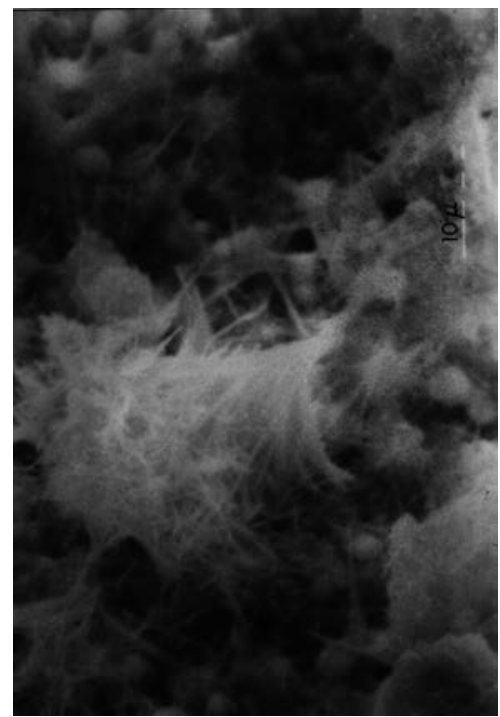

Figura 6 (b). Imágenes SEM de diatomeas fusiforme tipo $D$, después de haber desarrollado su actividad puzolánica con portlandita para originar geles CSH "externos" (= CSHE) (57-62) protectores del ataque del yeso. A 6000 aumentos.

Figure 6 (b). SEM images of diatomite type $D$, with spindle shape, after having developed its pozzolanic activity with portlandite to originate protective $\mathrm{CSH}$ "outer" gels (= CSHE) (57-62) against gypsum attack. At 6000x magnification.

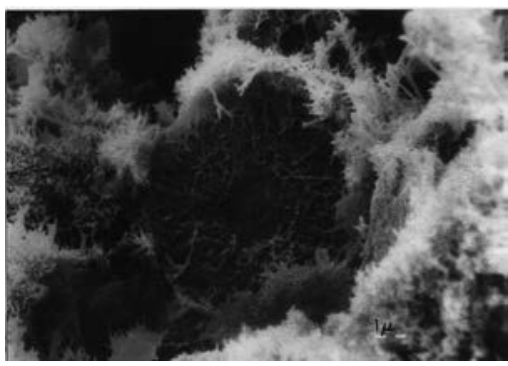

Figura 6 (e). Imágenes SEM de diatomeas céntricas tipo $D$, después de haber desarrollado su actividad puzolánica con portlandita

para originar geles CSHE protectores del ataque del yeso. A 3000 aumentos. Figure 6 (e). SEM images of central diatomite $D$ type, after having developed its pozzolanic activity with portlandite to originate protective CSHE gels against gypsum attack. At 3000x magnification.

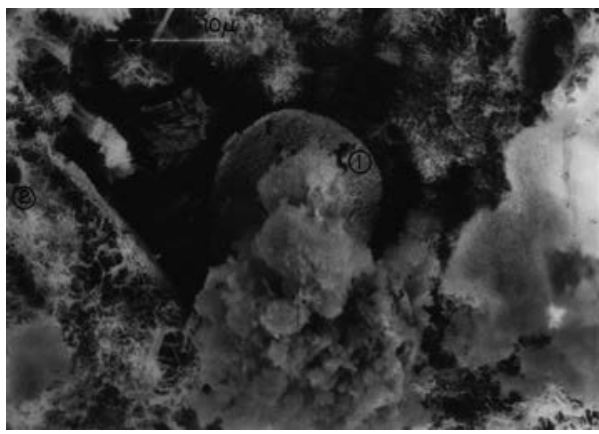

Figura 6 (c). Imágenes SEM de diatomeas tipo D: (1) céntricas y (2) pinnadas, en pleno desarrollo de su actividad puzolánica con portlandita para originar geles CSHE protectores del ataque del yeso.

Figure 6 (c). SEM images of diatomites $D$ type:(1) central and (2) pinnate diatomites, developing its pozzolanic activity with portlandite to originate protective CSHE gels against gypsum attack. At 2000x magnification.

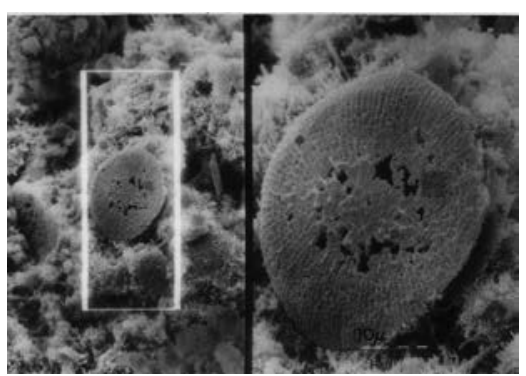

Figura 6 (f). Imágenes SEM de diatomeas céntricas tipo $D$, en pleno desarrollo de su actividad puzolánica con portlandita para originar geles CSHE protectores del ataque del yeso. A 800 y 2000 aumentos, respectivamente.

Figure $6(f)$. SEM images of central diatomite $D$ type, developing its pozzolanic activity with portlandite to originate protective CSHE gels against gypsum attack. At 800x and 2000x magnification, respectively.

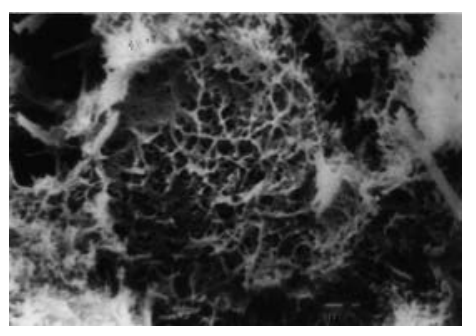

Figura 6 (g). Imágenes SEM de diatomeas céntricas tipo $D$, después de haber desarrollado su actividad puzolánica con portlandita para originar geles CSHE protectores del ataque del yeso. A 6000 aumentos.

Figure 6 (g). SEM images of central diatomite D type, after having developed its pozzolanic activity with portlandite to originate protective CSHE gels against gypsum attack. At 6000x magnification. 
correspondiente(s) PUZC, la cual alcanzaría además su máximo valor de Vcl más pronto, por lo general, 7-2860 días antes, que su respectivo CP puro.

4. Sea cual fuere el contenido de $\mathrm{C}_{3} \mathrm{~A}(\%)$ del $\mathrm{CP}$ que se considere, la curva de Gauss de su PUZC 80/20 es la más parecida de todas a la suya propia (Figuras 1(a)-(f), 2(g)(j), 3(a)-(d), 4(e)-(g) y 5(a)(b)).

Consideraciones previas: El objeto de la cineto-química es el estudio de la evolución de las reacciones químicas en función del tiempo. La cineto-química trata en especial la medición e interpretación de las velocidades de reacción, las cuales se definen mediante la siguiente ecuación: $\mathbf{R}=\mathbf{d X} / \mathbf{d t}$ [4]. Así, para una reacción química que tiene lugar a través de la interfase sólido <> líquido -como ocurre con la formación de la ettringita, los geles CSH y los grupos silanol, $\mathrm{Si}-\mathrm{OH}-$, si el área de dicha interfase no se conoce, como suele ser el caso habitualmente, se tienen que utilizar diferentes definiciones para la velocidad de reacción, tales como: $\mathbf{R}=(\mathbf{1} / \mathbf{W})(\mathbf{d X} / \mathbf{d t})$ [5] ó $r=\left(\mathbf{1} / \mathbf{V}^{\prime}\right)(\mathbf{d X} / \mathbf{d t})[\mathbf{6}]$, donde $\mathbf{W}$ y $\mathbf{V}^{\prime}$ son el peso $y$ el volumen de las partículas sólidas dispersas dentro de la fase líquida. No obstante y de acuerdo con lo anterior, la Vcl de las probetas ASTM C 452-68 puede considerarse lo suficientemente representativa para el objetivo primordial de esta investigación, puesto que:

- Ambos parámetros, $\mathbf{W}$ y $\mathbf{V}^{\prime}$, y los parámetros de los correspondientes productos de reacción (en este estudio, ettringita de origen $\mathrm{C}_{3} \mathrm{~A}$ del $\mathrm{CP}$ y geles $\mathrm{CSH}$ y grupos silanol, $\mathrm{Si}-\mathrm{OH}$ de origen $\mathrm{SiO}_{2}{ }^{\mathrm{r}-}$ de las puzolanas $\mathrm{Z}$ y geles $\mathrm{CSH}$ de origen $\mathrm{C}_{3} \mathrm{~S}$ y $\mathrm{C}_{2} \mathrm{~S}$ del $\mathrm{PC}$ ), son muy difíciles de separar y cuantificar con exactitud;

- No importa utilizar cualquiera de las dos ecuaciones anteriores [5] ó [6], puesto que la velocidad de reacción química debe de ser proporcional a la derivada del avance de la reacción en función del tiempo;

- El transcurso de la reacción química de formación de ettringita debe de estar representado, por tanto, por el aumento "total" del tamaño de la(s) probeta(s), o simplemente, por su mayor dimensión: su longitud (L); finalmente, la evolución del incremento porcentual de longitud de las probetas ASTM C 452-68 de cada cemento, en función del tiempo ó Velocidad de Crecimiento Longitudinal $=\Delta \mathbf{L}(\%) /$ día $=\mathbf{V c l}$, se ha considerado lo suficientemente representativa para el fin último de esta investigación, por cuyo motivo ha sido representado gráficamente y se puede ver en las Figuras 1 (a)-(f), 2 (g)-(j), 3 (a)-(d), 4 (e)-(g), y 5 (a)(b).

\section{* Deducciones de las observaciones (A):}

La mayor parte de la reacción química de formación de ett-If en las probetas ASTM C 452-68, tiene lugar durante los primeros 28 días del ensayo, de modo y manera que, en tanto en cuanto mayor es el contenido de $\mathrm{C}_{3} \mathrm{~A}(\%)$ del respective $\mathrm{POZC}$, where the $\mathrm{Vcl}$ value always peaked earlier - generally speaking, at 7-28-60 days- than in the respective plain PC.

4. Irrespective the $C_{3} A(\%)$ content of the $P C$ is, the more closely its Gauss curve resembled its 80/20 POZC curve, and vice versa (Figures 1(a)-(f), 2(g)-(j), 3(a)-(d), 4(e)(g) and $5(a)(b))$.

Prior consideration: The aim of the kinetic-chemistry is to study the evolution of chemical system(s) in terms of time. Kinetic-chemistry deals particularly with measurement and interpretation of reaction rates which are to be defined as $\boldsymbol{R}=\boldsymbol{d} \boldsymbol{X} / \boldsymbol{d} \boldsymbol{t}$ [4]. For a chemical reaction that takes place across a solid-liquid interface -as it occurs with ettringites and $\mathrm{CSH}$ gels and silanol groups, $\mathrm{Si}-\mathrm{OH}$-, if the interface area is not known, as is usually the case, different definitions for the "rate" should be used, such as: $R=(1 / W)(d X / d t)$ [5] or $r=\left(1 / V^{\prime}\right)(d X / d t)$ [6], where $\boldsymbol{W}$ and $\boldsymbol{V}^{\prime}$ are weight and volume of the solid particles dispersed within the liquid phase. $\mathbf{V c l}$ was nevertheless considered sufficiently representative for the primary objective of this study, since:

- Both $\boldsymbol{W}$ and $\boldsymbol{V}^{\prime}$ and the parameters for the corresponding reaction products formed (in this study, ettringite from $\mathrm{C}_{3} A$ origin of $\mathrm{PC}$ and $\mathrm{CSH}$ gels and silanol groups, $\mathrm{Si}-\mathrm{OH}$, from $\mathrm{SiO}_{2}{ }^{r-}$ origin of $\mathrm{Z}$ pozzolans and $\mathrm{CSH}$ gels from $C_{3} S$ and $C_{2} S$ origins of $P C$ ), are very difficult to separate and accurately quantify;

- Since the reaction rate must to be proportional to the derivative of the advance of the reaction over time, it is irrelevant whether expression [5] or [6] is used;

- The course of the ettringite formation chemical reaction may be represented by the "total" increase in specimen size or by its mayor dimension, i.e., its length $(\boldsymbol{L})$; the pattern of change in the Length Growth Rate $=\boldsymbol{\Delta L}(\%) / \boldsymbol{d a y}=\mathbf{V c l}$, is represented for ASTM C 452-68 specimens (Figures 1 (a)-( $f$ ), 2 (g)-(j), $3(a)-(d), 4(e)-(g)$, and 5 (a) (b)).

\section{* Deductions from the observations $(A)$ :}

The chemical reaction forming ett-If in ASTM C 452-68 specimens, takes place largely during the first 28 days of the test. The higher the $C_{3} A(\%)$ content in the $O P C$, the earlier the reaction reaches completion. This behaviour 
CPO, más pronto llega a su fin dicha reacción química. Y este comportamiento constituye una prueba más de que la formación de dicha ettringita debe de asimilarse bastante más al mecanismo topoquímico, $\mathbf{T P Q}$, con disolución previa, que al mecanismo de "through solution", TS, o si no, la primera de las dos curvas de Gauss de los CPO P-1, P-2, P-4, P-32 y P-31, habría sido la misma (14, 16, 18). $Y$ como no ha ocurrido eso sino lo contrario, dicha suposición no es correcta.

La acción doble "expansión $<>$ relleno de poros", que se debe de originar por la formación de ett-lf, vinculada a la supremacía del mecanismo TPQ con disolución previa, sobre el mecanismo de TS, debe de hacer que el 1er. valor máximo de $\mathbf{V c l}$ de la $1^{\mathrm{a}}$ curva de Gauss alcance más tarde su correspondiente valor mínimo y con menor acción de "relleno de poros", cuanto menor es el contenido de $\mathrm{C}_{3} \mathrm{~A}(\%)$ del $\mathrm{CP}$, como así ha ocurrido en esta investigación. Véanse las curvas de los $10 \mathrm{CP}$ en las Figuras 1 (a)-(f), 2 (g)-(j), 3 (a)-(d), 4 (e)-(g) y 5 (a)(b).

Finalmente y de todas estas observaciones, se puede deducir también que la mayor parte de la ettringita de lenta formación, ett-If (14-18), se origina durante los primeros 28 días de edad de las probetas ASTM C 452-68. Por esta razón, la especificación física opcional $\Delta \mathrm{L}_{14 d} \leq 0,040 \%$, que se utiliza actualmente para diferenciar los CPRS de los CPO, a diferencia de la que se utilizó en un principio, $\Delta \mathrm{L}_{28 \mathrm{~d}} \leq$ 0,054\%, "predice" más bien que "asegura" el probable comportamiento de un CP frente el ataque de los sulfatos. $Y$ eso que en este método de ensayo no hay tiempo suficiente para que el CP desarrolle toda su actividad hidráulica con agua, antes que comience el ataque de los sulfatos, puesto que ambos, hidratación y ataque selenitoso, comienzan simultáneamente. $Y$ aún hay mucho menor tiempo de hidratación con la $1^{\text {a }}$ especificación, $\Delta \mathrm{L}_{14 \mathrm{~d}} \leq 0,040 \%$ (50), que con la $2^{\mathrm{a}}, \Delta \mathrm{L}_{28 \mathrm{~d}} \leq 0,054 \%(34,51)$, pero a pesar de ello, este método de ensayo se utiliza para caracterizar y diferenciar, a 14 días de edad tan sólo, los CPO de los CPRS.

\section{* Deducciones de las observaciones (B):}

De acuerdo con las observaciones (B)1 y (B)2, cuanto mayor o menor ha sido el valor absoluto de la pendiente negativa de la curva de Vcl, mayor o menor debe de haber sido también su correspondiente pendiente positiva. $Y$ esta pendiente positiva ha correspondido por lo común en la mayoría de los PUZC, a la edad de 7 días. Estas observaciones justifican el siguiente razonamiento:

- Examinando en primer lugar, las curvas de los CP puros únicamente, se puede ver que, en general, el máximo valor de $\mathrm{Vcl}$, que se produce entre los 7 y los 60 días de edad, aumenta con el contenido de $\mathrm{C}_{3} \mathrm{~A}(\%)$ del $C P$, lo que, por otra parte, es lógico, y constitutes further proof that the $\mathbf{T P Q}$ mechanism with prior dissolution, must prevail over the TS mechanism; otherwise, OPC $P-1, P-2, P-4, P-32$ and $P-31$ would have formed the same first Gauss curve. Precisely the opposite behaviour was observed, however. The contrary assumption must, therefore, be ruled out.

The dual "filling-in $<>$ expansion" process, which must be produced by ett-If formation, linked to the TPQ mechanism with prior dissolution, prevailing over TS mechanism, must make that the first maximum $\mathbf{V c l}$ value of the first Gauss curve reaches its minimum value later, and with smaller ("filling-in"), the lower $C_{3} A(\%)$ content of the PC ("expansion") is, as obtained in this research. See 10 PC curves in Figures1 (a)-(f), 2 (g)-(j), 3 (a)-(d), 4 (e)-(g) and 5 (a)(b).

Finally it may be deduced from these observations as well, that most of the slow formation of ettringite from $C_{3} A$ origin present in PC or ett-If (14-18), takes place during the first 28 days in ASTM C 452-68 specimens (1). For this reason, the optional standard physical requirement $\Delta L_{14 d}$ $\leq 0.040 \%$ (50), which is presently used to differentiate SRPC from OPC, unlike the formerly $\Delta L_{28 d} \leq 0.054 \%$ $(34,51)$ criterion, "predicts" rather than "assures" the probable behaviour of a PC under gypsum attack. In addition, in this test procedure there is not sufficient time for the completion of the PC hydraulic reaction with water before sulphate attack starts, because both of them star simultaneously. And there is much lesser time still with the $1^{\text {st }}$ one criterion $\boldsymbol{\Delta L}_{\mathbf{1 4 d}} \leq 0.040 \%$ (50) than with the $2^{\text {nd }}$ one, $\boldsymbol{\Delta} \boldsymbol{L}_{\mathbf{2 8 d}} \leq 0.054 \%(34,51)$, but despite of all, this test method is used to characterize and to differentiate at 14 days age only, OPC and SRPC. See the continuation of this paragraph in the Section 6. Deductions, later on.

\section{* Deductions from the observations (B):}

According to observations (B)1 and (B)2, the bigger/ smaller the negative slope of the Vcl curve is, the bigger/ smaller must the respective positive slope be. The positive slope corresponds to the first 7 days. These observations support the following reasoning:

- Examining firstly only the plain PC curves, the maximum $\mathrm{VCl}$ value at 7-60 days age is found to increase -by and large-, with $P C C_{3} A(\%)$ content in the $P C$, and 
- Examinando en segundo lugar, las curvas de sus correspondientes PUZC con puzolana $\mathrm{Z}$ a la edad de 7 días, se puede observar que sea cual fuere el máximo valor de $\mathrm{Vcl}_{7 d}$ que se considere, dicho valor ha sido siempre menor que el correspondiente valor de $\mathrm{Vcl}_{7 \mathrm{~d}}$ que se habría alcanzado considerando la puzolana $Z$ como un "inerte $\mathrm{Rs}$ ". Independientemente de si el $\mathrm{VCl}_{7}$ 14d aumentó o disminuyó con la cantidad de puzolana $Z$ añadida. $Y$ cuanto mayor fue la cantidad de puzolana $Z$ que se añadió, más lenta resultó ser la reacción química de formación de ett-If o de origen $\mathrm{C}_{3} \mathrm{~A}$ del CPO cuando la hidratación selenitosa progresó, porque la puzolana $\mathrm{Z}$ ha sido siempre o terminó siendo obstructora, dificultadora e impedidora total incluso, según la cantidad añadida, de dicha hidratación selenitosa. Este comportamiento proporciona en cualquier caso, la ratificación del efecto químico-físico protector de la puzolana $Z$, en cantidad adecuada para cada $\mathrm{CP}$, debido a su muy especial y particular actividad puzolánica (de origen su contenido de $\mathrm{SiO}_{2}{ }^{\mathrm{r}}$-(\%) solamente) con la portlandita, formando geles CSH (subsiguientemente transformados en toberoritas) cuando reaccionan con los iones $\mathrm{Ca}^{2+}$, y grupos silanol, $\mathrm{Si}-\mathrm{OH}$ (más tarde convertidos en ácido silícico hidratado que finalmente reacciona también con la portlandita para formar más geles CSH), cuando reaccionan con los iones $\mathrm{OH}^{-}$, pero cuyo estado intermedio y final pueden verse en las Figuras 6(b)-(g). Lo que hace más difícil, en definitiva, le formación de ett-If de origen $C_{3} A$ del $\mathrm{CPO}$. Ambos iones, $\mathrm{Ca}^{2+}$ y $\mathrm{OH}^{-}$, están presentes en el ensayo de Frattini, en el ensayo ASTM C 452-68 o en cualquier otro ensayo, y en el hormigón de obra real. $Y$ el comportamiento dispar mostrado por las probetas del SF, desde la edad de 7 días hasta la de 28 ó Ec. [1], se justificaría por la estimulación de la hidratación, por vía directa y no-directa $(18,22,25,33)$ especialmente, que el SF (microesferas vítreas casi todo él) debió de ejercer sobre la fracción del CP con la que se había mezclado en cada PUZC-SF, y muy en particular, sobre su contenido de $C_{3} A$ (la estimulación por vía indirecta $(18,25)$ debió de ejercerla también, no obstante, el SF, porque el ensayo de Frattini (41) lo cumplió a la edad de 1 día, es decir, 7 ó 14 días antes de cuando debía (35), pero durante las 16 primeras horas a lo sumo de hidratación selenitosa nada más (22), por lo que debió de quedar solapada o enmascarada por las de las vías directa y no-directa), pues no en vano, su adsorción de humedad terminó por ser claramente, la mayor de las tres puzolanas Z a la edad de 28 días (Tabla 6); y aunque la adsorción de humedad de la puzolana $\mathrm{N}$ fue mayor hasta la edad de 21 días nada más, no es menos cierto tampoco, que esa supremacía debió de haber sido provocada por su $\approx 20,34 \%$ de filler calizo, y no tanto quizás por su otra fracción de $\approx 79,66 \%$ de diatomeas, puesto que la adsorción de humedad de la puzolana $D$, con $\approx 99 \%$ de diatomeas (frústulos o estuches vítreos
- Examining secondly, their POZC with Z pozzolan at 7 days age: any $\mathrm{VCl}_{7 d}$ value obtained has been always lower than the corresponding $\mathrm{VCl}_{7 d}$ value which would have been achieved regarding $Z$ pozzolan as being inert $_{S R}$ in terms of sulphate attack or "inert ${ }_{S R}$ ". Irrespective, whether $\mathrm{VCl}_{7-14 d}$ increased or decreased with the amount of $Z$ pozzolan added. And the larger the amount of $Z$ pozzolan added, the slower is the chemical reaction of ett-If formation from $C_{3} A$ origin of OPC as the selenitous hydration moves forward, because $Z$ pozzolan has always been or finished hindering or even preventing sulfatic hydration altogether. This provides in any case, further ratification of the chemical-physical protective effect of $Z$ pozzolan, in adequate amount for each $P C$, due to the very special and particular pozzolanic activity (from its $\mathrm{SiO}_{2}{ }^{-}(\%)$ content origin only) developed when it reacted with the $\mathrm{Ca}^{2+}$ and $\mathrm{OH}^{-}$ions, respectively of the portlandite -forming $\mathrm{CSH}$ gels (subsequently transformed into tobermorites), when reacts with $\mathrm{Ca}^{2+}$ ions, and silanol groups, $\mathrm{Si}-\mathrm{OH}$ (later converted into hydrated silicic acid which reacts also with portlandite forming more $\mathrm{CSH}$ gels finally), when reacts with $\mathrm{OH}^{-}$ions-, but whose intermediate and final state can be seen in Figures $6(b)-(g)$, which is an obstacle for the formation of ett-If of $C_{3} A$ origin from OPC. Both of them, $\mathrm{Ca}^{2+}$ and $\mathrm{OH}^{-}$, present in the Frattini test liquid phase, in ASTM C 452-68 specimens and/or in any other tests, or in real life situations: concretes. The despair behavior exhibited by the SF specimens, from the age of 7 days up to 28 days, or Eq. [1], could be justified by stimulation of hydration, by direct and non-direct way $(18,22,25,33)$ especially, since the SF (vitreous microspheres, principally) should have exerted its influence over the $P C$ fraction, with which it was mixed in each POZC-SF, and particularly, over its $C_{3} A$ content (stimulation by indirect way $(18,25)$, the SF should have exerted it also, since it has met the Frattini test requirements (41) at the very 1 day-age, that is to say, 7 or 14 days before the standard age (35), and particularly, at 16 hours of the beginning of selenitous hydration (22), that is why its action would have been overlapped by both direct and nondirect stimulations effects), not in vain, its humidity adsorption finished clearly being the highest from the other three $Z$ pozzolans at the age of 28 days (Table 6); although the humidity adsorption for $N$ pozzolan was major up to the age of 21 days, it is also true that this supremacy should have been provoked by its $\approx 20.34 \%$ of calcite filler, and not so much by its another fraction of $\approx 79.66 \%$ of diatomite, since the humidity adsorption of D pozzolan, with its $\approx 99 \%$ of diatomite (vitreous frustules, spongy and empty, of major size than, also vitreous, microspheres of the $S F)$, was, on the contrary, the lowest from the others. It must to be emphasized here that calcite filler 
agujereados y huecos, de mucho mayor tamaño que las microesferas también vítreas del SF), fue, por el contrario, la menor de las tres. Y no se olvide, tampoco, que el filler calizo no posee característica puzolánica alguna por ser totalmente cristalino. Por consiguiente, esta composición de la puzolana $\mathrm{N}$ la faculta para estimular la hidratación selenitosa, en este caso, del CPO con el que se mezcló la puzolana N, por vía directa, no-directa e indirecta pero sin actividad puzolánica alguna de por medio, motivo por el cual, le ha podido ser aplicable también a sus PUZC-N la Ec. [1]. Lo que resulta ser, en definitiva, una prueba de la veracidad de la hipótesis de comportamiento mostrado por las correspondientes probetas del SF referida antes.

Además, en todas las probetas ASTM C 452-68 de los PUZC con puzolana $Z$, la mayor parte de la reacción química de formación de ett-If 0 de origen $C_{3} A$ especialmente del CPO, tiene lugar durante los primeros 90-120 días de edad, es decir, cuando los valores de Vcl disminuyen hasta $0.00(\%) /$ día después de haber alcanzado su máximo valor, y mucho antes, por tanto, de la edad de 730 días o edad final del ensayo (Figuras 1 (a)-(f), 2 (g)-(j), 3 (a)(d), 4 (e)-(g) y 5 (a)(b)). Por consiguiente, la evidencia empírica anterior constituye razón suficiente para sustentar lo siguiente: does not possess any pozzolanic characteristic, since it is totally crystalline. Therefore, this composition of $Z$ pozzolan empowers it to stimulate the sulfatic hydration of the OPC, with that it has been mixed, by direct, non-direct and indirect way but without some pozzolanic activity present, and for this reason, the Ec. [1] could be applied to its POZC as well, which is a further proof of the behavioural hypothesis referred before for SF.

Moreover, for all ASTM C 452-68 specimens of POZC-Z pozzolan, most of the chemical reactions leading to the formation of ettringite from $C_{3} A$ origin mainly, present in $O P C$, take place during the first 90-120 days of age, i.e. when the $\mathrm{VCl}$ declines to have $0.00(\%) /$ day after having peaked. Indeed, as Figures 1 (a)-(f), 2 (g)-(j), 3 (a)-(d), $4(e)-(g)$ and $5(a)(b)$ show most of the area defined by the curves for all the blended cements studied correspond to ages zero to 90-120 days. Therefore, the above empirical evidence constitutes sufficient grounds to sustain the following:

Tabla 6 / Table 6

Adsorción de Humedad. Humidity Adsorption.

\begin{tabular}{|c|c|c|c|c|c|c|}
\hline \multirow{3}{*}{$\begin{array}{l}\text { Puzolanas I } \\
\text { Pozzolans }\end{array}$} & \multicolumn{6}{|c|}{ Adsorción de Humedad / Humidity absorption (\%) } \\
\hline & \multicolumn{6}{|c|}{ Edad / Age (días / days) } \\
\hline & 1 & 3 & 7 & 14 & 21 & 28 \\
\hline $\begin{array}{l}\text { SF } \\
\text { D } \\
\mathrm{N}\end{array}$ & $\begin{array}{l}5.59 \\
0.04 \\
8.31\end{array}$ & $\begin{array}{l}9.26 \\
1.50 \\
8.50\end{array}$ & $\begin{array}{c}12.20 \\
1.85 \\
8.92\end{array}$ & $\begin{array}{c}16.67 \\
1.85 \\
11.15\end{array}$ & $\begin{array}{c}18.88 \\
3.77 \\
13.99\end{array}$ & $\begin{array}{c}21.50 \\
3.77 \\
15.02\end{array}$ \\
\hline
\end{tabular}

1. La relación descrita en las Ecs. [2] y [3] y el elevado valor de $\mathrm{Vcl}_{7-28 \mathrm{~d}}$ producido, fueron una consecuencia directa derivada de la sustitución física de CPO por puzolana Z. Es decir, la $\mathrm{SiO}_{2}{ }^{\mathrm{r}-}$ de la puzolana $\mathrm{Z}$ al convertirse en geles $\mathrm{CSH}(57,58)$ prevalecieron más pronto (con la D y la N) o más tarde (con el SF), por su muy especial y particular actividad puzolánica, referida antes, haciendo por este motivo más difícil dicha formación de ett-If en tales probetas en este caso, de origen $\mathrm{C}_{3} \mathrm{~A}$ del $\mathrm{CPO}$. Además y por lo general, para muchos casos estudiados, el orden de magnitud de la $\mathrm{Vcl}$ fue infinitamente más pequeño desde antes de la edad de 7-28-60 días, disminuyendo cuando el contenido de puzolana $Z$ aumentó en todos los casos. Hasta tal punto y medida, que siempre fue menor que el correspondiente valor de $\mathrm{Vcl}$ que se hubiera obtenido considerando la puzolana $\mathrm{Z}$ un "inerte $\mathrm{RS}$ ", y de paso,
1. The relationship described in Eqs. [2] and [3] and the high $\mathbf{V C l}_{\mathbf{7 - 2 8 d}}$ values found were the direct consequence derived from the physical substitution of OPC by $Z$ pozzolan. That is to say, $\mathrm{SiO}_{2}{ }^{-}$present in $Z$ pozzolan when converted in CSH gels and silanol groups, prevailed sooner (with D and N pozzolans) or later (with SF), by its very especial and particular pozzolanic activity, referred before, which made more difficult ett-If formation from $C_{3} A$ origin present in OPC. This is tantamount to saying that $\mathrm{CSH}$ gels and silanol groups from $\mathrm{SiO}_{2}{ }^{\text {- }}$ origin present in $Z$ pozzolan, have necessarily to be the chief cause of relationship [2] and the high $\mathrm{VCl}_{7-28 d}$ values obtained for all POZC families tested. Furthermore and by and large, the order of magnitude of $\mathrm{VCl}$ was infinitely smaller from before 7-28-60 days for most cases studied, decreasing as the $Z$ pozzolan content increased in all cases, and to such 
mostrando también la consecuencia técnica derivada de esa muy especial y particular actividad puzolánica suya: impedir o al menos dificultar, la hidratación selenitosa del contenido de $\mathrm{C}_{3} \mathrm{~A}(\%)$ de la fracción del $\mathrm{CPO}$ con la que la puzolana $Z$ ha sido mezclada en cantidad adecuada o no, respectivamente. Véase y compárese la Figura 1(a) con el resto de Figuras hasta la Figura 5. Y en buena lógica, más y mejor aún lo impiden también, si el hormigón, mortero y/o pasta de su PUZC ha tenido un curado hídrico adecuado antes de sufrir el ataque sulfático (14, 18, 21, 22). Lo que se ha demostrado empíricamente una vez más: véanse las Figuras 7,8 y 9:

- Figuras 7 y 8, mediante el método ASTM C 452-68: ninguno de los PUZC P1/D pudo ser catalogado de "elevada" ni aún "moderada" resistencia sulfática (RS) (Figura 7), como tampoco lo fue su CPO P1 (14,11\% $\left.\mathrm{C}_{3} \mathrm{~A}\right)$; en cambio, sus correspondientes PUZC P1/DC fueron todos de "elevada" RS (Figura 8), y

- Figura 9, mediante el método L-A $(6,15,22,34)$ : todos los PUZC P1/D y P2/D pudieron ser catalogados de "elevada" RS, en cambio, sus respectivos CPO P1 y P2 (11,09\% $\left.C_{3} A\right)$ resultaron ser de "escasa" o "nula" RS, lógicamente $(14,15,21,22,31)$.

Y la razón, por otra parte, de esta disparidad de criterio es la siguiente: cuando el cemento (CP ó PUZC, en este an extent that, it was always lower than the corresponding $\mathrm{VCl}$ value which would have been achieved regarding $Z$ pozzolan as being inert ${ }_{S R}$, and on the way, showing also like this, the technical consequence derived of its very special and particular pozzolanic activity referred: hindering or even preventing sulfatic hydration of $C_{3} A(\%)$ present in the OPC fraction with which $Z$ pozzolan has been mixed, according to whether $C_{3} A(\%) / Z$ pozzolan ratio is adequate or not, respectively, and also, whether its concrete, mortar and/or paste POZC-Z pozzolan have had or not adequate prior curing water treatment before the sulphate attack (14, 18, 21, 22). See and compare Figure 1(a) with the rest of Figures up to Figure 5. Logically enough, more-even better prevent it as well, if its POZC-Z pozzolan concrete, mortar or paste has been submitted to adequate previous curing water before suffering sulfate attack $(14,18,21,22)$, which once again has been empirically demonstrated, see Figures 7, 8 and 9:

- $\quad$ Figures 7 and 8, by means of the ASTM C 452-68 test: No POZC P1/D could be classified as "high" or still "moderate" sulfate resistant (HSR nor MSR, respectively) (Figure 7), as nor its plain OPC P1 $\left(14.11 \% \mathrm{C}_{3} \mathrm{~A}\right)$; in contrast, their corresponding POZC P1/DC were all HSR (Figure 8), and

- Figure 9, by means of the L-A test $(6,15,22,34)$ : all POZC P1/D and P2/D could be classified as HSR, but, however, their respective OPC P1 and P2 (11.09\% $\left.\mathrm{C}_{3} \mathrm{~A}\right)$ could not, because both of them were LSR ( $\mathrm{L}=$ low) $(14,15,21,22,31)$, as logical.

The reason of this disparity in criteria is the following: when cement (PC or POZC) is submitted to the L-A test, a)

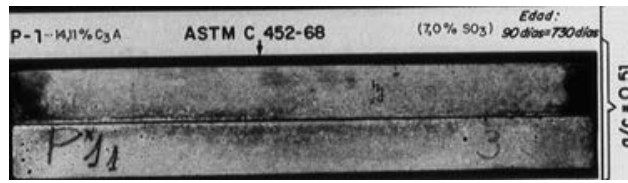

c)

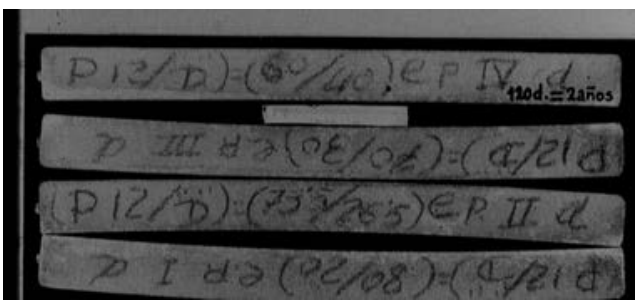

b)

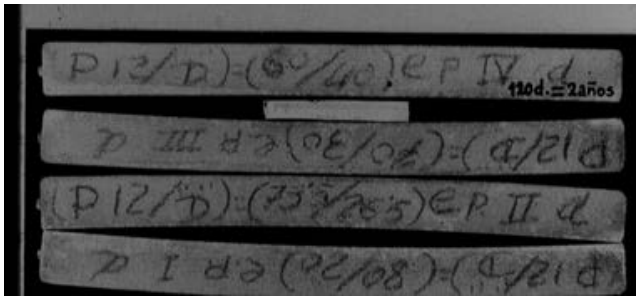

Figura 7. Probetas ASTM C 452-68: (a) 2 del CPO P1 a las edades de 90 y 730 días. Obsérvese que están ligeramente curvadas. (b) y (c) 4 de los PUZC P1/D 80,20, 73,5/26,5, 70/30 y 60/40 a las edades de 90, 120 días y 2 años. Obsérvese que todas las probetas menos las del PUZC P1/D 60/40 ya se habían curvado a la edad de 90 días, habiendo aumentado algo más su curvatura hasta la edad de 120 días nada más.

Figure 7. ASTM C 452-68 type specimens: (a) 2 of OPC P1. Ages: 90 and 730 days. Note that all the specimens, except the POZC P1/D $60 / 40$ specimens, were already bent at 90 days-age, having still increased their curvature up to 120 days-age only. 
caso) es sometido al ensayo L-A, es necesario curarlo hídricamente durante 14 días sumergido en agua destilada, antes de someterlo al ataque de los sulfatos. Lo que no ocurre cuando dicho cemento es ensayado mediante el método ASTM C 452-68 (pregunta: ¿Qué método es el más realista de los dos? Y aunque esta cuestión no ha sido objeto de este estudio, se considera de suficiente interés como para abordarla en profundidad en otro estudio venidero que se publicará próximamente). its previous 14-day curing water is essentially needed before gypsum attack starts, what does not occurs for the ASTM C 452-68 method at all. (Question: What method is then most realistic? And although this issue has not been object of the present study, it is found to be a question worth exploring in greater depth and in fact will be addressed in future publications). a)

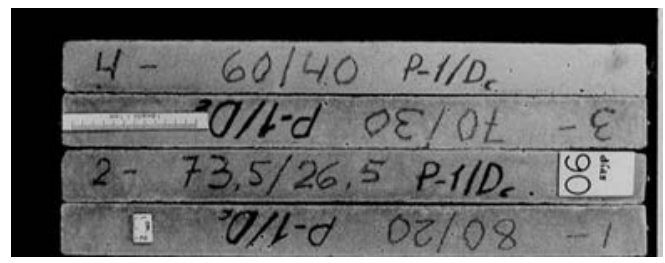

b)

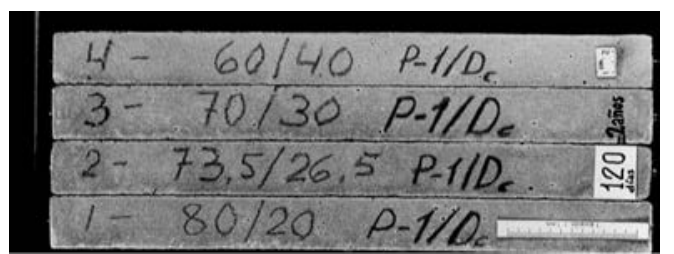

Figura 8. Probetas ASTM C 452-68 de los PUZC P1/Dc 80/20, 73,5/26,5, 70/30 y 60/40 a las edades de 90 y 120 días. La cantidad de puzolana $\mathrm{D}$ seca, se guardó en una bolsita cerrada de tejido de algodón, la cual se colocó suspendida de un hilo de plástico en una disolución permanentemente saturada de $\mathrm{Ca}(\mathrm{OH})_{2}$ durante 28 días, tras los cuales se secó en una estufa a $40^{\circ} \mathrm{C}$ exenta de $\mathrm{CO}_{2}$, para convertirse en una nueva puzolana Dc, que a continuación, se mezcló con la misma cantidad de CPO P1 que la del correspondiente PUZC P1/D. Obsérvese que ninguna de las probetas se curvó durante el ensayo, ni aún posteriormente, como es lógico, porque desde su inicio, esta nueva puzolana Dc protegió a dicho CPO P1 del ataque de los sulfatos.

Figure 8. ASTM C 452-68 specimens of POZC P1/DC 80/20, 73.5/26.4, 70/30 and 60/40 at 90 and 120 days-age. The D pozzolan amount dried was saved carefully in a small closed cotton bag, which was stored in $\mathrm{Ca}(\mathrm{OH})_{2}$ satured solution for 28 days, and after, it was dried to constant weight in an oven at $40{ }^{\circ} \mathrm{C}$ with and $\mathrm{CO}_{2}$ exempt atmosphere, having been converted in the new Dc pozzolan which was mixed with the same OPC P1 amount than the corresponding P1/D. Note that now no specimen was bent during the test, nor in a later time, as logical, because this new Dc pozzolan protected to the OPC P1 of sulphate attack from the start of the test.

En cambio, cuando se usó metakaolín (puzolana M ó MK, la cual es silícea y aluminosa en naturaleza (45) y alumínica en carácter químico (14-18, 22-25, 31)), ninguno de sus 30 PUZC preparados y ensayados también del mismo modo entonces, con ambos métodos de ensayo, el L-A y el ASTM C 452-68, pudieron ser catalogados de "elevada" ni "moderada" RS (14-18).

2. De acuerdo con las observaciones (B)3 y (B)4, la causa principal tiene que ser necesariamente una vez más, la misma que justificó el caso 1 anterior, es decir, la $\mathrm{SiO}_{2}{ }^{\mathrm{r}}$ de la puzolana $Z$ (Tabla 2) y su muy especial y particular reacción puzolánica en un medio acuoso con portlandita y yeso (probetas tipo ASTM C 452-68, en este estudio), la cual la desarrolló durante los primeros 28 días de edad (Tabla 3); y aún mucho más pronto el SF solamente, porque cumplió el ensayo de Frattini a la edad de 1 y 2 días incluso (Tabla 3), es decir, 26 antes de lo que debía. Y por lo general, cuanto mayor cantidad de puzolana Z estuvo presente, más pronto finalizaron estas reacciones químicas de formación de ett-If. Por lo que de acuerdo con estos últimos resultados y los respectivos valores de $\mathrm{Vcl}$ obtenidos, los nuevos productos de dicha reacción puzolánica originados, geles $\mathrm{CSH}$, han interferido lo suficiente a la correspondiente reacción de
Finally and in contrast, when metakaolin (M pozzolan or $M K$, which is siliceous and aluminous in nature (45) and aluminic in chemical character (14-18, 22-25, 31)) was used, no 30 POZC-MK, tested also by means of the L-A and ASTM C 452-68 tests, could be classified as HSR nor MSR (14-18).

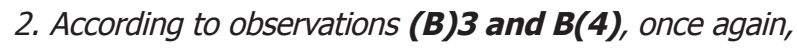
the chief cause has to be necessarily the $\mathrm{SiO}_{2}{ }^{-}$present in $Z$ pozzolan (Table 2) when converted into $\mathrm{CSH}$ gels and silanol groups, as a result of its also very special and particular pozzolanic activity in gypsum and water environments (ASTM C 452-68 specimens in this study) referred before. And the pozzolanic reaction from $\mathrm{SiO}_{2}{ }^{r-}$ origin, in this gypsum and water environment, has taken place during the first 28 days of age (Table 3) (and even perhaps much earlier for SF only, at 1 or 2 days age, because their Frattini test results were already by then positive (Table 3); but we do not think this is the case, due to the fact that their Frattini test results at 28 days, i.e. 26 days later, showed an even much clearer positive result), in most cases studied, and by an large, the more $Z$ pozzolan was added, the sooner these chemical reactions finished. According to the latest experimental 


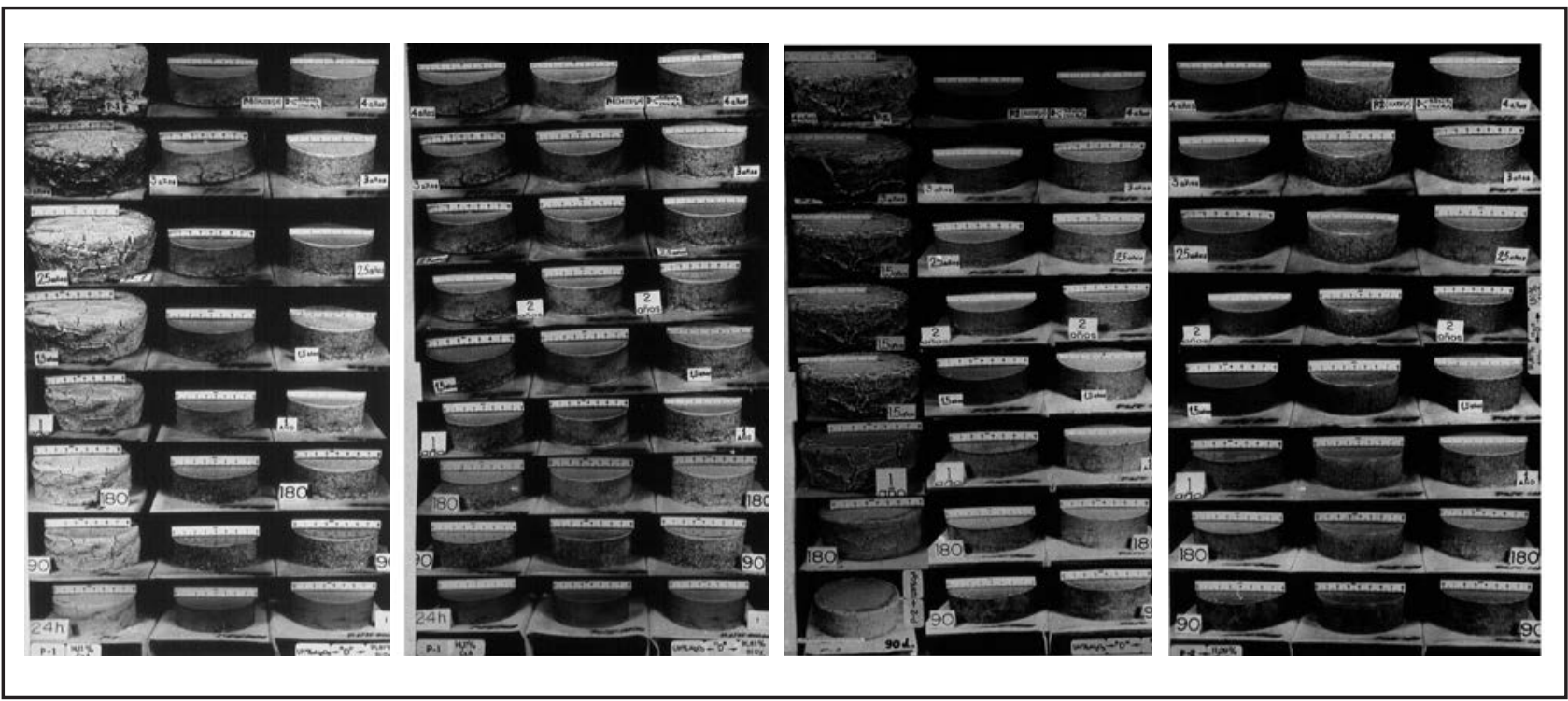

Figura 9. Probetas Le Chatelier-Anstett (L-A) de los CPO P1 (14,11\% $\left.C_{3} A\right)$ y P2 $\left(11,09 \% C_{3} A\right)$ y sus PUZC $80 / 20,70 / 30$ y $60 / 40$ con la puzolana D. Edades: Desde 1 día hasta 4 años. Todos los cementos tuvieron que ser conservados en agua durante 14 días antes de someterlos al ataque de los sulfatos. Resultados: CPO P1 y P2 = Cementos no RS; PUZC P1/D y P2/D 80/20, 70/30 y 60/40 = cementos RS.

Figure 9. L-A specimens of the OPC P1 (14.11\% $\left.C_{3} A\right)$ and P2 (11.09\% $\left.C_{3} A\right)$ and their POZC-D pozzolan 80/20, 70/30 and 60/40. Ages: From 1 day up to 4 years. All the POZC-D pozzolan had been stored in water for 14 days before having been submitted to sulphate attack. Results: OPC P1 and P2 = Not SR cements; POZC P1/D and P2/D 80/20, 70/30 and 60/40 = SR cements.

formación de la ett-If o de origen $\mathrm{C}_{3} \mathrm{~A}$ de su fracción de CPO ( $80 \%$, $70 \%$ y $60 \%)$, hasta hacer incluso que deje de formarse, a pesar de que sus reactivos formadores, $\mathrm{C}_{3} \mathrm{~A}$ del CPO, yeso y agua, continúen estando presentes en cantidad suficiente para que se continúe formando. Buena prueba de ello ha sido que, hasta la edad a la que la Vcl de las probetas de los CPO puros P2*, P4*, P32* y P31* alcanzó el valor cero o edad del fin de la formación de la cantidad total posible de ett-If, común para los cuatro, los valores de $\mathrm{Vcl}$ de las probetas de sus correspondientes PUZC P1/puzolana Z 80/20, 70/30 y 60/40 fueron siempre menores, a igualdad de edad y su correspondiente PUZC, y menores incluso, que si dicha puzolana $Z$ se hubiera comportado como "inerte $S_{R}$ ", y además, mostraron casi siempre un descenso continuado hasta alcanzar también el valor cero. Lo que era un indicio evidente de que los referidos productos de la reacción puzolánica de su respectiva cantidad de $\mathrm{SiO}_{2}{ }^{\text {r- }}$ con la portlandita, estaban consiguiendo dificultar, con el transcurso del ensayo, la formación de dicha cantidad común de ett-If hasta llegar a conseguir que incluso dejara de formarse. Por esta razón, se puede decir con fundamento que, la velocidad de formación, $V_{f}$, de la ett-If 0 de origen $C_{3} A$ del $C P$ de cada PUZC, termina siendo siempre necesariamente menor que la $V_{f}$ de los referidos productos de la reacción puzolánica de la $\mathrm{SiO}_{2}{ }^{\mathrm{r}-}$ de cada puzolana $\mathrm{Z}$ con la portlandita, cuando más puzolana $Z$ se le ha añadido de reemplazo (40\%). Lo que provoca que la $\mathrm{Vcl}$ de sus probetas se alcance más pronto, mientras que con $20 \%$ de reemplazo se alcanzó siempre finalmente más tarde, como era lógico. Además y como ya se indicara en artículos previos (18, 21, 22), results and their respective $\mathrm{Vcl}$ values obtained, those particular pozzolanic reactions owing to $\mathrm{SiO}_{2}{ }^{- \text {- interfered }}$ sufficiently to the corresponding ett-If formation from $C_{3} A$ origin present in its OPC fraction ( $80 \%, 70 \%$ or $60 \%)$, and for this reason, it can be rightly said that the $\boldsymbol{V}_{\boldsymbol{f}}$ of the ettIf from $C_{3} A$ origin present in any plain OPC, has to end up being necessarily lower than the $\boldsymbol{V}_{\boldsymbol{f}}$ of $\mathrm{CSH}$ gels and silanol groups from $\mathrm{SiO}_{2}{ }^{-}$origin present in its corresponding POZC-Z pozzolan, when more $Z$ pozzolan has been added. Nevertheless, it can be shown, as noted in earlier papers, that the wider apart the $\mathrm{SiO}_{2}{ }^{r-}$ and $\mathrm{C}_{3} A$ particles are to one another, the ett-If formation from $C_{3} A$ origin of OPC is originated later, and in fact, it may be hindered and even prevented from being formed, even though its forming reactive, $C_{3} A$, gypsum and water, continue being present in appropriate amounts to continue forming ettIf. Further proof of this behaviour has been that until the common age when $\mathrm{VCl}$ was zero for the plain OPC $P 2^{*}$, $P 4^{*}, P 32^{*}$ and $P 31^{*}$ specimens, i.e., when all these OPC stopped forming ett-If, the $\mathrm{VCl}$ values of their respective OPC/Z pozzolan specimens, 80/20, 70/30 and 60/40, were always lower than those for their respective plain OPC, and lower yet than if $Z$ pozzolan has behaved as "inert ${ }_{S R}$ ". It was a clear sign that pozzolanic reaction products, $\mathrm{CSH}$ gels and silanol, Si-OH groups, which end up also reacting with portlandite to originate more $\mathrm{CSH}$ gels, were making more difficult the ett-If formation until it became null. For this reason, it can be rightly said that the ett-If formation rate, $V_{f}$ ends up definitively being lower than the $V_{f}$ of the reaction products from $\mathrm{SiO}_{2}{ }^{-}$- origin present in these $Z$ pozzolans, being, in addition, lower yet, the greater 
cuanto mayor sea la relación "partículas de $\mathrm{SiO}_{2}{ }^{\mathrm{r}-} /$ partículas de $\mathrm{C}_{3} \mathrm{~A}^{\prime \prime}$, la formación de la ett-lf se produce más tarde todavía, y de hecho, las partículas de $\mathrm{SiO}_{2}{ }^{\mathrm{r}}$, en cantidad adecuada para cada $\mathrm{CP}$, pueden incluso llegar a impedir que se forme. $Y$ tales condiciones, es decir, elevada proporción de puzolana Z (40\%) y un CPO con un bajo contenido de $\mathrm{C}_{3} \mathrm{~A}(\%)$, se pueden encontrar en este estudio con las mezclas 70/30 y 60/40 especialmente, y más concretamente, con los PUZC P5/puzolana Z (porque los CP PY5, PY1, PY4 y PY6 ya son de por sí CPRS, y aumentarles su RS con las puzolanas SF, D ó $\mathrm{N}$ no es necesario), cuando se compara, por ejemplo, con las familias $\mathrm{P} 1 / \mathrm{Z}$, P2/Z y P4/Z. Y una prueba más de esta hipótesis se puede tener en los siguientes cálculos:

\section{- Familia de PUZC P1/SF:}

- Valor de $\mathrm{Vcl}_{7 \mathrm{~d}}$ del CPO P1 = 0,0134\%/día; su 80\%, $70 \%$ y $60 \%$ es $0,01072,0,00938$ y $0,00804 \%$ /día, respectivamente.

- Valor de $\mathrm{VCl}_{7 \mathrm{~d}}$ del PUZC P1/SF 80/20 = 0,00750\%/ día < 0,01072\%/día2* < 0,0134\%/día.

- Valor de $\mathrm{VCl}_{7 \mathrm{~d}}$ del PUZC P1/SF 70/30 = 0,04486\%/ día $<0,00938 \%$ día2* $<0,0134 \%$ día.

- Valor de $\mathrm{VCl}_{7 d}$ del PUZC P1/SF 60/40 = 0,03457\%/ día $<0,00804 \%$ día $2^{*}<0,0134 \% / d i ́ a$.

- $\quad$ Familia de PUZC P1/D:

- Valor de $\mathrm{Vcl}_{7 \mathrm{~d}}$ del PUZC P1/D 80/20 = 0,00971\%/ día $<0,01072 \%$ /día ${ }^{*}<0,0134 \% /$ día.

- Valor de $\mathrm{Vcl}_{7 \mathrm{~d}}$ del PUZC P1/D 70/30 = 0,00943\%/ día < 0,00938\%/día2* < 0,0134\%/día.

- Valor de Vcl $7 d$ del PUZC P1/D 60/40 = 0,00729\%/ día $<0,00804 \% /$ día $^{*}<0,0134 \%$ día.

$-$

- Familia de PUZ P1/N:

- Valor de Vcl Vd $_{\text {d }}$ del PUZC P1/N 80/20 = 0,00743\%/ día $<0,01072 \% /$ día $^{*}<0,0134 \%$ día.

- Valor de $\mathrm{Vcl}_{7 d}$ del POZC P1/N 70/30 = 0,00914\%/ día $<0,00938 \%$ /día ${ }^{*}<0,0134 \% /$ día.

- Valor de $\mathrm{VCl}_{7 \mathrm{~d}}$ del PUZC P1/N 60/40 = 0,01010\%/ día $<0,00804 \% /$ día $^{*}<0,0134 \% /$ día.

Por consiguiente, la razón del efecto protector del $\mathrm{C}_{3} \mathrm{~A}$ por los geles $\mathrm{CSH}$, de origen la $\mathrm{SiO}_{2}{ }^{\mathrm{r}-}$ de la puzolana $Z$, en un medio selenitoso, debe de ser de naturaleza química más que física. Aunque no obstante y por esta última razón precisamente, podría estar permitido

\footnotetext{
* $\mathrm{CP} P 2\left(=11,09 \% \mathrm{C}_{3} \mathrm{~A} \approx 11,288 \% \mathrm{C}_{3} \mathrm{~A}=80 \%\right.$ de $14,11 \% \mathrm{C}_{3} \mathrm{~A}$ del CP P1); CP P4 $\left(=10,71 \% \mathrm{C}_{3} \mathrm{~A} \approx 9,877 \% \mathrm{C}_{3} \mathrm{~A}=70 \%\right.$ de $14,11 \% \mathrm{C}_{3} \mathrm{~A}$ del CP P1); CP P32 (= 9,30\% $\mathrm{C}_{3} \mathrm{~A} \approx 9,877 \% \mathrm{C}_{3} \mathrm{~A}$ $=70 \%$ de $14.11 \% \mathrm{C}_{3} \mathrm{~A}$ del $\mathrm{CP}$ P 1$) ; \mathrm{CP}$ P31 $\left(=7,70 \% \mathrm{C}_{3} \mathrm{~A} \approx\right.$ $8,466 \% C_{3} A=60 \%$ de $14,11 \% C_{3} A$ del CP P 1$)$.
}

the amount added of $Z$ pozzolan is, which had already been said in previous articles $(18,21,22)$. In short, the greater the "SiO ${ }^{r-}$ particles $/ C_{3} A$ particles" ratio is, ettIf formation is occurring later, or indeed may never be formed if such ratio is appropriate for each OPC. Such conditions, i.e., a high proportion of $Z$ pozzolan (40\%) and a OPC with low $C_{3} A(\%)$ content, can be found in this study in the 60/40 and 70/30 mixes, namely, the P5/Z pozzolan (because PY5, PY1, PY4 and PY6 are already $S R P C$ and to increase their SR with SF, D or N pozzolan is not commonly needed), as compared, for instance, with $P 1 / Z, P 2 / Z, P 4 / Z$ families. Further proof of this hypothesis can be deduced from the following:

\section{- POZC family P1/SF:}

- $\mathrm{Vcl}_{7 \mathrm{~d}}$ value for OPC P1 $=0.0134 \% /$ day; its $80 \%$, $70 \%$ and $60 \%$ is $0.01072,0.00938$ and 0.00804 $\% /$ day, respectively,

- $\quad \mathrm{Vcl}_{7 \mathrm{~d}}$ value for POZC P1/SF 80/20 $=0.00750 \% /$ day $<0.01072 \% /$ day $2 *<0.0134 \% /$ day,

- $\mathrm{Vcl}_{7 \mathrm{~d}}$ value for POZC P1/SF 70/30 = 0.04486\%/ day $<0.00938 \% /$ day $2 *<0.0134 \% /$ day,

- $\mathrm{VCl}_{7 \mathrm{~d}}$ value for POZC P-2/M 60/40 = 0.03457\%/ day $<0.00804 \% /$ day $2 *<0.0134 \% /$ day.

\section{- POZC family P1/D:}

- $\quad$ Vcl $_{7 d}$ value for POZC P1/D 80/20 = 0.00971\%/day $<0.01072 \% /$ day $2 *<0.0134 \% /$ day,

- $\quad \mathrm{Vcl}_{7 \mathrm{~d}}$ value for POZC P1/D 70/30 = 0.00943\%/day $<0.00938 \% /$ day $2 *<0.0134 \% /$ day,

- $\quad \mathrm{Vcl}_{7 \mathrm{~d}}$ value for POZC P1/D 60/40 = 0.00729\%/day $<0.00804 \% /$ day $2 *<0.0134 \% /$ day.

- $P O Z C$ family $\mathrm{P} 1 / \mathrm{N}$ :

- $\quad \mathrm{VCl}_{7 \mathrm{~d}}$ value for POZC P1/N 80/20 = 0.00743\%/day $<0.01072 \% /$ day $2 *<0.0134 \% /$ day,

- $\quad \mathrm{Vcl}_{7 \mathrm{~d}}$ value for POZC P1/N 70/30 = 0.00914\%/day $<0.00938 \%$ /day $2 *<0.0134 \% /$ day,

- $\quad \mathrm{Vcl}_{7 \mathrm{~d}}$ value for POZC P1/N 60/40 = 0.01010\%/day $<0.00804 \% /$ day $2 *<0.0134 \% /$ day.

Therefore, the reason for the protection afforded $C_{3} A$ by $\mathrm{SiO}_{2}{ }^{r-}$ in a gypsum and water environment must be of a more chemical than physical nature. Although for this last one reason indeed, it could also be permissible to think nonetheless, that the protective effect of the

* $C P P 2\left(=11.09 \% C_{3} A \approx 11.288 \% C_{3} A=80 \%\right.$ de $14.11 \% C_{3} A$ del CP P1); CP P4 (=10.71\% $C_{3} A \approx 9,877 \% C_{3} A=70 \%$ de $14.11 \% C_{3} A$ del $C P$ P1); CP P32 (=9.30\% $C_{3} A \approx 9,877 \% C_{3} A$ $=70 \%$ de $14.11 \% C_{3} A$ del $C P$ P 1$) ; C P P 31\left(=7.70 \% C_{3} A \approx\right.$ $8.466 \% C_{3} A=60 \%$ de $14.11 \% C_{3} A$ del $\left.C P P 1\right)$. 
creer que el efecto protector del SF es más físico que químico. Pero esta posibilidad no puede ser aceptada, porque cuando se utilizó la diatomea $D$, cuyos contenidos totales de $\mathrm{SiO}_{2}(\%)$ y $\mathrm{SiO}_{2}{ }^{\mathrm{r}-}(\%)$ son muy similares a los del SF (Tabla 2), pero sin embargo, su morfología y SE BET (Tabla 2) son claramente diferentes, hasta el punto que sus relaciones agua/cemento (Tabla 4) y cantidades de adsorción de humedad en función del tiempo (Tabla 6), fueron bastante diferentes también, y, además, más desfavorables, no por ello y, a igualdad de todo lo demás, la puzolana $\mathrm{D}$ dejó de impedir o dificultar al menos, el ataque sulfático al CPO con el que se había mezclado en cantidad apropiada o no, respectivamente $(14,18,21,22)$. Y una prueba adicional de la veracidad de esta otra hipótesis de comportamiento, se puede ver en las microfografías de la puzolana $D$, antes y después de haber desarrollado su actividad puzolánica parcial o total, de origen su respectivo contenido de $\mathrm{SiO}_{2}{ }^{\mathrm{r}-}(\%)$, Figuras 6(b)-(g), fruto de la cual, cuando estas mismas puzolanas $\mathrm{Z}$, $\mathrm{D}$ y $\mathrm{N}$, se ensayaron conforme el método acelerado L-A (14, 15, 21, 22), no sólo protegieron también del ataque sulfático al CPO con el que se mezclaron, sino que además, consiguieron que su protección fuera aún mayor y más determinante. Puesto que con este método L-A consiguieron proteger incluso a $\mathrm{CPO}$ con un mayor contenido de $\mathrm{C}_{3} \mathrm{~A}(\%)$ que con el método ASTM C 452-68. Y la razón estribó en el curado hídrico durante 14 días al que fueron sometidos sus PUZC antes de enfrentarlos al ataque sulfático.

En definitiva, el efecto protector "anti-sulfato" de estas puzolanas $Z$ es siempre más químico que físico, aunque el de tipo químico termina prevaleciendo siempre, a pesar de que el de tipo físico pueda llegar a ser significativo inicialmente aunque con resultado dispar, como así ha ocurrido con el SF, dada su mayor SE-BET (Tabla 2). En cambio, con las puzolanas D (con $89,16 \%$ de $\mathrm{SiO}_{2}{ }^{\mathrm{r}-}$ ) y $\mathrm{N}$ (con $42,65 \%$ de $\mathrm{SiO}_{2}{ }^{\mathrm{r}-}$ ), el efecto protector inicial de tipo físico resulta ser prácticamente nulo desde el principio al final del ensayo, debido a sus mayores tamaños de partícula por tratarse de esqueletos o "frústulos" o pequeños estuches huecos y perforados (Figura 6(a)). Lo que provoca una elevada succión capilar de agua, la cual se traduce en una notable demanda de agua de amasado (Tabla 4), lógicamente, con las consecuencias al caso para las resistencias mecánicas, que son significativamente menores (Tablas $3(a)(b)$ y $(c)$ ), y para su efecto protector anti-sulfato cuya efectividad, termina siendo siempre menor, a igualdad de PUZC, que la del SF (Figuras 1, 3 y 5). Por último y además, el efecto de dilución física del CP por estas tres puzolanas o por

${ }^{2 *}$ Valores de $\mathrm{Vcl}_{7 \mathrm{~d}}$ que se habrían obtenido considerando la puzolana $Z$ un INERTE $E_{R S}$. El resto de PUZC cumplió con estas relaciones a la edad de 7 días y/o a la edad de 14 días.
SF is more physical than chemical. But this possibility is not acceptable because when diatomite, D, was used, whose total $\mathrm{SiO}_{2}(\%)$ content and $\mathrm{SiO}_{2}{ }^{-}(\%)$ content are very similar to those for SF (Table 2), but however, their morphology and BET-SS (Table 2) are clearly different, until the point that their water/binder ratios (Table 4) and humidity adsorption amounts vs. time (Table 6) are also enough different, but mainly, more unfavorable, but not for that reason, to equality of all others, $D$ let protect to the $C_{3} A$ of the sulfate attack as well $(14,18$, $21,22)$. Further proof of this hypothesis can be seen in the following microphotographs of different $D$ pozzolans, before and after having developed their partial or total pozzolanic activity from their respective $\mathrm{SiO}_{2}{ }^{r-}(\%)$ content origin: Figures $6(b)-(g)$. The result of this is that when the $Z$ pozzolans, $D$ and $N$, were submitted to $L-A$ test (14, $15,21,22)$, their protective effect was larger and more significant, because both of them even failed to protect of sulphate attack to OPC whose $C_{3} A(\%)$ content was greater for 14 days. The reason of this better behaviour is the previous curing water of their respective POZC-Z pozzolan before being submitted to sulphate attack.

In summary, the "ant-sulfate" protective effect of these $Z$ pozolans is always more chemical than physical, although the chemical type will always prevail over the physical type. Nevertheless, the physical type may be initially significant although with varied results, which is what has happened with SF due to its greater SS-BET (Table 2). However, with $D$ (with $89.16 \% \mathrm{SiO}_{2}{ }^{--}$) and $\mathrm{N}$ (with $42.54 \% \mathrm{SiO}_{2}{ }^{-}$), its initial protective effect of physical type is null practically from the beginning up to the final of the test, due to their greater particle sizes: $D$ and N pozzolans are big particles empty, perforated sheaths skeletons termed "frustules" (Figure 6(a)) which provoke very high capillary suction pressure that drew mixing water into their interior diluting in this manner the usual concentration of portlandite that brings about slowing down pozzolanic reaction and, as a consequence, the mixing water demand increases (Table 4), as logical, and the mechanical strengths decline very significantly (Tables 3(a)(b) and (c)), and their effective protective effect against gypsum attack finishes always being lower than SF (Figures 1,3 and 5). In addition, a further factor to bear in mind is that the physical dilution

2* $\mathrm{VCl}_{7 d}$ values which would have been achieved regarding $Z$ pozzolan as being inert $t_{S R}$. The rest of POZC fulfilled also these relationships at 7 days age and/or 14 days age. 
cualquier otra(s) puzolana(s) silícica(s), deberá de tenerse en cuenta también para el objetivo protector final que provocan frente al ataque de los sulfatos, aunque sea común para todas ellas.

Finalmente, la observación (B)4 justifica sin más que, dicha formación de ett-If y de geles CSH tiene lugar independientemente entre sí, es decir, no inter-dependientemente, ni de una forma conjunta, ni combinada, ni interactiva -como si lo es, en cambio, la co-precipitación de ett-rf y ett-If en un medio selenitoso común (16, 18) - , y además, a diferente velocidad de formación, $V_{\mathrm{f}}$ Y $\mathrm{Y}$ a tenor de los resultados obtenidos de $\mathrm{Vcl}$ de las probetas y su evolución con el transcurso del ensayo, la velocidad de formación, $V_{f}$, de la ett-If, debe de ser claramente mayor que la de los geles CSH resultantes de la actividad puzolánica de la $\mathrm{SiO}_{2}{ }^{\mathrm{r}-}$ de cada puzolana Z con la portlandita, aunque sólo hasta la edad inicial del ensayo que sus respectivas probetas alcanzan su mayor valor de Vcl. Puesto que a partir de esa edad, dicha Vcl comienza a disminuir hasta llegar incluso a ser nula, aún cuando la $V_{\mathrm{f}}$ de dichos geles $\mathrm{CSH}$ no ha debido de cambiar para continuar siendo la misma desde el inicio del ensayo (o cambiar quizás muy poco, porque ya para entonces las probetas deben de estar algo más colmatadas por ambos productos de reacción: ett-If y geles $\mathrm{CSH}$, de primeras edades y de edades posteriores). Por este motivo, los efectos derivados de esa formación independiente, o no inter-dependiente, o no de forma conjunta, ni combinada, ni interactiva de la ett-If y de los geles $\mathrm{CSH}$, si son, en cambio, inter-dependientes, o mejor quizás aún, están vinculados entre sí. Hasta el punto de que la de estos últimos menoscaba cada vez más, con el transcurso del ensayo, el de aquélla -su innata expansividad - hasta llegar a conseguir incluso anularla cuando se han formado en cantidad adecuada para cada CPO.

En resumen, de las observaciones (B) discutidas e interpretadas, se ha podido deducir también, que la mayor parte de la ettringita de origen $\mathrm{C}_{3} \mathrm{~A}$, presente en la fracción de CP del correspondiente PUZC, o ett-If(14-18), se origina en los primeros 28 días del ensayo ASTM C 45268. No obstante y de acuerdo con el preceptivo ensayo de Frattini (41) y/o la norma EN 450 (42), que han de cumplir las puzolanas naturales y artificiales, antes de ser ensayadas conforme el ensayo ASTM C 452-68, la especificación física más apropiada -y de hecho preceptiva - para diferenciar a los PUZC de elevada RS, de aquellos otros PUZC que no lo son tanto, tiene que ser necesariamente que el $\Delta \mathbf{L}_{\mathbf{2 8 d}}$ sea $\leq \mathbf{0 . 0 5 4 \%}(14,16,34,51)$. Este requerimiento físico sería entonces, por tanto, más importante que cualquier otro, ya sea químico - puzolanicidad (ensayo de Frattini (41)), contenido de sílice reactiva, $\mathrm{SiO}_{2}{ }^{\mathrm{r}-}(\%)$, $(36,40)$, etc. - y/o físico (53-56) y/o mecánico (43-46) -índice de actividad puzolánica (43),etc.-. effect of plain OPC under these conditions of sulphate attack must be taken into account as well although it is common for all of them.

Finally, the observation (B)4 justifies without further ado, that ett-If and $\mathrm{CSH}$ gels and silanol groups, Si-OH, formation take place independently from one another, i.e., not inter-dependently in a joint way or interactive way like ettrf and ett-If co-precipitating in a common plaster-bearing solution $(16,18)$. In addition, the $V_{f}$ of the CSH gels and silanol groups from $\mathrm{SiO}_{2}{ }^{r-}$ origin present in $Z$ pozzolan, ends up being considerably higher than the $\boldsymbol{V}_{\boldsymbol{f}}$ of the ett-If from $C_{3} A$ origin of OPC, and the higher is, the more $Z$ pozzolan has been added, and the sulfatic hydration moves forward. And according to the $V_{c l}$ results obtained for the mortars and its evolution along the trial, it can be claimed that the formation rate, $V_{f}$ of ett-If, must be clearly greater than that of the CSH gels resultant of pozzolanic activity exhibited by $\mathrm{SiO}_{2}{ }^{\text {r- }}$ of each $\mathrm{Z}$ pozzolan with portlandite, although, up to this very initial age of the trial only when its respective mortars reach its $V_{c l}$ larger value; since, from this very age, the mentioned $V_{c l}$ parameter starts decreasing, up to the point, when it even reaches a null value, and still, if the $V_{f}$ of its $\mathrm{CSH}$ gels should not have to change in order to remain the same from the beginning of the trial (or change perhaps a little bit, since, at this very moment, the mortars should have been silted already by both the reaction products: ett-If and CSH gels, of both early and later ages). For this reason, the derived effect from this independent formation, or not inter-dependent, or not by joint way, neither combined nor interactive of the ett-If and CSH gels, they are, in return, inter-dependent, or, perhaps, linked between each other. All of this, up to the point that, along the trial duration, the former reduces progressively the latter -its innate expansivity - provoking evens its disappearance when formed in appropriate quantity for each CPO.

In summary, it may also be deduced from the observations discussed under (B) above that, most of the ettringite formed from the $C_{3} A$ origin present in the $P C$ fraction of correspondent POZC, or ett-If (14-18), is also generated during the first 28 days of the ASTM C 452-68 test. Nevertheless, according to the mandatory Frattini test (41) and EN 450 Standard (42), which must be applied to the natural or artificial pozzolan prior to the ASTM C 452-68 test, the most appropriate -and in fact mandatoryphysical criterion for differentiating high SRPOZC from low SRPOZC is $\mathbf{\Delta} \mathbf{L}_{\mathbf{2 8 d}} \leq 0.054 \%(14,16,34,51)$. This physi$\mathrm{cal}$ requirement would be, then, the more important than any other, whether chemical -pozzolanicity (Frattini test (41)), reactive silica content, $\operatorname{SiO}_{2}{ }^{--}(36,40)$, etc.- and/or physical (53-56) and/or mechanical (43-46) -pozzolanic activity index (43), etc.-. 
Por consiguiente y si en las mismas circunstancias, toda o la mayor parte de la reacción puzolánica de origen la $\mathrm{SiO}_{2}{ }^{\mathrm{r}}$ presente en la puzolana $\mathrm{Z}$, ha llegado a completarse también a la edad de 28 días, el método ASTM C 452-68 es, por consiguiente, válido para caracterizar y diferenciar a 28 días de edad, los PUZC preparados con esta puzolanas $\mathrm{Z}$ o con cualquier otra puzolana natural o artificial (cenizas volantes, metakaolines, arcillas activadas, esquistos calcinados, etc.), que puedan provocar el desarrollo de elevada, moderada o baja resistencia sulfática (SR). Y el único requisito sería establecer apropiados requerimientos y especificaciones normalizadas.

\section{CONCLUSIONES}

De la discusión e interpretación de los valores de Vcl, proporcionados por las probetas ASTM C 452-68 de los PUZCpuzolana $\mathrm{Z}$, se han obtenido las siguientes conclusiones:

1. El parámetro $\mathrm{Vcl}$ ha demostrado que las reacciones puzolánicas de origen la $\mathrm{SiO}_{2}{ }^{\mathrm{r}-}$ de las puzolanas $\mathrm{Z}$ con la portlandita, en un medio con yeso y agua - probetas ASTM C 452-68, en este caso-, prevalecieron más pronto (con las diatomeas D y N) o más tarde (con el SF), sobre la hidratación selenitosa de sus PUZC, habiendo alcanzado siempre esta última su finalización en los primeros 28 días de edad de sus probetas; y por lo general, cuanto mayor fue el contenido de $\mathrm{C}_{3} \mathrm{~A}(\%)$ del $\mathrm{CP}$ y mayor también el reemplazo de puzolana $Z$, más pronto dichas reacciones puzolánicas alcanzaron su fin. Independientemente de si la composición mineralógica, las características químicas y físicas, la SEB y los tiempos de fraguado del CP (CPO ó CPRS) con el que se mezclaron fueran más o menos apropiados. No obstante y en cualquier caso, el efecto químico protector final resultante del SF, en cantidad adecuada para cada CP contra el ataque del yeso, terminó siendo mayor que el de las puzolanas $\mathrm{D}$ y $\mathrm{N}$, por causa de su mayor SE-BET principalmente (debida a su vez al muy pequeño tamaño de su partícula esférica), y, como consecuencia, debido a su mayor, más rápida y temprana actividad puzolánica desarrollada. Además, esta mayor SE-BET del SF (con un contenido de $\mathrm{SiO}_{2}{ }^{\mathrm{r}-}$ del $88,46 \%$ ), origina también un efecto protector adicional de tipo físico, por el efecto dilución, desde el principio al final del ensayo, pero teniendo siempre supremacía el de tipo químico, porque con las puzolanas $\mathrm{D}$ (con un contenido de $\mathrm{SiO}_{2}{ }^{\mathrm{r}-}$ del $89,16 \%$ ) y $\mathrm{N}$ el efecto físico protector inicial es prácticamente nulo, debido al mayor tamaño medio de sus partículas con forma de frústulos (estuches perforados y huecos), los cuales provocan una elevada succión capilar de agua en su interior. Finalmente, el efecto de dilución física del CPO debe de tenerse en cuenta también, aunque este otro efecto es común para estas tres puzolanas silícicas en carácter químico.
Therefore and in the same circumstances, whether all or the greatest part of the pozzolanic reactions from $\mathrm{SiO}_{2}{ }^{r-}$ origin present in $Z$ pozzolan become to their completion at 28 days age, the ASTM C 452-68 test (1) can be validity used to characterize and to differentiate 28-days, POZC prepared with these $Z$ pozzolans or with any other from natural or artificial (fly ash) origin, which may or may not give rise to the development of low, moderate or high sulphate resistance (SR). The only requisite would be to establish suitable standard physical-chemical requirements and specifications.

\section{CONCLUSIONS}

In the present discussion and interpretation of the $\mathrm{VCl}$ values, the following conclusions were drawn:

1. The $\mathrm{VCl}$ parameter has shown that the pozzolanic reactions from $\mathrm{SiO}_{2}{ }^{--}$origin - present in $Z$ pozzolanswith the portlandite, in a gypsum and water environment -ASTM C 452-68 specimens in this case-, prevailed sooner (with $D$ and $N$ pozzolans) or later (with SF pozzolan), over the original sulfatic hydration of its POZC, reaching nevertheless for this reason completion, in the first 28 days; by and large, the higher the $C_{3} A(\%)$ content in the $P C$ and more $Z$ pozzolan was added, the sooner those pozzolanic reactions came to an end, irrespective of whether the mineralogical composition, chemical and physic characteristics, BSS and setting times of plain OPC and SRPC, were more or less appropriate. Nevertheless and in any case, the final resulting chemical protective effect of SF in adequate amount for each PC against gypsum attack, ended up being higher than the of $D$ and $N$ pozzolans, because of its higher BET SS mainly (due to its very small particle size and sphere shape). This higher BET SS of SF (with $88.46 \% \mathrm{SiO}_{2}{ }^{\text {- }}$ content) also gives rise to an additional and initial physical protective effect, but having finally the chemical protective effect priority,

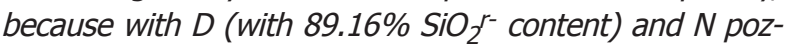
zolans this initial physical protective effect is practically null from the beginning up to the end of the test, due to its bigger than the SF one particles size and its frustules shape (empty, perforated sheaths), which provoke high capillarity suction pressure and, in effect, absorption of mixing water into its interior structure. Finally, the physical dilution effect of plain OPC must also be taken into account, even though it is common for these three silicic pozzolans in chemical character. 
2. La velocidad de tales reacciones puzolánicas termina siendo siempre mayor que la de la ett-lf o de origen $\mathrm{C}_{3} \mathrm{~A}$ especialmente del CPO, la cual, tras haber alcanzado su plenitud o máximo valor, en los primeros 28 días de edad, disminuye hasta llegar a hacerse incluso nula. Esta aminoración hasta su nulidad ha sido provocada por dichos productos de reacción puzolánica precisamente (esta conclusión se continúa en la 3), y no tanto, por agotamiento de alguno(s) de sus reactivos químicos que la originaron: $\mathrm{C}_{3} \mathrm{~A}$, portlandita, yeso o agua. Como consecuencia, el efecto protector del ataque sulfático de los CPO por las puzolanas silícicas, termina por ser efectivo en cantidad adecuada para cada contenido de $\mathrm{C}_{3} \mathrm{~A}(\%)$, es decir, para cada CPO. Y con curado hídrico previo adecuado en calidad y tiempo, más y mejor aún. En este último caso, el contenido de $\mathrm{C}_{3} \mathrm{~A}(\%)$ del $\mathrm{CPO}$ puede además ser un poco mayor (véase a continuación el párrafo final de la conclusión 5).

3. En las probetas ASTM C 452-68 de estos PUZC-puzolana Z, la formación de ett-If y la de los geles C-S-H, fruto de dicha actividad puzolánica tan especial y particular de la $\mathrm{SiO}_{2}{ }^{\mathrm{r}-}$ de las puzolanas $\mathrm{Z}$ con la portlandita, ha tenido lugar en mayor o menor medida, independientemente entre sí, es decir, no inter-dependientemente, ni de forma conjunta, ni combinada, ni interactiva, no habiendo estado además dichos productos de la reacción puzolánica más cercanos a la ett-If cuando menor cantidad de puzolana $\mathrm{Z}(20 \%)$ reemplazó al CPO con elevado contenido de $\mathrm{C}_{3} \mathrm{~A}$ (el P1, 14,11\%), sino todo lo contrario (40\%).

En cambio, los efectos derivados de ambos productos de reacción, de la ett-If y de los geles C-S-H, si son interdependientes, o mejor quizás aún, están vinculados entre sí. Y tanto más vinculados, cuanto mayor cantidad de reemplazo de puzolana $\mathrm{Z}$ por $\mathrm{CP}$ y mayor cantidad de $\mathrm{C}_{3} \mathrm{~A}$ posee este último. Hasta el punto de que, el aumento de la formación de los últimos con el transcurso del ensayo, menoscaba cada vez más la formación de aquélla, la ett-If, $y$, de este modo, su expansividad aparejada a su formación, hasta llegar a conseguir incluso que sea nula porque deje de formarse cuando aquéllos han logrado formarse en cantidad adecuada para cada CPO. Aunque no obstante y en cualquier caso, habiendo tenido siempre el mecanismo TPQ con disolución previa preponderancia sobre el mecanismo de TS. Finalmente, la formación en las mismas circunstancias, de ett-vlf de origen $\mathrm{C}_{4} \mathrm{AF}$, también presente en el mismo $\mathrm{CP}$, deberá ser, lógicamente, más independiente aún.

4. La especificación física que se utiliza actualmente para caracterizar y diferenciar los CPO de los CPRS, establecida en la norma ASTM C 150 (50) $-\Delta \mathrm{L}_{14 d} \leq 0,040 \%-$ "predice" más que "asegura" el comportamiento, en potencia, del CP frente al ataque del yeso, en contraste con la que se utilizaba antes $\Delta \mathrm{L}_{28 \mathrm{~d}} \leq 0,054 \%$ (51) para
2. The formation rate of the pozzolanic reaction products from $\mathrm{SiO}_{2}{ }^{r-}$ origin, of $Z$ pozzolan, with the portlandite ends up being greater than the formation rate of ettIf from $C_{3} A$ origin of $O P C$, which decreases up to being nil, in spite of that the sulfatic hydration of $C_{3} A$ continues present, and as a consequence, the protective effect of the silicic pozzolans to the sulfatic attack of OPC, ends up also being effective in adequate amount for each $C_{3} A(\%)$ content, and with prior adequate water curing, more and better yet. In this latest case, the $C_{3} A(\%)$ content of the OPC can additionally be a bit greater (see the final paragraph of the conclusion 5 bellow).

3. In all these POZC-Z pozzolan ASTM C 452-68 specimens, the formation of the ett-If from $C_{3} A$ origin of $O P C$ and $\mathrm{CSH}$ gels and silanol groups, $\mathrm{Si}-\mathrm{OH}$, from $\mathrm{SiO}_{2}{ }^{r-}$ origin of $Z$ pozzolan, reacting with portlandite, has taken place independently from one another, i.e., not inter-dependently in a joint way or interactive way, to a larger or smaller extent, and the reaction products are not closer ett-If when more $Z$ pozzolan is added (40\%), and vice versa (20\%);

However, the derivate effects of both reactions products, ett-If and CSH gels, are inter-dependent, or perhaps better, each reaction product is inextricably linked with the other, i.e., both of them are mutually dependent, and the more dependent are, the more substitution of $P C$ by $Z$ pozzolan has been made. By such an extension that, the increase in $\mathrm{CSH}$ gels formation decreases the ett-If formation until no longer forms, because its formation is null, when $\mathrm{CSH}$ gels from $\mathrm{SiO}_{2}{ }^{-}$of $Z$ pozzolan have been formed in appropriate amount for each OPC; but in any event, TPQ mechanism with prior dissolution must once again be preponderant over TS mechanism. In addition, the formation in the same circumstances, of ett-vlf from $C_{4} A F$ present also in the same $P C$, must be logically more independent yet.

4. The criterion presently used to characterize and differentiate OPC from SRPC, laid down in ASTM C 150

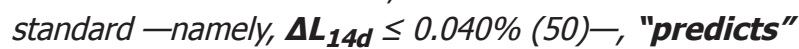
rather than "assures" the potential performance of OPC under gypsum attack, by contrast to the criterion formerly used $-\mathbf{\Delta L}_{\mathbf{2 8 d}} \leq \mathbf{0 . 0 5 4 \%}$ (51)- for this purpose, as 
dicho propósito. Así y con esta última especificación física, propuesta por R. Talero $(14,16,34)$ para los PUZCpuzolana $\mathrm{Z}$ de origen $\mathrm{CPO}$,

- 3 PUZC-puzolana D y 2 PUZC-puzolana $\mathrm{N}$ han podido ser clasificados como cementos de "elevada RS" (ERS),

- 3 PUZC-puzolana D, 1 PUZC-puzolana N y 1 PUZCpuzolana SF, han podido ser clasificados como cementos de "moderada RS" (MRS), y

- el resto, 44 PUZC-puzolana Z, han sido clasificados como cementos de "baja RS" (BRS).

(la limitada extensión de este artículo ha impedido poder incluir en él además, los valores de $\Delta \mathrm{L}_{28 \mathrm{~d}}(\%)$ de sus correspondientes probetas ASTM C 452-68, los cuales se incluirán en otro artículo que se publicará próximamente).

Sin embargo, cuando los PUZC-puzolana Z fueron ensayados con el método Le Chatelier-Ansttet (L-A), TODOS ellos excepto uno, pudieron ser clasificados como de ERS (14, 21, 22), mientras que el PUZC P-1/SF 80/20 pudo ser clasificado tan sólo como de MRS (22). Este comportamiento justifica, por tanto, las dos últimas frases de la conclusión 2.

En cambio, cuando se utilizó metakaolín, (MK o puzolana M, silícea y aluminosa, en naturaleza (45) y alumínica, en carácter químico (14-18, 22-25, 31)), ninguno de sus 30 PUZC-MK se pudo catalogar de "elevada" (ERS) y ni aún de "moderada" (MRS) resistencia sulfática, mediante ninguno de estos dos métodos acelerados de ensayo: L-A $(6,14,15,21,22,31)$ ni ASTM C 452-68 (1).

\section{DEDUCCIONES}

1. De acuerdo con las conclusiones anteriores 1. 2. y 3., y siempre y cuando el resultado del ensayo de Frattini a la edad de 7 ó 28 días (37) (en lugar de a las edades de 8 ó 15 días (35)), haya sido positivo, así como, los resultados de los ensayos: EN 196-1 (55), EN 196-3 (56), UNE 80225-93 $(35,41)$ y EN 450 (42) y/o ASTM C 311-94b (43) y/o ASTM 618-95a (45), principalmente, el método ASTM C 452-68 es válido para ser usado también en la caracterización y diferenciación, a la edad de 28 días, de los PUZC fabricados con puzolana Z (puzolanas con carácter químico silicico) $(14,18,21,22,24,25)$ (y este artículo), o con metakaolin (MK) (16) (puzolana con carácter químico alumínico (14-18, 22-25)). Y con cualquier otra puzolana natural o artificial también. Ya sea ésta sub-producto, como las cenizas volantes o no, la cual podrá o no provocar que su PUZC posea BRS, MRS o ERS, según sea su carácter químico, el cual será siempre una combinación o mezcla aleatoria de inferred in the title of the ASTM C 452-68 standard. With this new physical specification proposed by R. Talero (14, $16,34)$ for POZC-Z pozzolan of OPC origin:

- 3 D-containing POZC and $2 \mathrm{~N}$-containing POZC can be classified as "high sulphate-resistant" (HSR),

- 3 D-containing POZC, $1 \mathrm{~N}$-containing POZC and 1 SF-containing POZC can be classified as "moderate sulphate-resistant" (MSR), and finally

- the rest, 44 POZC-Z pozzolan, are classified "low sulphate-resistant" (LSR).

(although the limited scope of this paper has precluded their proof, justification and quantification here, they will addressed in the near future in subsequent paper).

However, when the POZC-SF pozzolan and POZC-D pozzolan were submitted to the Le Chatelier-Ansttet ( $L-A)$ test, ALL except one, were classified as HSR (14, 21, 22), whereas the 80/20 POZC P-1/SF could be acknowledged as MSR (22). This behaviour justifies, therefore, the last two sentences of the conclusion 2.

In contrast, when metakaolin ( $M$ pozzolan or MK (siliceous and aluminous in nature (45) and aluminic in chemical character (14-18, 22-25, 31)) was used, none of its 30 POZC prepared could be considered to be highly (HSR) or even moderately (MSR) sulfate-resistant (14-18, 22) $(24,25,31)$ by means of neither of these two method: L-A $(6,14,15,21,22,31)$ nor ASTM C 452-68 (1).

\section{DEDUCTIONS}

1. According to conclusions 1, 2. and 3. above, after positive result is obtained in the Frattini test (EN 196-5 (41), at 28 and/or 7 days only instead of at 15 and/or 8 days only (35), as well as in the tests set out in standards, EN 196-1 (55), EN 196-3 (56) and EN 450 (42) and/or ASTM C 311$94 b$ (43) and/or ASTM 618-95a (45), mainly, the ASTM C 452-68 test (1) can be validly used to characterize and to differentiate 28-days, POZC prepared with Z pozzolan and this paper — with silicic chemical character $(14,18,21,22$, 24, 25) - or with MK (16) -with aluminic chemical character (14-18, 22-25)—, and with any other natural or artificial (by product, fly ash, or other) pozzolan, which may or may not give rise to the development of low, moderate or high sulphate resistance (SR) according to its chemi$\mathrm{cal}$ character, which is always an aleatory combination of these two extremes: i.e., they will be either silicic-aluminic because their $\mathrm{SiO}_{2}{ }^{-}(\%)$ and $\mathrm{Al}_{2} \mathrm{O}_{3}{ }^{-}(\%)$ contents are 
estos dos caracteres químicos extremos: silícico-alumínicas, porque sus contenido de $\mathrm{SiO}_{2}{ }^{\mathrm{r}-}(\%)$ y $\mathrm{Al}_{2} \mathrm{O}_{3}{ }^{\mathrm{r}}$ (\%) son tales que es más silícica que alumínica, en carácter químico, o al contrario, es decir, ellas serán alumínico-silícicas, porque ambos contenidos son todo lo contrario en cantidad. Independientemente de si tales puzolanas naturales o artificiales son silíceas y aluminosas en naturaleza, según la norma ASTM C 618-94a (45), como el MK. El único requisito sería establecer apropiados requerimientos y especificaciones químico-físicas normalizadas $(6,14,16,20)$.

2. El resultado de este ataque sulfático (14-18, 21, 22), por un lado, y el del ataque de los cloruros $(24,25)$, por otro, determinan además el carácter químico de cualquier puzolana natural o artificial, el cual puede serle determinado también frente al ataque del yeso únicamente. Por consiguiente, este método de ensayo ASTM C 452-68, adaptado por R. Talero $(14,49)$, puede ser utilizado además para determinar el carácter químico de dicha puzolana en un corto espacio de tiempo: 28 días tan sólo (como se podrá demostrar mediante un nuevo artículo a publicar), para así poder deducir de él sin más, el más que probable comportamiento de su hormigón, mortero y pasta frente a un medio agresivo o no determinado: sulfatos, cloruros, agua de mar, carbonatación, RAA, etc. such that they are more silicic than aluminic in chemical character, or the contrary, they will be aluminic-silicic for the opposite reason. Irrespective of if they are in nature, siliceous and aluminous materials according to ASTM C 618-94a (45) like MK. The only requisite would be to establish suitable standard physical-chemical requirements and specifications $(6,14,16,20)$.

2. This sulfatic attack $(14-18,21,22)$ and the chloride attack $(24,25)$, separately, determine the chemical character of any pozzolan, natural or artificial, according to the behaviour of its POZC of PC origin in front of gypsum attack, and this ASTM C 452-68 test (1) can, therefore, be also validity used to determine the chemical character of such pozzolan within a short period of time: 28 days only, even though adapted by $R$. Talero for this another purpose $(14,49)$. In addition, this sulfatic characterization of pozzolans will allow to predict their potential behaviour in front of different chemical attack (sulphates, chlorides, sea water, carbonation, ASR, etc.).

\section{BIBLIOGRAFÍA / BIBLIOGRAPHY}

(1) ASTM C 452-68 Standard: Standard Test Method for Potential Expansion of Portland Cement Mortars Exposed to Sulphate. ANNUAL BOOK OF ASTM STANDARDS. Part 9, Cement;Lime;Gypsum, pp. 298-300 (1968).

(2) Gospodinov, P.N.; Kazandjiev, R.F.; Partalin, T.A.; Mironova, M.K.: "Diffusion of sulphate ions into cement stone regarding simultaneous chemical reactions and resulting effects". Cem. Concr. Res. vol. 29, no 10 (1999), pp. 1591-1596. http:// dx.doi.org/10.1016/S0008-8846(99)00138-6

(3) Marchand, J.; Skalny J.P.: "Materials Science of Concrete: Sulphate Attack Mechanism". Published by the American Ceramic Society, 735, Ceramic Place, Westerville, $\mathrm{OH}$ 43081.USA.

(4) Santhanam, M; Cohen, M.D; Olek, J: "Sulphate attack research - whither now?" Cem. Concr. Res. vol. 31 , nº 6 (2001), pp. 845-851. http://dx.doi.org/10.1016/S0008-8846(01)00510-5

(5) Bensted, J.: A discussion of the review paper "Sulphate attack research-whiter now? By M. Santhanam, M.D. Cohen; J. Olek. Cem. Concr. Res. Vol. 32, no 6 (2002), pp. 995-1000. http://dx.doi.org/10.1016/S0008-8846(02)00731-7

(6) Jaspers, M.J. : "Contribution à l'étude experimentale de la mesure per l'essai Le Chatelier-Ansttet de la resistance des ciments aux sulfates et chlorures". Rev. Mat. Constr. Trav. Public. 633-634 (1968), pp. 244-256.

(7) Jaspers M.J.M.: "Contribution à I'etude expérimentale de la mesure de la résistance aux sulfates des ciments selon la méthode ASTM C 452-68". Rev. Mat. Constr. Trav. Publics. No 656 (1970), pp. 135-143.

(8) Mather, K.: "Factors affecting sulphate resistance of mortars". Proceedings of the 7thinternational Congress on the Chemistry of Cement, Paris, vol. IV (1980), pp. 580-585.

(9) Mehta, P.K.: "Mechanism of sulphate attack on Portland cement concrete. Another look". Cem. Concr. Res. vol. 13, no 3 (1983), pp. 401-406. http://dx.doi.org/10.1016/0008-8846(83)90040-6

(10) Mehta, P.K.: "Effect of fly ash composition on sulphate resistance of cement". ACI Journal, vol. 83, n 6 (1986), pp. 994-1000.

(11) Tikalsky, P.J.; Carrasquillo, R.L.: "Influence of fly ash on the sulphate resistance of concrete". ACI Materials Journal, vol. 89, no 1 (1992), pp. 69-75.

(12) Mather, K.: "Tests and evaluation of Portland and blended cements for resistance to sulphate attack". Symposium on Cement Standards - Evolution and Trends, STP-663, ASTM, Philadelphia, St. Louis, Mo., pp.74-86, 7 dec. 1977. 
(13) Corr, D.J.; Monteiro P.J.M.; Kurtis, K.E.; Der Kiureghian, A.: "Sulphate attack of concrete: Reliability analysis". ACI MATERIALS JOURNAL, Technical Paper, vol. 98, n.2, March/April 2001.

(14) Talero, R.: "Contribution to the Analytical and Physical-Chemical Study of the System: Pozzolanic Cements-GypsumWater $\left(20^{\circ} \pm 3^{\circ} \mathrm{C}\right)^{\prime \prime}$. Tesis Doctoral, Univ. Complutense de Madrid, 20 nov. 1986.

(15) Talero, R.: "Kinetochemical and morphological differentiation of ettringites by the Le Chatelier-Ansttet test". Cem. Concr. Res., vol. 32, no 5 (2002), pp. 707-717. http://dx.doi.org/10.1016/S0008-8846(01)00749-9

(16) Talero, R.: "Performance of metakaolin and portland cements in ettringite formation as determined by ASTM C 45268: Kinetic and morphological differences". Cem. Concr. Res., vol. 32, no 7 (2005), pp. 269-284.

(17) Talero, R.: "Co-precipitation of rapid and slow forming ettringite. Consequence: Expansive Synergic Effect." Mater. Construcc., vol. 61, no 303 (2011), pp. 37-52.

(18) Talero, R.: "Expansive Synergic Effect of ettringite from pozzolan (metakaolin) and from OPC, co-precipitating in a common plaster-bearing solution. Part II: Fundamentals, explanation and justification". Constr. and Build. Mater., vol. 25, no 3 (2011), pp. 1139-1158. http://dx.doi.org/10.1016/j.conbuildmat.2010.09.006

(19) Cohen, D.; Mather, B.: "Sulfate Attack on Concrete - Research Needs". ACI Materials Journal vol. 88, n 1 (1991), pp. $62-69$.

(20) Hooton, R.D.: "Bridging the gap between research and standards". Cem. Concr. Res., vol. 38, no 2 (2008), pp. 47-58. http://dx.doi.org/10.1016/j.cemconres.2007.09.012

(21) Talero, R.: "Pozzolanic cements with greater sulphate-resistance than SRPC and vice verse. Mater. Construcc.", vol. 37, no 207 (1987), pp. 37-50. http://dx.doi.org/10.3989/mc.1987.v37.i207.861

(22) Talero, R.; Rahhal, V.: "Calorimetric comparison of portland cement containing silica fume and metakaolin: Is silica fume, like metakaolin, characterized by pozzolanic activity that is more specific than generic?" J. Therm. Anal. Cal., vol. 2, no 2 (2009), pp. 383-393. http://dx.doi.org/10.1007/s10973-008-9096-x

(23) Trusilewicz, L.; Fernández-Martínez, F.; Talero, R.: "TEM and SAED Characterization of Metakaolin. Pozzolanic Activity". J. Am. Ceram. Soc., vol. 95, no 9 (2012), pp. 2989-2996. http://dx.doi.org/10.1111/j.1551-2916.2012.05325.x

(24) Mejía, R.; Delvasto, S.; Talero, R.: "Chloride diffusion measured by a modified permeability test in normal and blended cements". Advances in Cement Research, vol. 15, no 3 (2003), pp. 113-118. http://dx.doi.org/10.1680/adcr.2003.15.3.113

(25) Talero, R.: "Synergic Effect of Friedel's salt from pozzolan and from OPC, co-precipitating in a common chlorides solution: Part II: demonstration, fundamentals and justification". Constr. and Build. Mater., vol. 25, no 3 (2012), pp. 11391158. http://dx.doi.org/10.1016/j.conbuildmat.2010.09.006

(26) Felekoğlu, B.; Ramyar, K.; Tosum, K.; Musal, B.: "Sulphate resistances of different types of Turkish Portland cements by selecting the appropriate test methods". Constr. and Build. Mater., vol. 20, no 9 (2006), pp. 819-823. http://dx.doi. org/10.1016/j.conbuildmat.2005.01.048

(27) ASTM C 1012 Standard: Standard Test Method for Length Change of Hydraulic-Cement Mortars Exposed to a Sulphate Solution. ANNUAL BOKK OF ASTM STANDARDS, Section 4, Vol. 04.01 Cement; Lime; Gypsum, pp. 450-454.

(28) ASTM C 778-92a: Standard Specification for Standard Sand. ANNUAL BOKK OF ASTM STANDARDS, Section 4, vol. 04.01 Cement; Lime; Gypsum, pp. 329-331.

(29) Tosun, K., Felekoğlu, B., Baradan, B., Akin Altun, İ.: "Effects of limestone replacement ratio on the sulphate resistance of Portland limestone cement mortars exposed to extraordinary high sulphate concentrations". Constr. and Build. Mater., vol. 23, no 7 (2009), pp. 2534-2544. http://dx.doi.org/10.1016/j.conbuildmat.2009.02.039

(30) Calleja, J.; Aguanell, M.: "Considerations about the ANSTTET test and the behaviour of cements in front of sulfates". Mater. Constr. vol. 179 (1980), pp. 39-48. http://dx.doi.org/10.3989/mc.1980.v30.i179.1048

(31) Talero, R., Pedrajas, C., Delgado, A., Rahhal, V.: "Re-use of incinerated agro-industrial waste as pozzolanic addition. Comparison with Spanish silica fume". Mater. Construcc. Vol. 59, no 296 (2009), pp. 53-89. http://dx.doi.org/10.3989/ mc.2009.49809

(32) Irassar, E.F.; Bonavetti, V.L.; González, M.: "Microstructural study of sulfate attack on ordinary and limestone Portland cements at ambient temperature". Cem. Concr. Res., vol. 33, no 1 (2003), pp. 31-41. http://dx.doi.org/10.1016/S00088846(02)00914-6

(33) Rahhal, V., Bonavetti, V., Trusilewicz, L., Pedrajas, C., Talero, R.: "Role of the filler on Portland cement hydration at early ages", Constr. and Build. Mater., vol. 27, no 1 (2012), pp. 82-90. http://dx.doi.org/10.1016/j.conbuildmat.2011.07.021

(34) Talero R.: Los cementos Pótland de moderada resistencia sulfática. Métodos acelerados de ensayo para determinarla. Bases para su caracterización y control. Monografía no 399 del IETcc-CSIC, dic. 1989.

(35) Instrucción para la Recepción de Cementos RC-08 (R.D. 956/2008 de 6 de junio; BOE nº 148 del 19 de junio de 2008).

(36) EN 197-1:2011: Cemento. Parte 1: Composición, especificaciones y criterios de conformidad de los cementos comunes. AENOR, Calle Génova, 6, 28004-MADRID-España.

(37) Pliego de Prescripciones Técnicas Generales para la Recepción de Cementos, 1975 (Decreto de la Presidencia del Gobierno 1964/1975 de 23 de mayo; B.O.E. núm. 206 de 28 e agosto de 1975).

(38) EN 196-2:2005 Standard. Methods of testing cement. Chemical analysis of cement. AENOR. 
(39) ASTM C 311-07 Standard. Standard Test Methods for Sampling and Testing Fly Ash or Natural Pozzolans for Use in Portland-Cement Concrete. Annual Book of ASTM Standards, vol. 04.02, 2007.

(40) UNE 80-225-93 Standard: Métodos de ensayo de cementos. Análisis Químico: Determinación del dióxido de silicio $\left(\mathrm{SiO}_{2}\right)$ reactivo en los cementos, en las puzolanas y en las cenizas volantes. AENOR.

(41) Frattini, N.: "Solubilità dell'idrato di calcio in presenza di idrato di potassio e idrato di sodio". Ann. Chim. Applicata, vol. 39, (1949), pp. 616-20 = Pliego de Prescripciones Técnicas Generales para la Recepción de Cementos RC-75(BOE no 206 de 28 de agosto de 1975) EN 196-5 Standard (Pozzolanicity test for POZC).

(42) EN 450 Standard: Fly ash for concrete. Definitions, requirements and quality control. AENOR.

(43) EN 13263-1 Standard. Silica fume for concrete. Part 1: Definitions, requirements and conformity criteria. AENOR.

(44) ASTM C 593-76a Standard: Standards Specifications for Fly Ash and Other Pozzolans for Use with Lime. ANNUAL BOOK OF ASTM STANDARDS, Section 04 Construction Vol. 04.01 Cement; Lime; Gypsum, pp.286-296290. 1995.

(45) ASTM C 618-95a. Standard Specification for Fly Ash and Raw or Calcined Natural Pozzolan for Use as Mineral Admixture in Portland Cement Concrete. American Society for Testing and Materials, Annual Book of ASTM Standards, vol. 04.02, 1994.

(46) ASTM C 595M-95 Standard: Standard Specification for Blended Hydraulic Cements.- ANNUAL BOOK OF ASTM STANDARS, Section 4 Construction, vol. 04.01 Cement; Lime; Gypsum, pp. 291-296. 1995.

(47) Hime, W., Backus, L. A. Discussion of the paper: "Redefining cement characteristics of sulphate-resistant Pórtland cement". Cem. Concr. Res., vol. 33, no 11 (2003), pp.1907. http://dx.doi.org/10.1016/S0008-8846(03)00153-4

(48) Tikalsky, P.J., Roy, D.M., Scheetz B., Krize, T. Reply to the discussion by W.Hime and L.Backus of the paper "Redefining cement characteristics of sulphate-resistant Portland cement". Cem. Concr. Res., vol. 33, no 11 (2003), pp.1909. http://dx.doi.org/10.1016/S0008-8846(03)00154-6

(49) Talero, R.: "Sulphatic characterization of pozzolanic aditions: accelerated test methods to determine it (Le ChatelierAnsett and ASTM C 452 methods)". 10 ${ }^{\text {TH }}$ International Coal Ash Symposium. Proceedings, Vol. 2, Section 8: Concrete III, Orlando - Florida - USA, jan. 1993.

(50) ASTM C 150-95 Standard: Standard Specification for Portland Cement.- ANNUAL BOOK OF ASTM STANDARDS.- Sec. 4 Construction, Vol. 04. 01 Cement;Lime;Gypsum.pp.128-132,1995.

(51) A Performance Test for the Potential Sulfate Resistance of Portland Cement. Reported by the Working Committee on Sulfate Resistance of ASTM Committee C-1 on Cement.- ASTM Bulletin 212, pp. 37-44, feb. 1956.

(52) Eitel, W.: "Recent Investigations of the System: Lime-Alumina-Calcium Sulphate-Water and its importance in Building Research Problems". J. Am. Concr. Inst., vol. 28, no 7 (1957), pp. 679-698.

(53) UNE 80-103:1986. Métodos de ensayo de cementos. Ensayos físicos. Determinación de la densidad real. AENOR.

(54) UNE 80-122:1991. Métodos de ensayo de cementos. Determinación de la finura. AENOR (= EN 196-7:1990 standard).

(55) EN 196-1 Standard: Methods for testing cement. Part 1: Determination of mechanical strengts.- AENOR.

(56) EN 196-3:1996 Standard: Métodos de ensayo de cementos. Parte 3: Determinación del tiempo de fraguado (Setting times determination) y estabilidad de volumen (volume stability by Le Chatelier needles).- AENOR.

(57) Richardson I.G.: "The nature of C-S-H in hardened cements". Cem. Concr. Res., vol. 29, no 8 (1999), pp. $1131-1147$. http://dx.doi.org/10.1016/S0008-8846(99)00168-4

(58) Richardson I.G., Groves G.W.: "Microstructure and microanalysis of hardened ordinary Portland cement pastes". Journal of Materials Science, vol. 28, no 1 (1993), pp. 265-277. http://dx.doi.org/10.1007/BF00349061

(59) Williamson, R.B.: "Solidification in Portland cement". Progress in Materials Science, vol. 15, n 3 (1972), pp. $189-286$. http://dx.doi.org/10.1016/0079-6425(72)90001-1

(60) Groves, G.W.: "Microcrystalline calcium hydroxide in Portland cement pastes of low water/cement ratio". Cem. Concr. Res. vol. 11, no 2 (1981), pp. 713-718. http://dx.doi.org/10.1016/0008-8846(81)90029-6

(61) Jennings, H.M.; Dalgleish, B.J.; Pratt, P.L.: "Morphological development of hydrating tricalcium silicate as exanimate by electro microscopy techniques". J. Am. Cer. Soc., vol. 64, no 10 (1981), pp. 567-572. http://dx.doi. org/10.1111/j.1151-2916.1981.tb10219.x

(62) Shahsavari, R.; Buehler, M.J.; Pellenq, R. J.M.; Ulm F-J.: "First-Principles Study of Elastic Constants and Interlayer Interactions of Complex Hydrated Oxides: Case Study of Tobermorite and Jennite". J. Am. Ceram. Soc. vol. 92, no (10) (2009), pp. 2323-2330. 